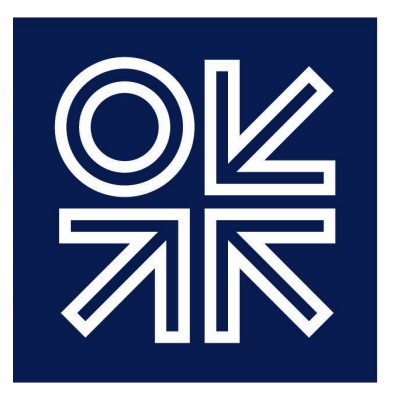

THE OXFORD

INSTITUTE

FOR ENERGY

STUDIES

July 2015

\title{
The Impact of Lower Gas and Oil Prices on Global Gas and LNG Markets
}

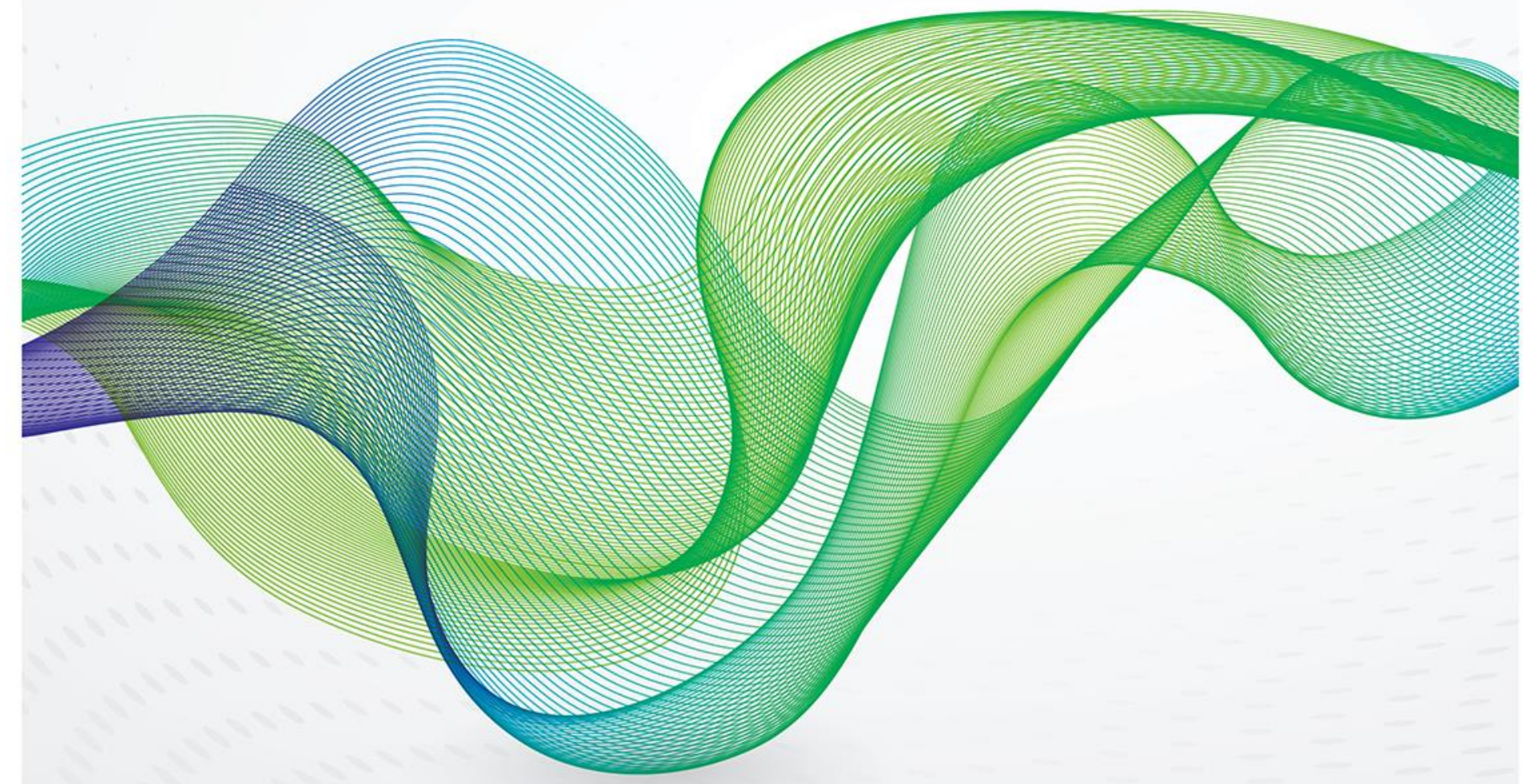



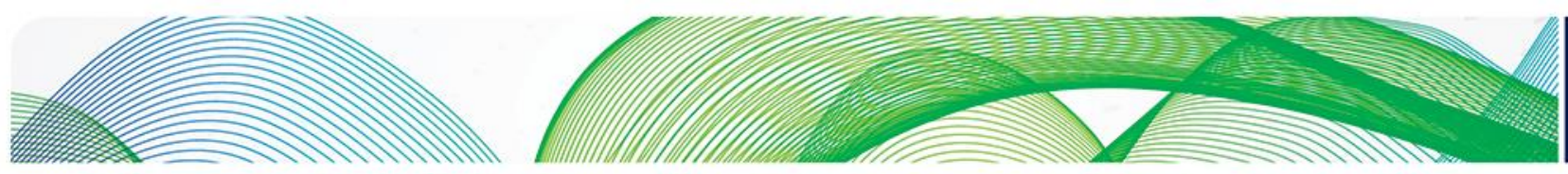

\section{O는}

The contents of this paper are the authors' sole responsibility. They do not necessarily represent the views of the Oxford Institute for Energy Studies or any of its members.

\section{Copyright () 2015}

\section{Oxford Institute for Energy Studies}

(Registered Charity, No. 286084)

This publication may be reproduced in part for educational or non-profit purposes without special permission from the copyright holder, provided acknowledgment of the source is made. No use of this publication may be made for resale or for any other commercial purpose whatsoever without prior permission in writing from the Oxford Institute for Energy Studies.

ISBN 978-1-78467-033-7 

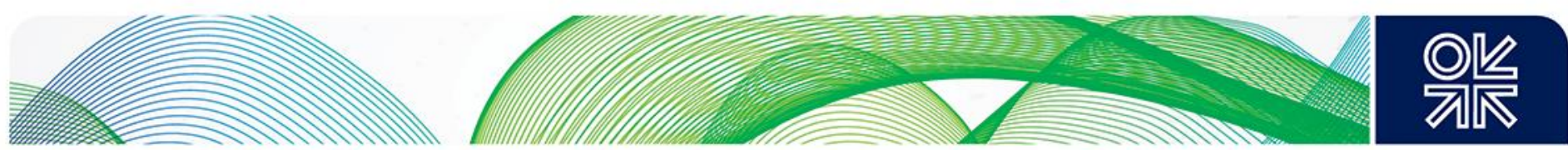

\section{Preface}

This paper continues our series on natural gas pricing which began back in 2007 and has since been a significant theme of OIES Gas Programme research. The paper was originally conceived as a response to the question: what has been the impact on gas and LNG of the fall in crude oil prices? However, the fact that (spot) market-based gas prices in both Europe and Asia fell significantly in advance of the crude oil price collapse, was another demonstration of an important trend documented in our research, that the dynamics of gas and oil markets and prices have increasingly diverged. Unlike Europe where more than $60 \%$ of gas sold in wholesale markets is now based on hub prices, the majority of long term Asian LNG contracts remain based on and indexed to crude oil, and those prices therefore continue to exercise significant price influence on the gas market.

As we move further into the 2010s, all gas markets which are exposed to international trade are displaying a secular trend towards market (supply/demand) pricing. This makes our research on gas pricing far more complicated than when we started nearly 10 years ago. Instead of focusing on crude oil and oil product prices, and how formulae in long term gas contracts would respond to changes in these prices, global and regional gas supply/demand dynamics have become the principal metric for assessing how prices will evolve in future. Moreover, a decade ago the impact of developments in one regional gas market on supply, demand and prices elsewhere in the world, was extremely limited. But the past decade has seen that the North American shale gas revolution and the closure of Japanese nuclear power stations (to name only two examples) have had major impacts on European gas supply and prices. This increasing "connectedness" - which it is tempting (but misleading) to call "globalisation" - of regional gas markets creates additional complexity for supply/demand and price scenario research.

The scenarios in this study are based on the global gas model first developed by Howard Rogers in 2009 , and progressively refined and expanded to encompass a greater geographical scope and increasing methodological complexity. The great advantage of the model is its ability to adapt to rapid changes in the supply/demand outlook in different regions, the timing of individual export project startups, and the likely impact of significant price changes. It is a very powerful tool for examining the potential interactions of demand uncertainties in China, Europe and new markets such as transportation; and uncertainties in LNG supply from the US and Australia, and pipeline gas from Russia. The results, which are set out in this study, are a valuable aid to understanding complex and fast-moving price changes which have evolved during 2014-15, and how these may play out in the period up to 2030 .

Jonathan Stern

June 2015 

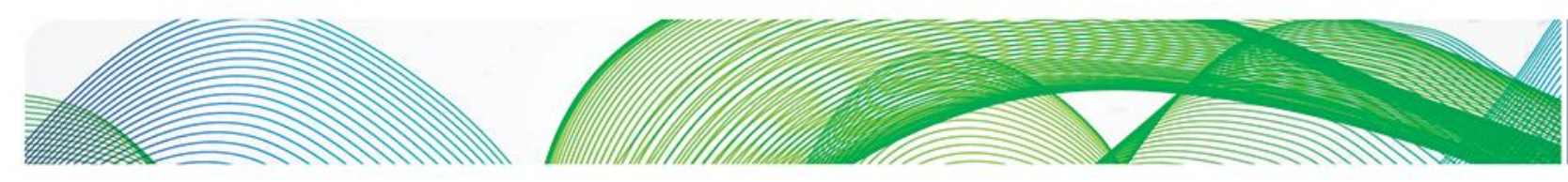

\section{Contents}

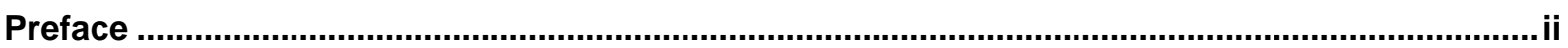

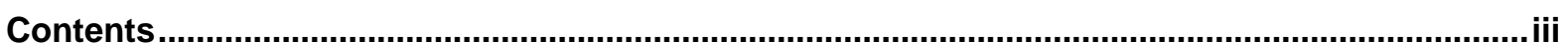

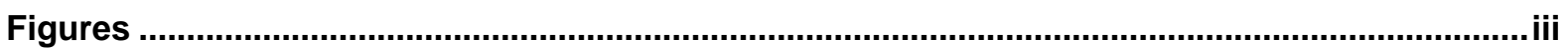

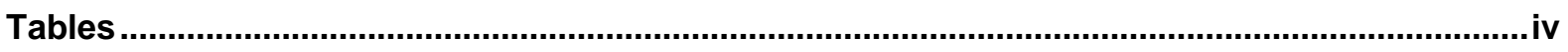

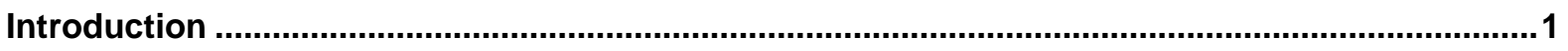

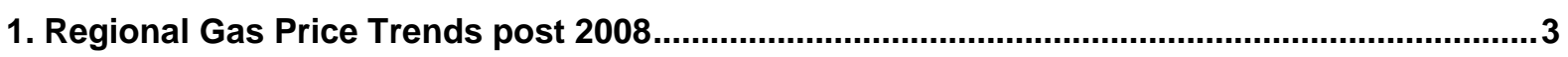

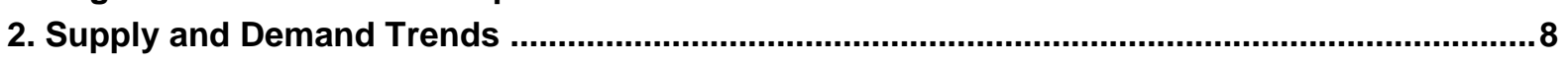

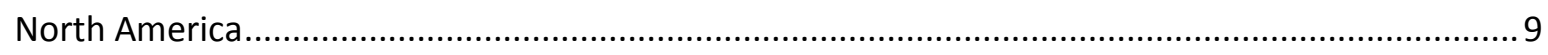

Europe

Asia

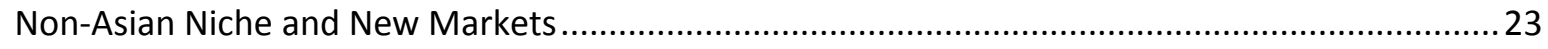

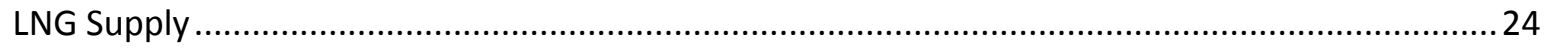

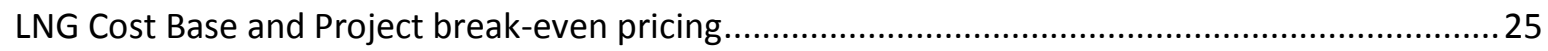

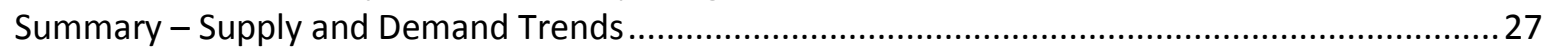

3. Russian Price - Volume Strategy in the European Market ..................................................28

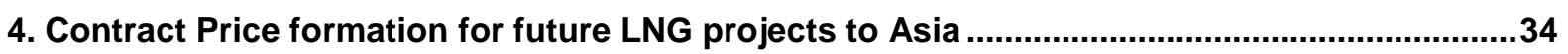

An Asian Spot Index - such as: Platts JKM, ICIS' East Asia Index (EAX) or Argus' NEA ...................... 34

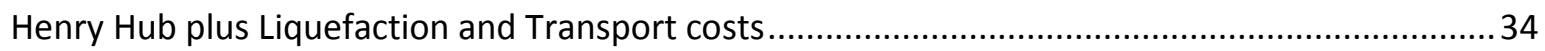

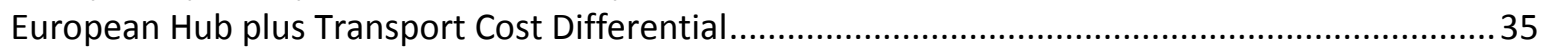

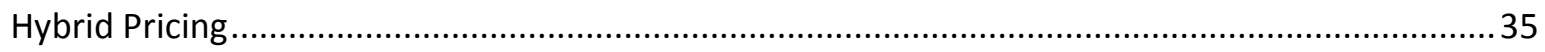

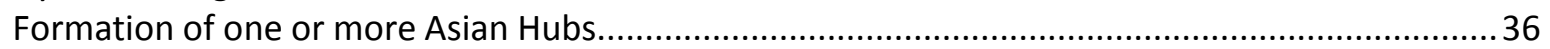

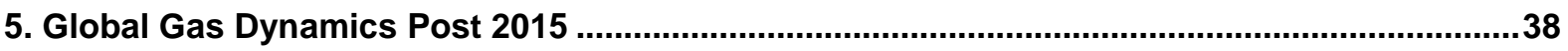

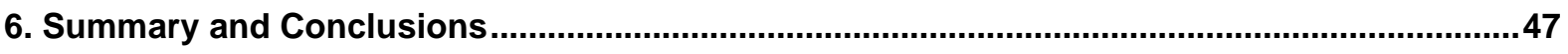

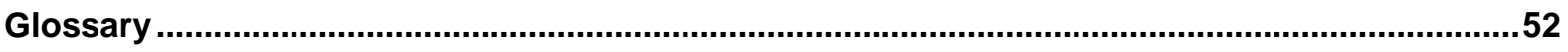

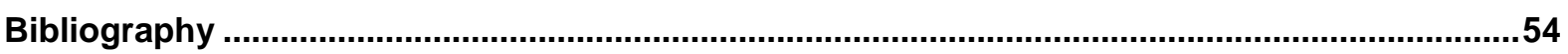

\section{Figures}

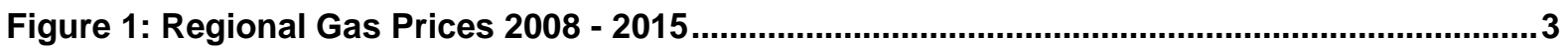

Figure 2: Brent FOB Spot Daily Price, January 2014 to June 2015 ........................................6

Figure 3: Monthly Brent Price and Futures (January 2014 - December 2015) ..............................

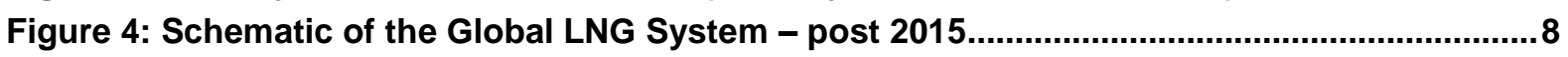

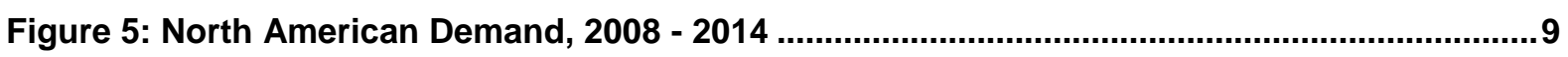

Figure 6: North American Production, 2008 - 2014

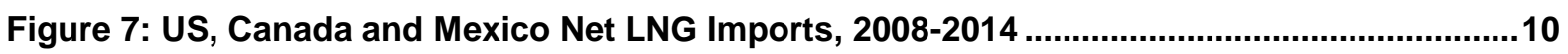

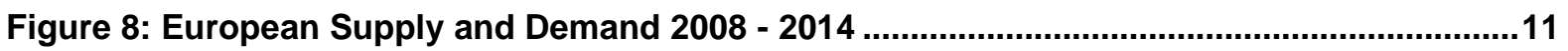

Figure 9: European Demand 2008 - 2030

Figure 10: European Domestic Production 2005 - 2030 ........................................................13

Figure 11: Historic and Future Outlook for Europe Region Pipeline Imports ............................14

Figure 12: Russian long-term export contracts with OECD European countries to 2030: annual

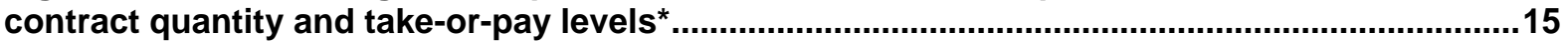

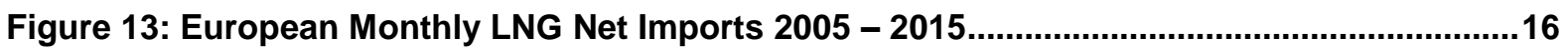

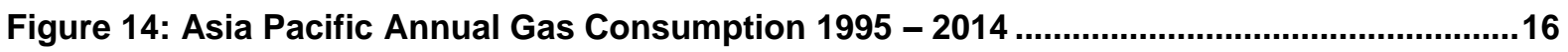



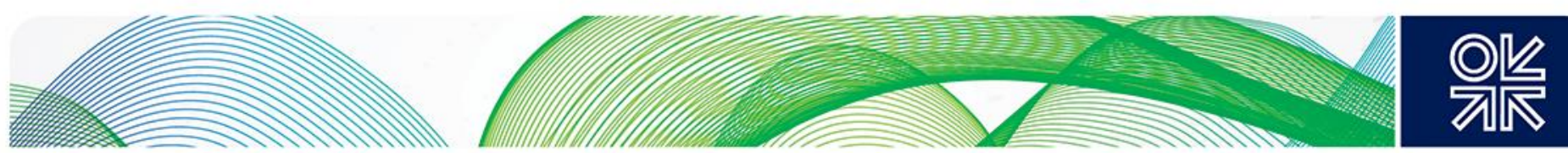

Figure 15: Asia Pacific Annual Gas Production 1995 - 2014

Figure 16: Composition of Primary Energy Consumption in Key Asian LNG Importing Markets 1995 - 2014

Figure 17: China Natural Gas Demand - Low and High Cases .....................................................20

Figure 18: Chinese Demand and Supply Composition - Low Case .............................................21

Figure 19: Chinese Demand and Supply Composition - High Case ........................................21

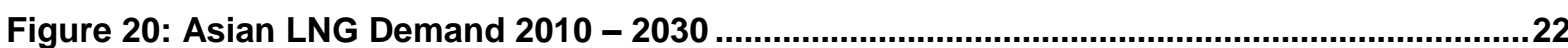

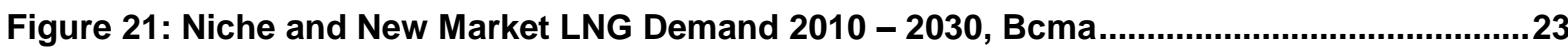

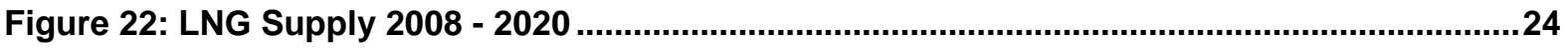

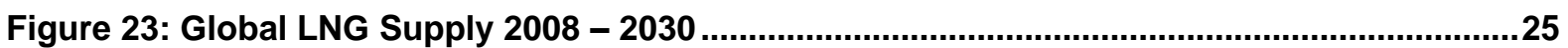

Figure 24: Comparison of Delivered Costs to Japan (Project Breakeven Price) ........................26

Figure 25: Russian Pipeline Gas Imported into Europe 2007 - 2010 ........................................28

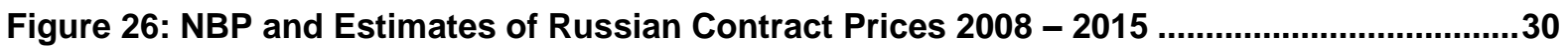

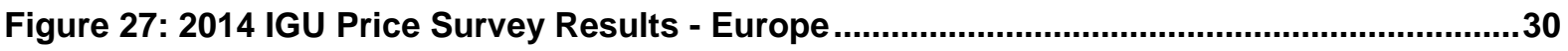

Figure 28: The Breakeven Price of Gazprom Exports to Europe ..................................................32

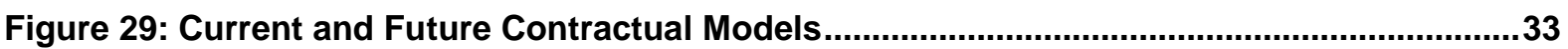

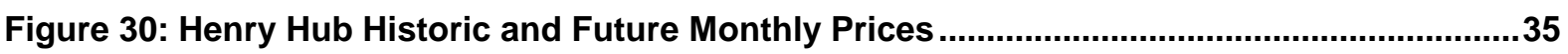

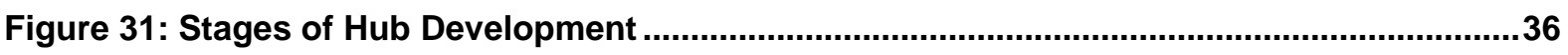

Figure 32: Scenarios - Combinations of Chinese and European Demand Cases .......................38

Figure 33: Scenario 1, High Chinese LNG Demand, Base Case European Demand, Russia

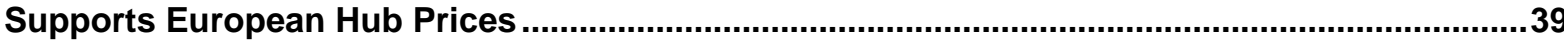

Figure 34: Scenario 2, Low Chinese LNG Demand, Base Case European Demand, Russia

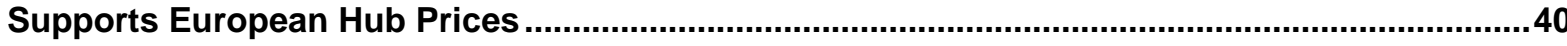

Figure 35: Indicative Price Paths 2010 to 2030 for Scenarios 1 and 2, with Russia supporting European Hub Prices

Figure 36: Indicative Price Paths 2010 to 2030 for Scenarios 1 and 2, with Russia Keeping European Hub Prices Low.

Figure 37: Scenario 2, Low Chinese LNG Demand, Base Case European Demand, Russia Keeps European Hub Prices Low.

Figure 38: Scenario 3, Low Chinese LNG Demand, Low European Demand, Russia Supports European Hub Prices.

Figure 39: Scenario 4, High Chinese LNG Demand, Low European Demand, Russia Supports European Hub Prices.

Figure 40: Scenario 4, High Chinese LNG Demand, Low European Demand, Russia Keeps European Hub Prices Low.

\section{Tables}

Table 1: Asian LNG Demand (Bcma) 2010 to 2030

Table 2: Timings and Probability-Weighted Capacities of Future LNG Liquefaction Projects with Start-up timings as viewed in early 2014. 

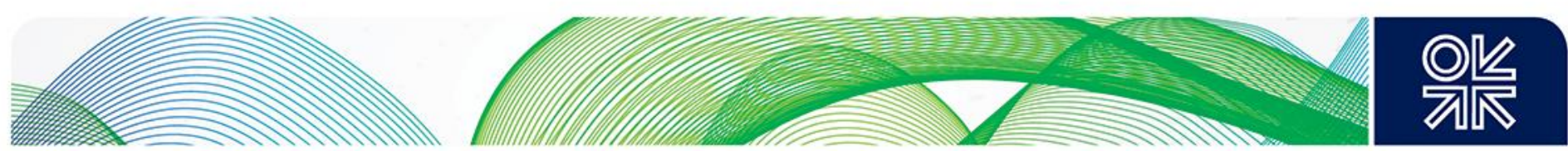

\section{Introduction}

The period spanning 2011 to the end of 2013 witnessed distinct price 'corridors' for key regional gas reference prices, specifically:

- Henry Hub $\$ 2$ to $\$ 5 / \mathrm{mmbtu}$,

- European Hubs $\$ 8$ to $\$ 11 / \mathrm{mmbtu}$,

- Asian LNG contract prices $\$ 15$ to $\$ 18 / \mathrm{mmbtu}$; and,

- Asian LNG spot prices $\$ 13$ to $\$ 19 / \mathrm{mmbtu}$.

In the expectation that these price levels would continue and that the significant spread between Henry Hub and Asian and European prices would be maintained, (primarily due to strong Asian LNG demand growth and the support provided by a continued high oil price on Asian JCC-linked LNG contracts), LNG industry players embarked upon developing numerous LNG supply projects with the aim of bringing them online ahead of the competition.

Reduced winter natural gas demand in Europe and Asia in early 2014, and a perception that Asian LNG demand growth was slowing, led to a reduction in European hub and Asian LNG spot prices in early to mid - 2014. The collapse in oil prices in October 2014 has driven down Asian LNG JCClinked contract prices and has effectively 'put on hold' FIDs on many LNG projects which would otherwise have moved into the construction phase in 2015 and 2016. This said, some $85 \mathrm{bcma}$ of Australian LNG projects, which gained FIDs between 2009 to $2012^{1}$ have, or will come onstream between end 2014 and 2018; and, 77 bcma of US LNG export projects are under construction, the first such facility expected to commence exports at the end of 2015/early 2016.

Expectations for natural gas demand growth in China have been downgraded from a government target of $400-420$ bcma by $2020^{2}$ to the November 2014 IEA WEO New Policies Scenario of 295 bcma. With a $38 \mathrm{bcma}$ pipeline deal signed between China and Russia and another for $30 \mathrm{bcma}$, for which a heads of agreement was signed in May 2015 (both potentially onstream in the early 2020s), the potential future demand for LNG in China has been significantly reduced.

Even if oil prices do not recover within the next year or two, it is unlikely that Asian buyers will willingly accept a return to JCC-linked pricing unless accompanied by a very strong price review clause which allows for radical changes. For the upstream LNG industry this is a paradigm shift. The attendant pressing need to reduce its cost base, requires an evolution to a more competitive mind-set in what appears to be a lower demand growth era.

This paper seeks to address the following questions:

- What has been the impact of lower oil and lower gas prices on existing and future gas and LNG projects?

- What is the outlook for the period to 2030 for markets connected by flexible LNG supplies given the uncertainty in regional demand outlooks in the light of new LNG supply currently under construction?

- What is the impact of the probable delay to new LNG project FIDs given demand uncertainties and the apparent need to move from oil indexation to new price formation contract structures?

- To what extent can Russia, using its market power in Europe to 'control' hub prices, influence such outcomes?

Chapter 1 describes the evolution of key regional gas reference prices from 2008 to 2015.

${ }^{1}$ Ledesma, Palmer and Henderson (2014) , P. 15
${ }^{2}$ Chen (2014), P. 4 

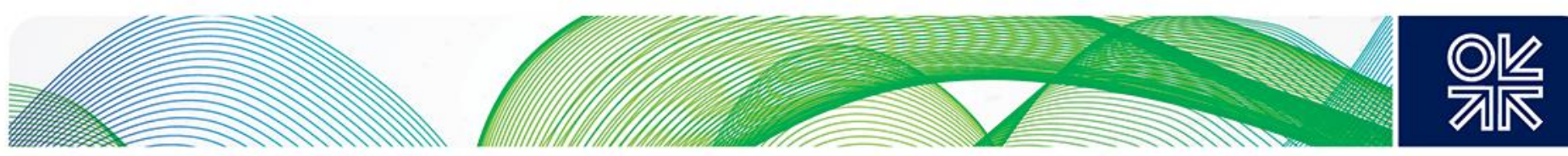

Chapter 2 reviews past and future supply and demand trends and in particular the changed expectations for Chinese LNG demand and uncertainties on future European gas demand in general.

In Chapter 3 the position of Russia and its market power in the European gas market is addressed, both in terms of new business models it could adopt and its current geopolitical issues which distract from developing a more rational commercial gas strategy.

In Chapter 4 the issue of contract price formation mechanisms for future LNG projects to Asian markets is addressed both in terms of new 'hybrid' pricing and Asian hub pricing in the longer term.

Chapter 5 combines a quantitative analysis of a matrix of low and high/base case demand outlooks for China and Europe with assumed delays in new LNG project FIDs and differing Russian price strategies for the European gas market.

Chapter 6 presents the paper's summary and conclusions. 

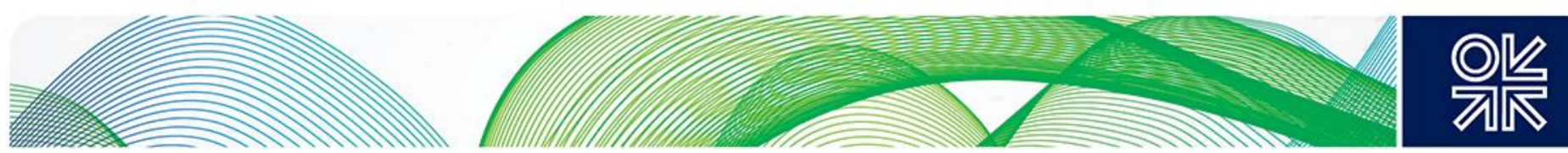

\section{Regional Gas Price Trends post 2008}

Figure 1: Regional Gas Prices 2008 - 2015

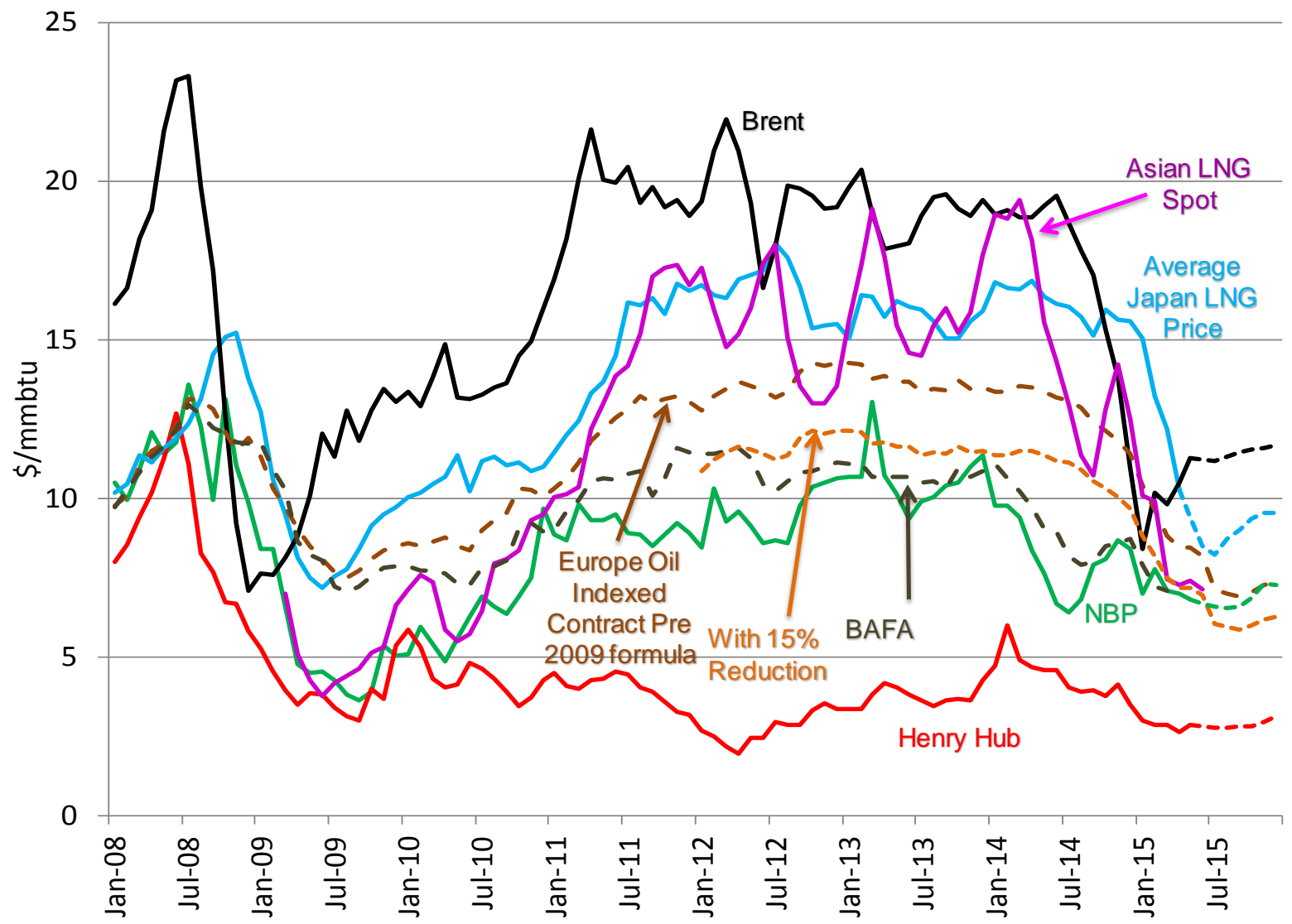

Sources: Platts, EIA, Argus, CME

Notes: dashed lines post March 2015 are (or are derived from) futures prices. BAFA: German average border price for natural gas imports, reported at http://www.bafa.de/bafa/de/energie/erdgas/index.html.

The financial crisis of 2008 had a dramatic effect on demand for natural gas and oil products and created uncertainty around future consumption trends. By early 2011 however oil prices recovered to levels above $\$ 100 / \mathrm{bbl}$ (Brent) and apart from in June 2012, they remained (on a monthly average basis) within a band of $\$ 100$ to $120 / \mathrm{bbl}$ up until September 2014 .

For natural gas (see Figure 1) it is important to distinguish between regional reference prices which are formulaically linked to crude or oil products prices and those which are determined by the forces of supply and demand. In the former category The Japanese Average LNG import price (comprising mainly long term contracted LNG linked to the average of Japanese Customs Cleared Crude oil import prices) exhibited a strong linkage to oil prices, lagged by some 4 to 5 months. By mid-2011 this had reached levels in excess of $\$ 15 / \mathrm{mmbtu}$, having touched a low of $\$ 7.18 / \mathrm{mmbtu}$ in 2009 . The average Japanese LNG import price remained in the band $\$ 15.30 / \mathrm{mmbtu}$ to $\$ 18 / \mathrm{mmbtu}$ until the end of 2014. Estimates of Russian oil-product indexed gas (indexed to gasoil and fuel oil with a 9 month 

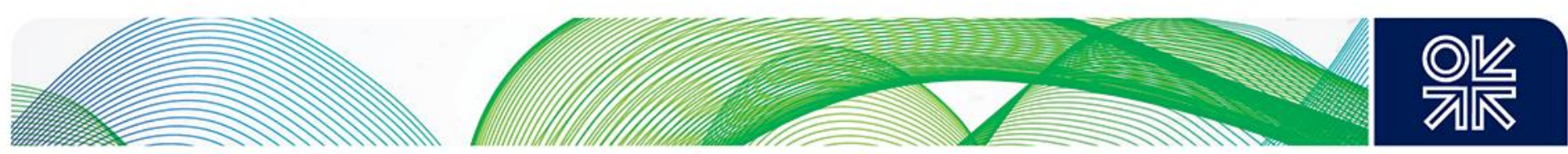

averaging lag) in Europe reached $\$ 13 / \mathrm{mmbtu}$ by mid-2011 but were the subject of negotiated price concessions and arbitrations described in Stern and Rogers $(2014)^{3}$. It is widely understood that a significant volume of gas sold under Russian long term contracts, post 2012, was a) sold on a hubindexed basis, b) subject to rebates bridging most of the gap between contract price and hub price, or c) was at least granted significant discounts relative to the original contract price formulae.

From 2009 to March 2015, Henry Hub prices remained in the $\$ 2 / \mathrm{mmbtu}$ to $\$ 5 / \mathrm{mmbtu}$ band apart from April 2012 when the monthly average fell to $\$ 1.95 / \mathrm{mmbtu}$, and during the exceptionally cold month of February 2014 when it reached $\$ 6 / \mathrm{mmbtu}$. The established and more liquid European hubs (NBP in the UK and TTF in Holland) between January 2011 and April 2014 remained in a price band of $\$ 8$ to $\$ 10.70 / \mathrm{mmbtu}$. The Asian LNG spot price, one measure of which is the Platts Japan Korea Marker Price (JKM) from mid 2009 to early 2011 remained within $\$ 2 / \mathrm{mmbtu}$ of NBP, and significantly below the average Japanese import price during this period.

The Fukushima disaster of March 2011 resulted in the shutdown of Japan's nuclear generation fleet and an increased requirement (up to $20 \mathrm{bcma}$ ) of $L N G$ to compensate for part of this power generation loss. This additional LNG consumption by Japan, on top of the resurgent LNG demand growth of China, South Korea, Taiwan and India in the post 2009 economic recovery period resulted in a 'tight' Asian market for spot LNG cargoes which was compensated for by a slow shift in LNG trade-flows away from Europe and towards Asia. In the period April 2011 to May 2014 the JKM price oscillated around the Japanese LNG import price with an average over the period of $\$ 15.91 / \mathrm{mmbtu}$ but reaching a maximum (monthly average) of $\$ 19.14 / \mathrm{mmbtu}$ in March 2013.

Thus for the period from 2011 to early in 2014 the regional gas prices described above, appeared to be held within ranges which gave rise to significant inter-regional 'spreads': Henry Hub $\$ 2$ to $\$ 5 / \mathrm{mmbtu}$, European Hubs $\$ 8$ to $\$ 11 / \mathrm{mmbtu}$, Asian LNG contract prices $\$ 15$ to $\$ 18 / \mathrm{mmbtu}$ and Asian LNG spot prices (JKM) $\$ 13$ to $\$ 19 / \mathrm{mmbtu}$. The primary causes for such spreads were:

- Henry Hub prices remaining depressed due to shale gas production (whether from dry or wet shale plays and associated gas production from shale oil plays) continuing to outstrip demand growth. With only Mexico as a (pipeline) export market, US gas prices remained low while production, somewhat surprisingly, continued to grow.

- Oil and oil product prices with crude above $\$ 100 /$ bbl, kept Asian LNG oil indexed contract prices above $\$ 15 / \mathrm{mmbtu}$. In Europe the linkage between oil product prices and long term gas contract prices became somewhat muted towards the end of this period as a) producers such as Gas Terra and Statoil moved away from oil product indexation towards hub indexation and b) Gazprom introduced price concessions and rebates.

- The tightening of the global flexible LNG market as a consequence of the Fukushima disaster resulting in a) high and volatile Asian LNG spot prices and b) a progressive re-direction of LNG away from Europe and towards Asia, albeit at a pace which did not materially lower Asian spot LNG prices prior to 2014.

The regional demand trends prevailing during the period 2011 to 2014 will be described in Chapter 2 . On supply, we witnessed significant activity as the industry sought to bring new LNG projects to the point of FID in several areas including:

- the US (mainly the conversion of existing regas import terminals to export facilities through the addition of liquefaction plant),

- Canada - to monetise gas resources for export to (mainly) Asian markets,

- Australia where seven new LNG projects continued construction with significant additional future expansions in prospect,

\footnotetext{
${ }^{3}$ Stern and Rogers (2014), pp. 11 - 13
} 

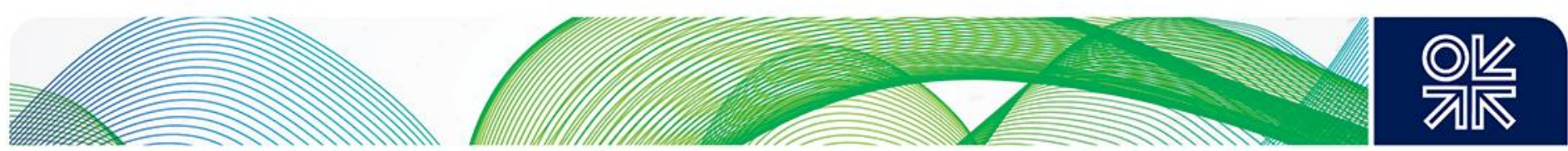

- East Africa where the industry sought to develop some of the large offshore discoveries made during the period 2009 to 2013; and,

- Russia where a number of LNG projects were proposed, of which Yamal LNG is the only project under construction in 2015. These are discussed in more detail in Chapter 2.

The chief incentive for these projects appeared to be a belief that

a) Asian demand for LNG would continue on a high growth trajectory,

b) the price that Asian LNG buyers would be willing to pay would remunerate investment in LNG projects (especially if contract prices were linked to oil at $\$ 100 / \mathrm{bbl}+$ ) and

c) if Asian LNG demand was at times saturated Europe, with hub prices at around $\$ 10 / \mathrm{mmbtu}$, would offer a satisfactory secondary market.

The outlook for regional gas pricing levels and spreads changed significantly during the course of 2014. In Europe the mild winter of 2013-2014 resulted in demand for the European region ${ }^{4}$ being $12.3 \%$ lower than the previous winter (October - March) ${ }^{5}$ and storage at end March 2014 was $44.9 \%$ full versus $23.8 \%$ in March $2013^{6}$. European hub prices (as exemplified by NBP) fell from over $\$ 11 / \mathrm{mmbtu}$ at the end of 2013 to $\$ 6.41 / \mathrm{mmbtu}$ in July 2014 (monthly average), significantly pre-dating the fall in crude oil prices, which saw gas displacing coal in the UK (aided by a higher carbon price than that prevalent in the rest of Europe $)^{7}$. In Asia by mid-2014 LNG spot prices were in free-fall. Initially this was attributed to a mild 2013-2014 winter in some Asian importing countries but a growing concern appeared to be the reduced pace of Asian LNG demand growth. By the third quarter of 2014 the gas market fundamentals in Europe and Asia were weighing heavily on those regional reference prices which were determined by supply and demand.

As has been extensively observed throughout the energy and general media, oil prices which had been declining since June 2014 due to sluggish global demand and rising US oil production fell significantly following the $27^{\text {th }}$ November 2014 OPEC Meeting, with Brent falling to $\$ 66 / \mathrm{bbl}$ on the $28^{\text {th }}$ November (see Figure 2). At this meeting OPEC ministers left the group's output ceiling unchanged despite observed global oversupply, marking a major shift away from its long-standing policy of defending prices.

From January to June 2015 Brent has oscillated between the mid-50s and mid-60s (\$/bbl) as market participants observed, anticipated and weighed the following factors:

- OPEC production levels,

- Evidence of a reduction in US oil production growth consequent upon the observed rapid and significant reduction in oil-directed drilling rig count,

- US oil storage inventory levels which in April 2015 continued to grow,

- Signs of supply changes in the MENA region, whether positive (easing of Iranian sanctions) or negative (continued turmoil in Iraq, Libya and - more recently - Yemen) for increased supply,

- Evidence of demand increases in response to lower product prices within an overall more sluggish world economic outlook.

\footnotetext{
${ }^{4}$ For the purposes of this regional analysis Europe is assumed to include: Austria, Belgium, Bulgaria, Croatia, Czech Republic, Denmark, Estonia, Finland, France, Germany, Greece, Hungary, Ireland, Italy, Latvia, Lithuania Luxembourg, Netherlands, Norway, Poland, Portugal, Romania, Serbia, Slovakia, Slovenia, Spain, Sweden, Switzerland, Turkey, UK.

${ }^{5}$ Data derived from IEA Monthly Gas Data Service

${ }^{6}$ Data from GIE, http://transparency.gie.eu/index.php/historical?code=99_99_99

${ }^{7}$ The UK has introduced a premium on top of the EU ETS $\mathrm{CO}_{2}$ price. In $\overline{2} 01 \overline{5}$ the UK element of the carbon price floor was capped at $£ 18 /$ tonne $\mathrm{CO}_{2}$.
} 

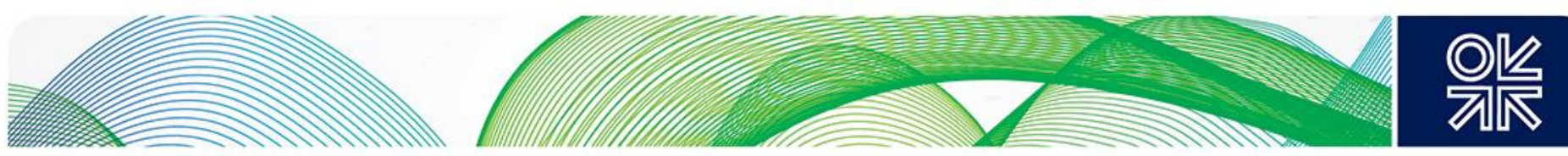

Figure 2: Brent FOB Spot Daily Price, January 2014 to June 2015

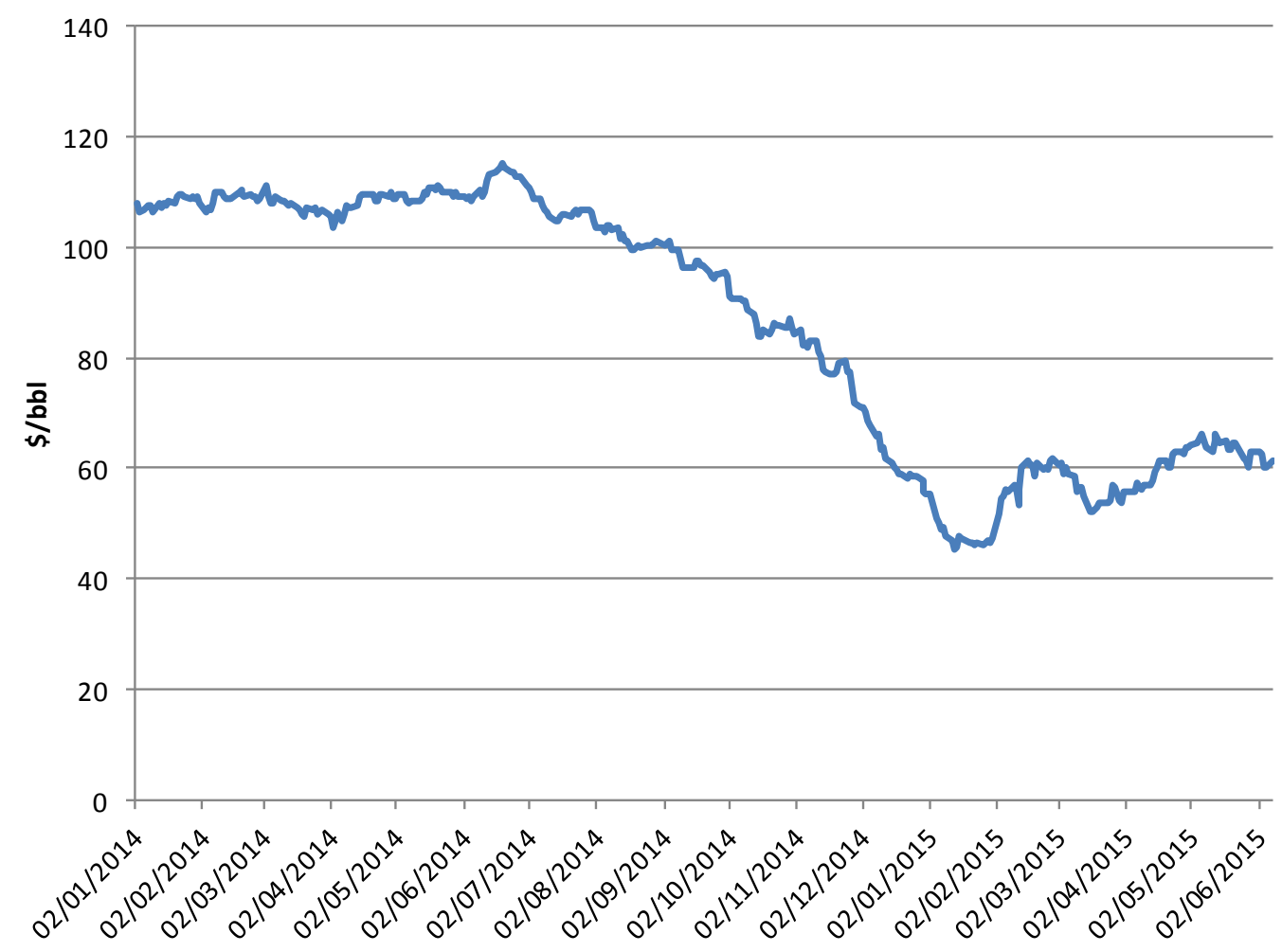

Source: EIA website, http://www.eia.gov/dnav/pet/pet pri spt s1 d.htm

In April 2015 the forward curve for Brent crude showed a gentle rise/contango ${ }^{8}$ reaching $\$ 67 /$ bbl by December 2015 (Figure 3).

The immediate consequences for gas prices which are related through formulae to oil or oil product prices are:

- The Average Japanese LNG prices, generally driven by a 4 to 5 month rolling average of oil price will have fallen by mid-2015 to around $\$ 8 / \mathrm{mmbtu}$.

- The Russian long term contract price (on a pre-concession/rebate basis), generally driven by a 9 month rolling average of gasoil and fuel oil, will fall to around $\$ 7.50 / \mathrm{mmbtu}$ by the third quarter of 2015.

- Any increase in these gas reference prices will be subject to a recovery in oil prices, irrespective of gas market fundamentals.

\footnotetext{
${ }^{8} \mathrm{~A}$ Contango is a situation where the futures price (or forward price) of a commodity is higher than the current price.
} 

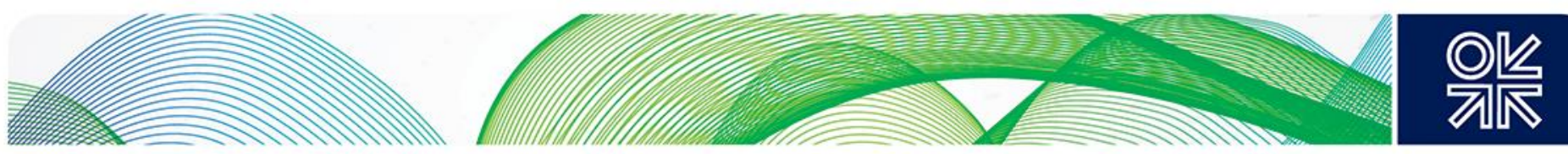

Figure 3: Monthly Brent Price and Futures (January 2014 - December 2015)

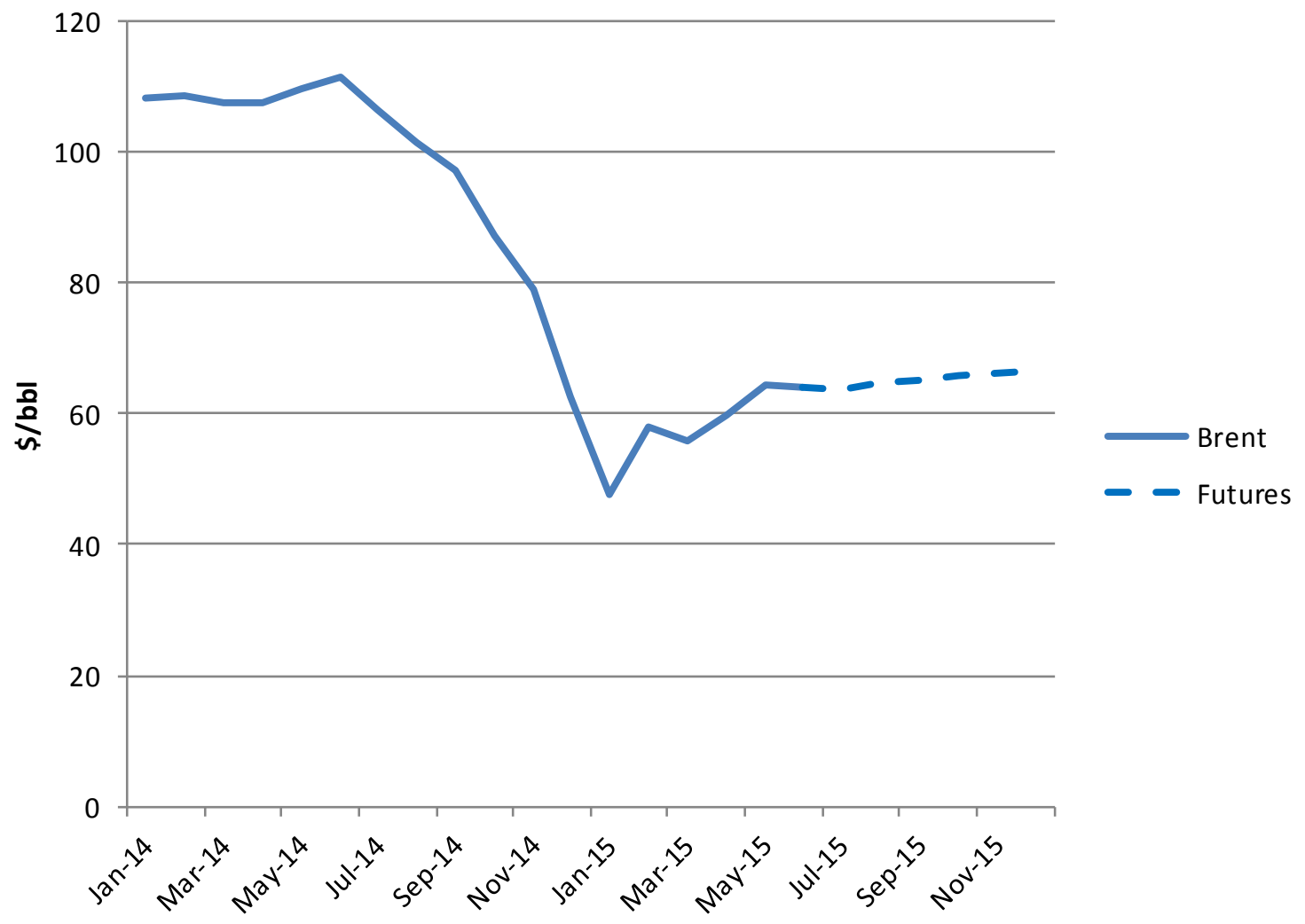

Source: Argus Global LNG, CME

Long-term gas contract prices, except during a 'tight' market provide a ceiling for hub prices, since any move of hub prices above contract prices would cause higher contract nominations or (theoretically) a move by the upstream supplier to sell higher volumes onto the hubs.

In the period to 2020 however, with some 160 bcma of new LNG supply under construction and coming onstream, there is a potential for periods of much lower hub prices as the market attempts to clear by triggering increased demand or curtailing high cost supply. In the next chapter we examine the demand trends and key uncertainties which could create such dynamics. 

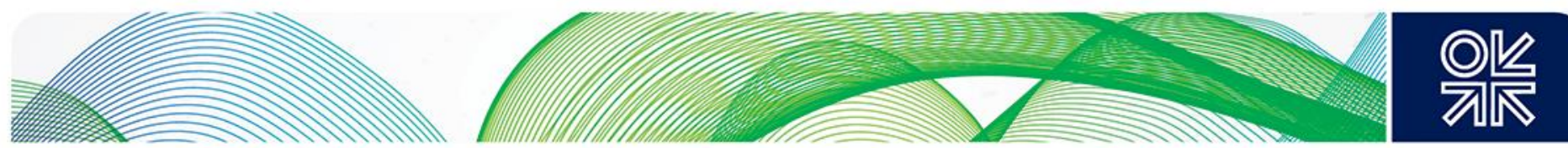

\section{Supply and Demand Trends}

Figure 4: Schematic of the Global LNG System - post 2015

\section{Global LNG System}

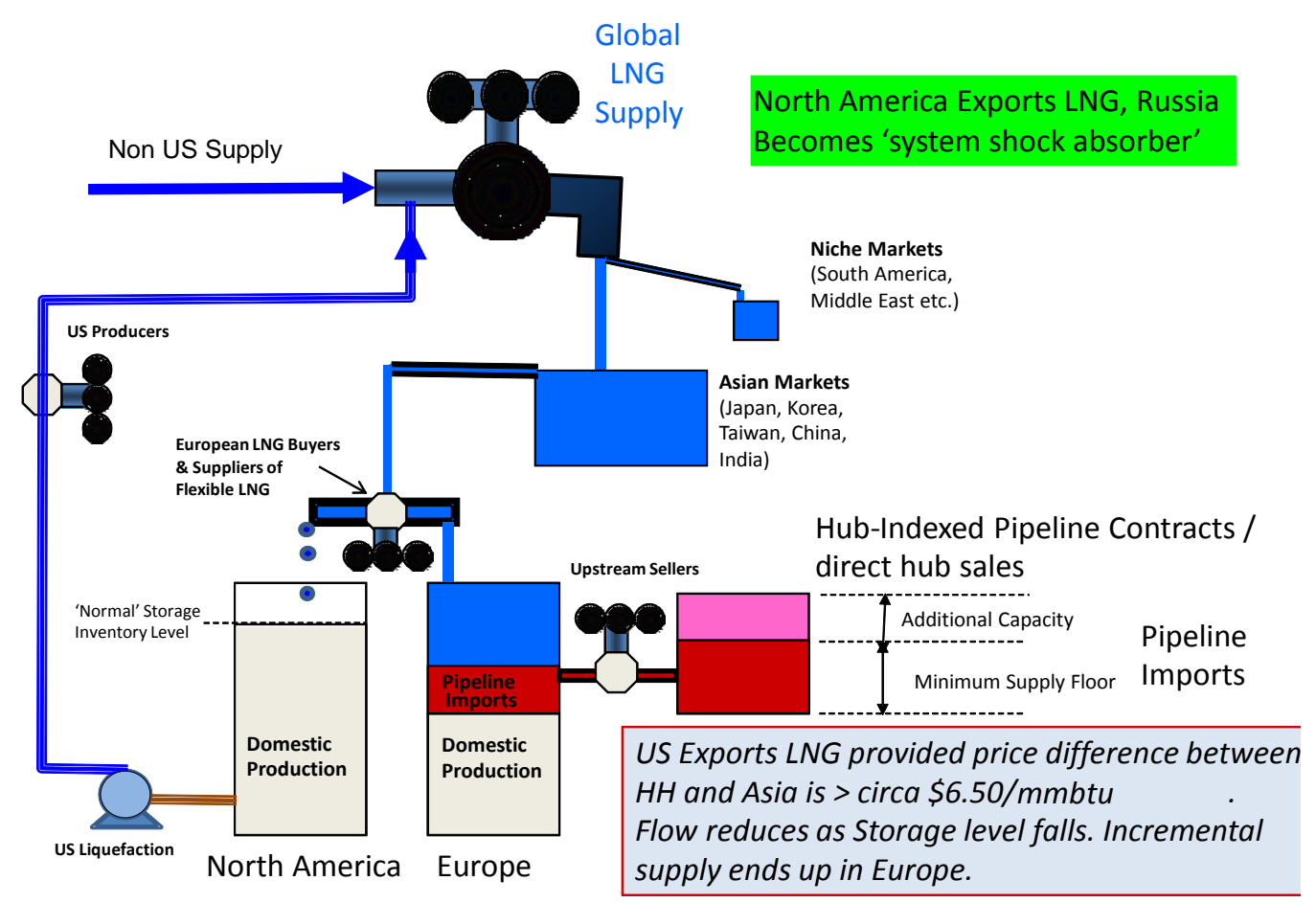

The post 2015 'Global System' is represented schematically in Figure 4. In this representation, Global LNG supply (from US and non-US sources) is first taken by the Asian LNG markets (with Japan, Korea and Taiwan having no other source of natural gas). Also included here are the niche markets including South America, the Middle East and other new markets.

What is left over is available for the markets of North America and Europe. North American requirements are limited to those of Mexico (due to pipeline bottleneck constraints in its ability to import US supplies) and isolated demand pockets on the US East coast which require LNG due to insufficient pipeline supply. In addition to its legacy LNG contracts, Europe will receive LNG volumes which are surplus to requirements from other markets. After domestic production and contracted pipeline imports, the balancing item tends to be Russian pipeline supply9.

Recent and future trends in supply and demand for the key elements included in Figure 4 are addressed in the remainder of this chapter.

\footnotetext{
${ }^{9}$ With the advent of new LNG supply post 2015 we may see a more active LNG arbitrage between Europe and Asia rather than merely the flow of excess volumes to Europe. With limited storage for gas and LNG in major Asian LNG markets however, the net physical effect will be essentially as described here.
} 

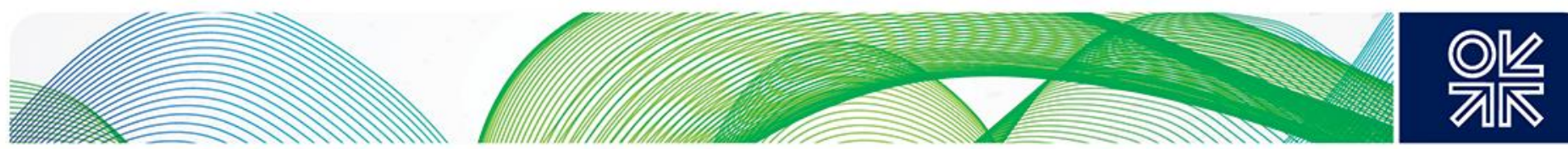

\section{North America}

Figure 5 shows annual demand for the US, Canada and Mexico from 2008 to 2014. Annual average growth rates for this period were $2.4 \%, 3.4 \%$ and $2.9 \%$ respectively with the corresponding rate for North America in aggregate being $2.5 \%$.

Figure 5: North American Demand, 2008 - 2014

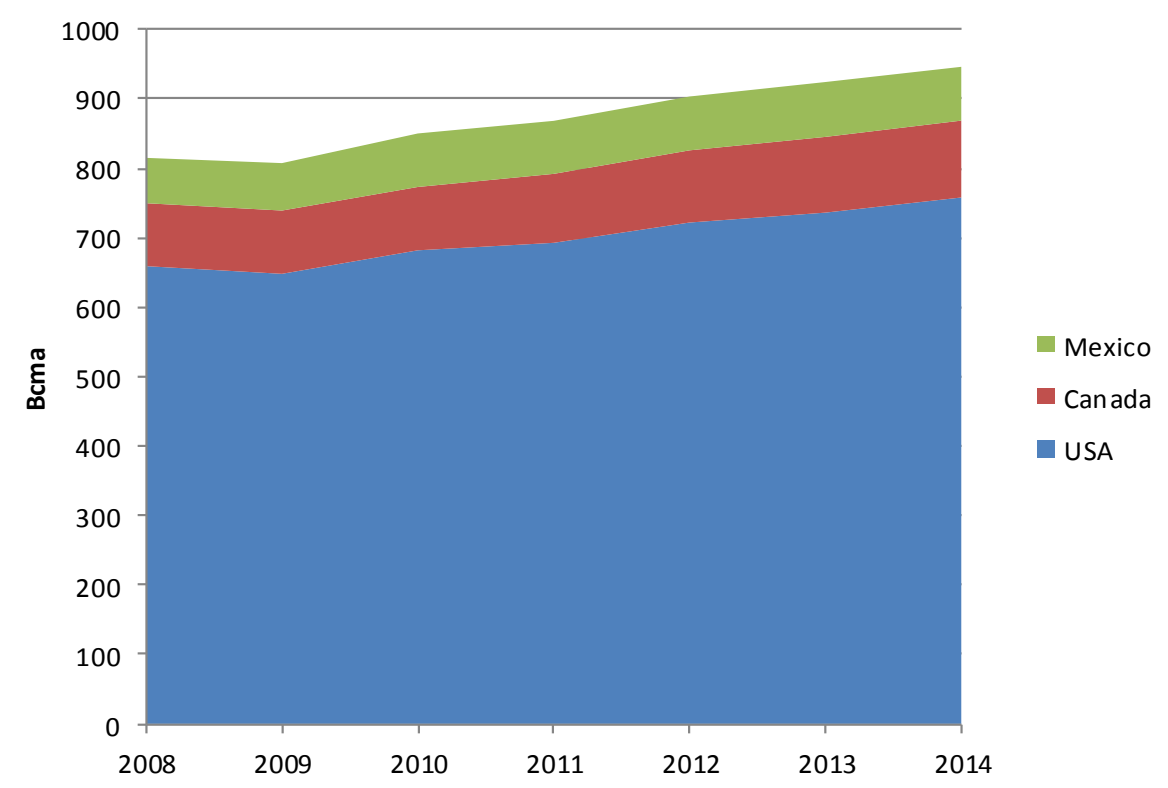

Sources EIA, IEA monthly data service.

Figure 6: North American Production, 2008 - 2014

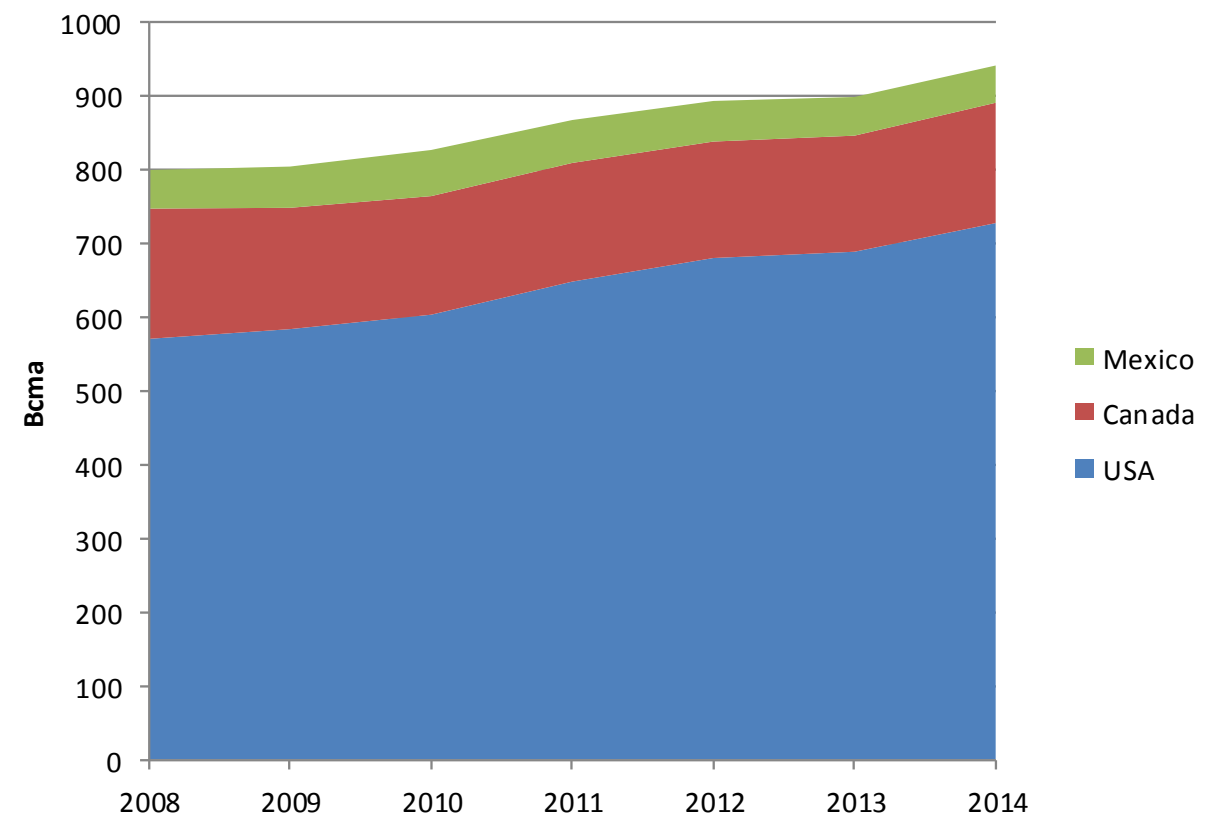

Sources EIA, IEA monthly data service. 

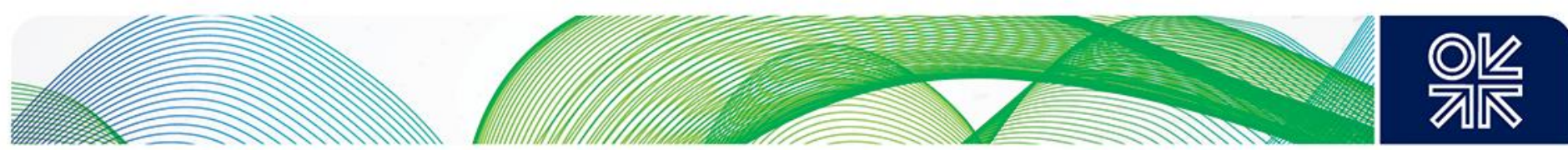

Figure 6 shows the production for the US, Canada and Mexico for the same period in which the annual average growth rates were $4.1 \%,-1.3 \%$ and $-0.6 \%$ respectively with an overall North American growth rate of $2.8 \%$.

Net LNG imports ${ }^{10}$ for the same period are shown in Figure 7.

Figure 7: US, Canada and Mexico Net LNG Imports, 2008-2014

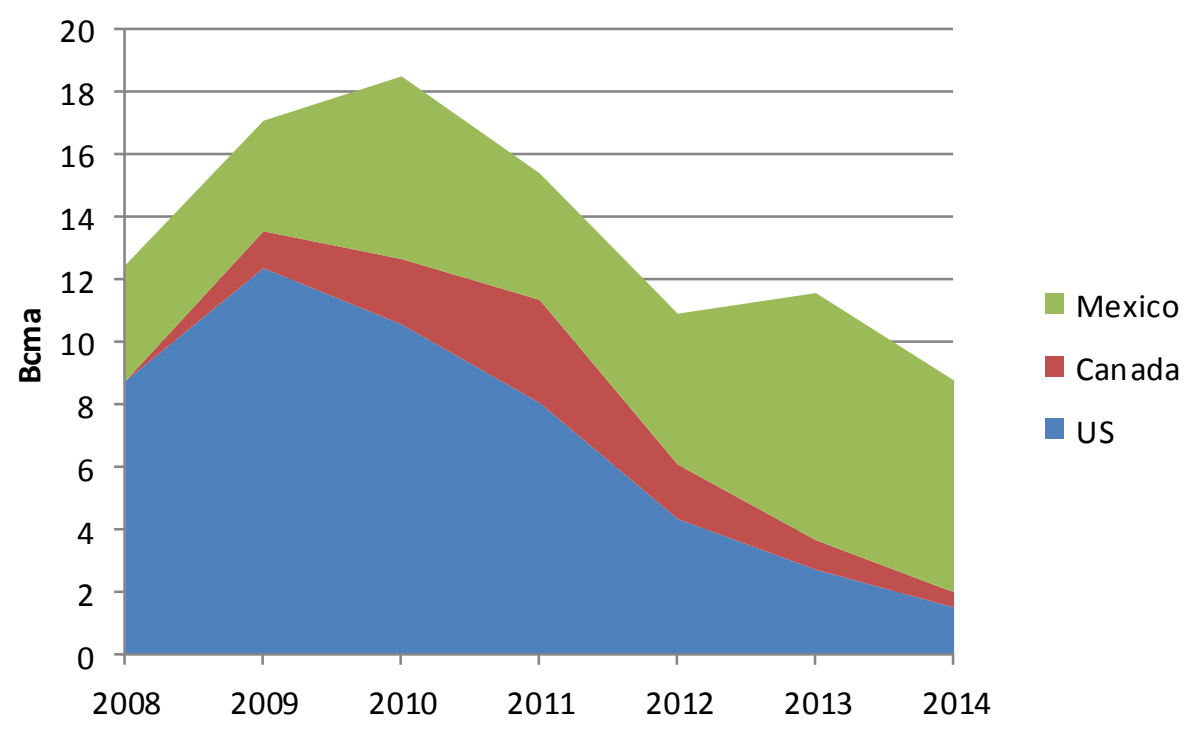

Sources: GIIGNL, Platts LNG Service

From 2008 to 2014 the net storage injection in the US and Canada has been $8 \mathrm{bcm}$ over the period. This figure was depressed by the cold-weather induced exceptional net withdrawal of $18.4 \mathrm{bcm}$ in 2013.

The overall picture is one of growing US production resulting in a reduction in production in Canada and Mexico through the action of lower prices with net LNG imports reduced in tandem.

Future projections of North American demand vary depending upon assumptions of US industrial sector growth (especially petrochemicals) and in the power sector (where fuel price competition and, more importantly for the longer term, regulations on emissions could increase gas use at the expense of coal). In terms of its interaction with the global system depicted in Figure 4, the important questions are:

- What will be the future capacity build of LNG export projects from North America? and,

- Will US shale gas production be sufficient to provide the scale of feed gas required, at US prices which are low enough for project viability?

As of June 2015 the Sabine Pass, Corpus Christi, Freeport, Dominion Cove Point and Cameron LNG projects have some 77 bcma of export capacity which has achieved FID and is under construction. Sabine Pass Trains 5 and 6 and Corpus Christi Train 3 projects are planned to reach FID in 2015.

The outlook for Canadian LNG exports is covered in detail in Gomes (2015) ${ }^{11}$. As of March 2015 there were 25 completed applications for LNG export projects submitted to the National Energy Board representing some $500 \mathrm{bcma}$ of capacity. Due to project approval and fiscal complexity (and

\footnotetext{
${ }^{10}$ The term 'Net' taking into account LNG re-exports.

${ }^{11}$ Gomes (2015), Natural Gas in Canada: what are the options going forward?
} 

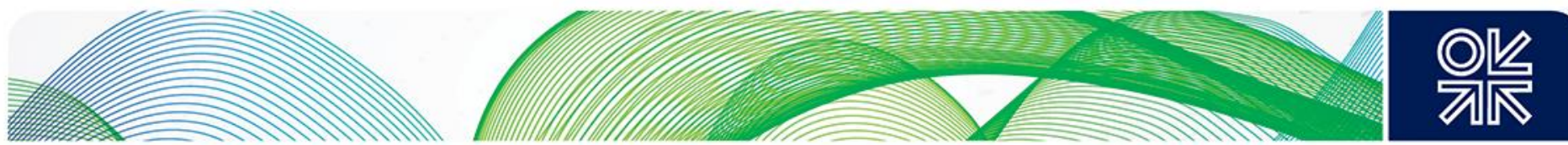

uncertainty) and a potentially high cost base, none are firmly progressing to FID in the current (2015) oil and gas price environment.

The author expects independent US quantitative studies to validate the EIA's estimates of shale gas production at least to 2030. Although the EIA tends to focus on the US market it should not be overlooked that Canadian gas exports to the US could in future ramp up if price signals indicated a requirement for Canadian gas to supplement supplies to meet US demand, Mexican exports and LNG exports from the US.

\section{Europe $^{12}$}

\section{Figure 8: European Supply and Demand 2008 - 2014}

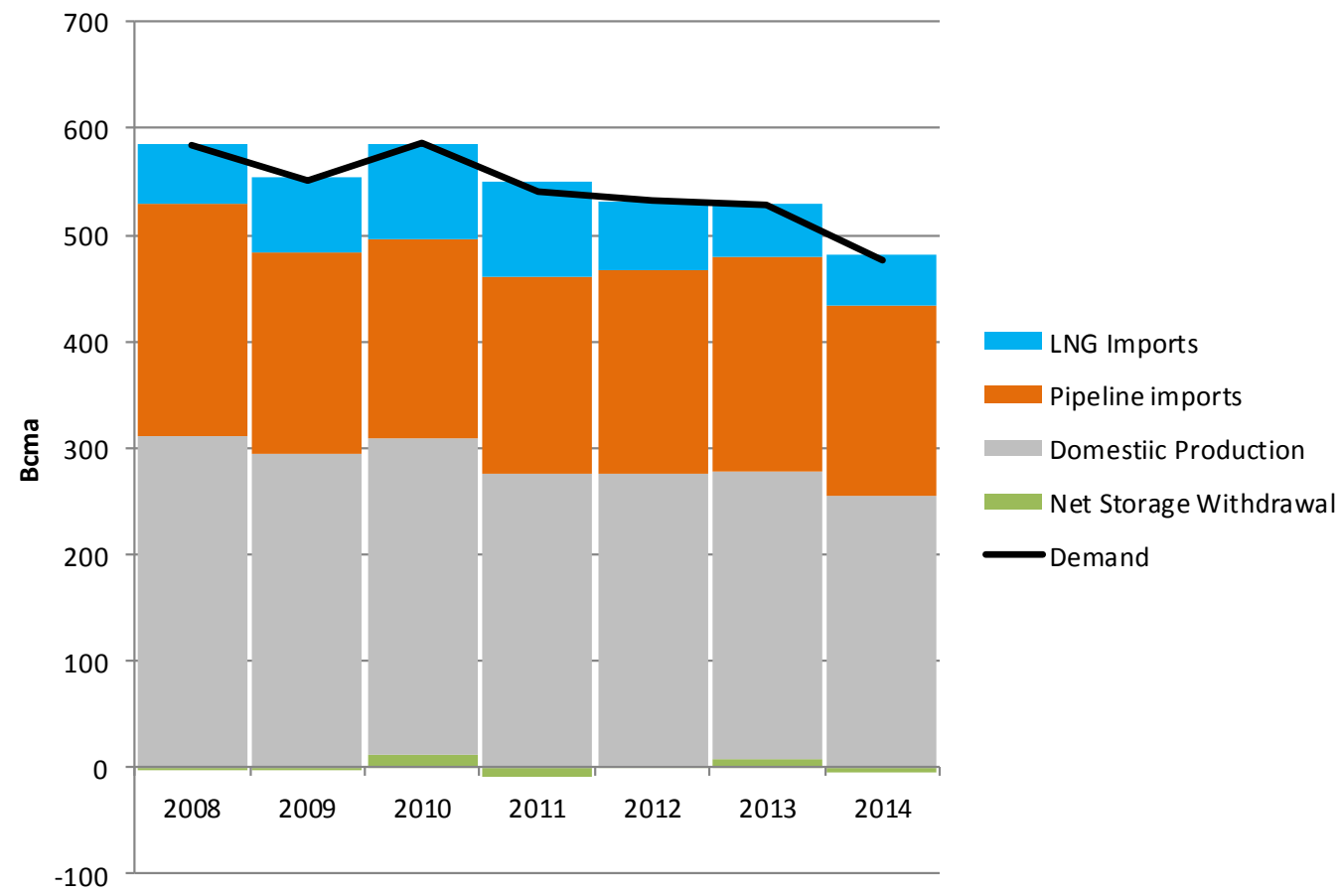

Sources: IEA Monthly Data Service, GIIGNL, Platts LNG Service

European gas demand since 2008 has reduced as a consequence of:

- The economic recession which has led to gas consumption in the industrial sector still below prerecession levels in 2014.

- Displacement of gas in the power sector by:

- Coal, especially in the UK and to a lesser degree in Spain.

- Renewables, especially in Germany, UK, Spain and Italy

- In the residential and commercial sectors, efficiency measures such as improved insulation, replacement of old central heating boilers with more efficient new condensing units and voluntary lower thermostat settings in the context of higher retail electricity prices and low disposable income growth.

\footnotetext{
${ }^{12}$ For the purposes of this regional analysis Europe is assumed to include: Austria, Belgium, Bulgaria, Croatia, Czech Republic, Denmark, Estonia, Finland, France, Germany, Greece, Hungary, Ireland, Italy, Latvia, Lithuania Luxembourg, Netherlands, Norway, Poland, Portugal, Romania, Serbia, Slovakia, Slovenia, Spain, Sweden, Switzerland, Turkey, UK.
} 

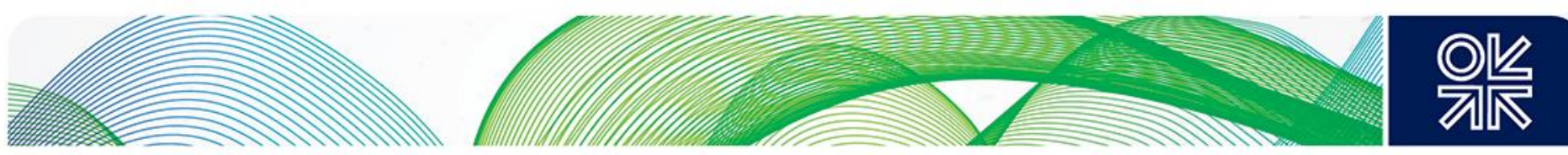

With reference to Figure 8, since the 2008 financial crisis, 2010 demand increased due to low winter temperatures, but subsequently demand has declined for the reasons suggested above with the mild winter of 2013/2014 leading to an even lower outcome relative to the general trend.

In her 2014 paper Anouk Honore ${ }^{13}$ proposes a trajectory for European demand with future increases due to:

- Increased use of gas in the power generation sector as a consequence of:

- Nuclear capacity net reduction

- Coal fired generation net reduction

- Limitations on wind and solar build-out due to state financing constraints.

- No significant reduction in Residential, Commercial and Industrial consumption levels given an assumed recovery in EU economic performance; and

- Tentative growth in the Natural Gas Transportation sector.

Figure 9 shows Anouk Honore's outlook (in blue) post 2016, and a notional lower demand case (red) which is not derived in a quantitative sense but would be generally consistent with:

- Continuing low Eurozone GDP growth and sluggish growth in energy intensive industries.

- No significant growth in gas in transport.

- No significant growth in gas in the power sector due to the inability of governments to curtail coal fired generation while at the same time investing heavily in renewable generation. No significant investment in commercial scale gas with CCS generation. Some nuclear prolongations.

Figure 9: European Demand 2008 - 2030

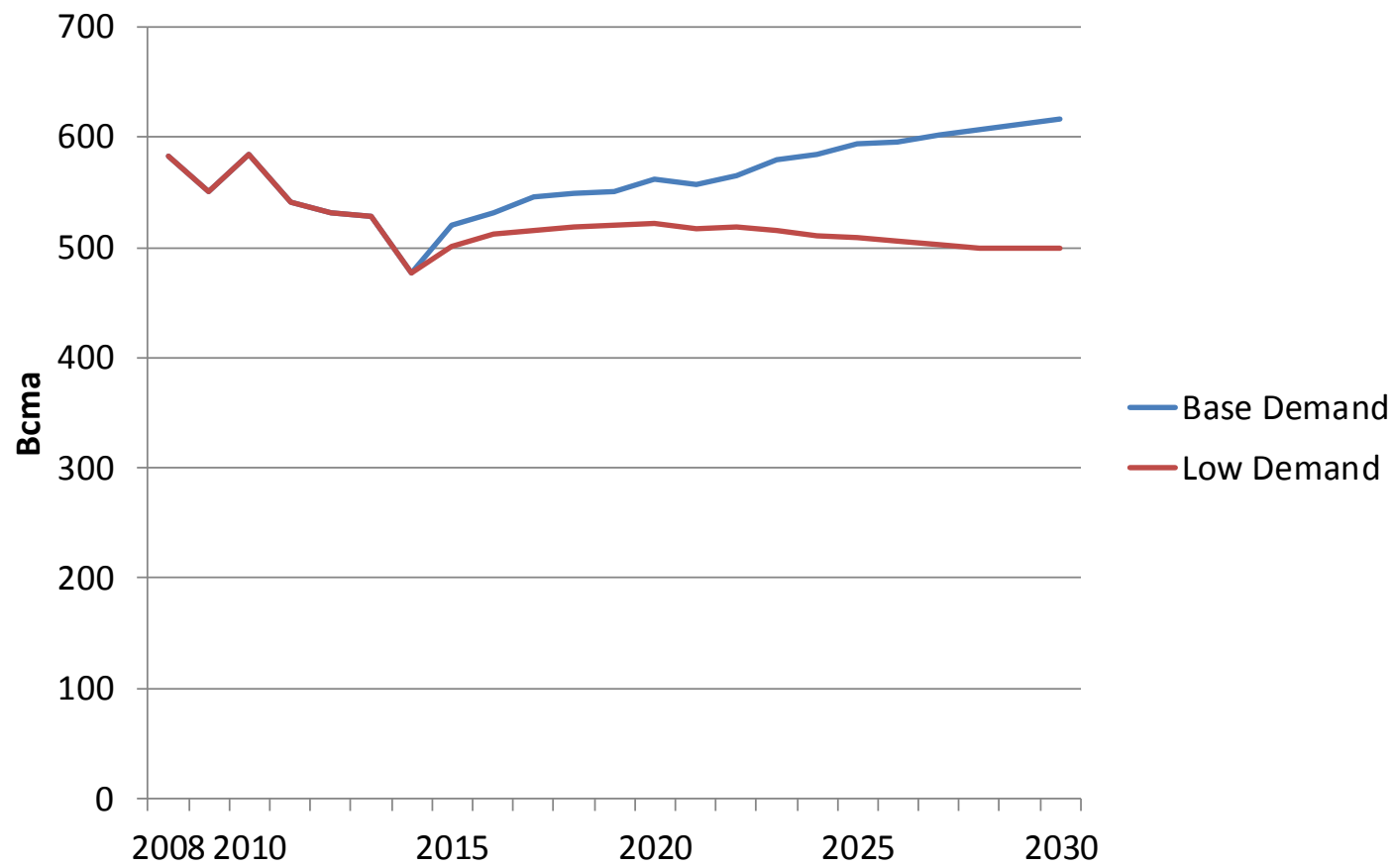

Source: Honore (2014), IEA Monthly Data Service, Author's Assumptions.

\footnotetext{
${ }^{13}$ Honore (2014), The Outlook for Natural Gas Demand in Europe
} 

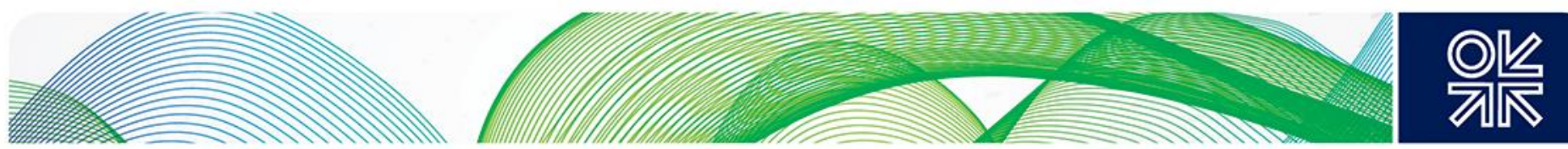

European Domestic Production (including Norway) is shown historically and as a future outlook in Figure 10.

Figure 10: European Domestic Production 2005 - 2030

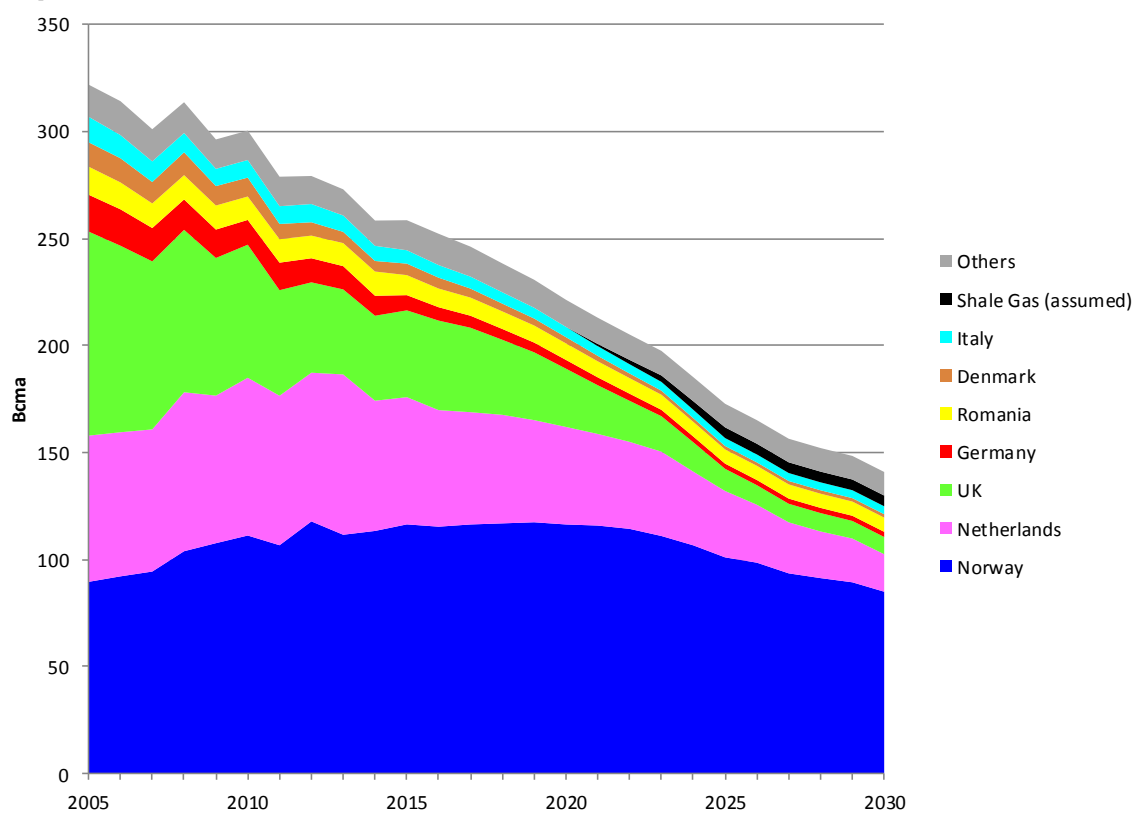

Source: Wood Mackenzie, Norwegian Ministry of Petroleum and Energy, Dutch Ministry of Economic Affairs, Energie Styrelsen (Denmark), overlaid by Author's Assumptions.

The main uncertainties in the outlook presented in Figure 10 are:

- The ability of Norway to maintain production from more northerly (and costly) new developments post 2020 . It is assumed that by 2030 production has fallen to $85 \mathrm{bcma}$.

- Restrictions on Groningen field production in the Netherlands. Pending final official limits the limit to Groningen production is assumed to be 30 bcma between 2015 and 2022. Contingent Resources and Yet to Find were also assumed to be below levels contained in the most recent Dutch Ministry of Economic Affairs outlook. By 2030 Dutch production is assumed to have fallen to $17 \mathrm{bcma}$.

- The rate of decline in the UKCS. The absolute level of production to 2030 will depend on the extent to which production from ageing fields can be maintained. By 2030 it is assumed production levels have declined to $8 \mathrm{bcma}$.

- Shale Gas success - a level of 5 bcma across Europe is assumed in Figure 10.Currently this appears optimistic given the level of public and institutional opposition to fracking in Europe and the sclerotic nature of approval and consent processes.

The European Region (including Turkey) receives imports of pipeline gas from Russia, Algeria, Libya, Azerbaijan and Iran. Figure 11 shows the historic and future outlook for pipeline imports from these sources. 

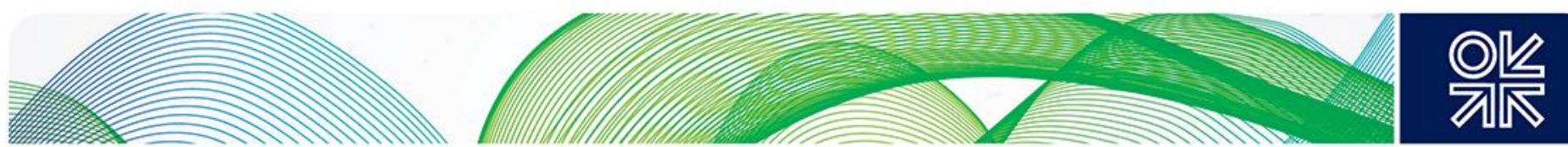

Figure 11: Historic and Future Outlook for Europe Region Pipeline Imports

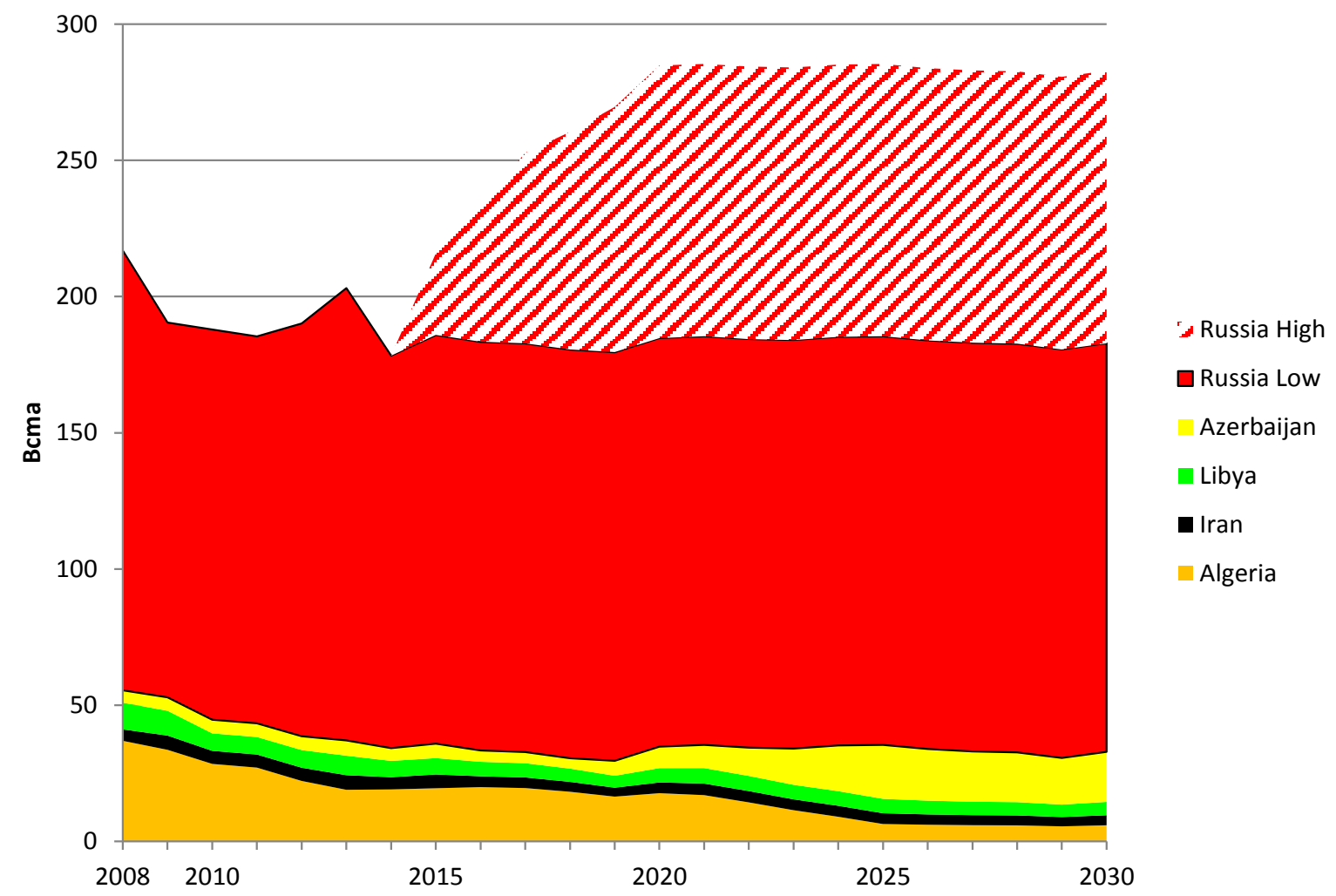

Sources: BP Statistical Review of World Energy, IEA, Author's Assumptions

Future North African pipeline imports to Europe are limited due to ${ }^{14}$ :

- The failure of Algeria's upstream developments to keep pace with burgeoning domestic demand (stimulated by low regulated domestic prices); and,

- Uncertain future gas prospectivity and ongoing civil unrest in Libya

The prospect for Azerbaijan supplies shows growth towards the end of this decade with the commissioning of Shah Deniz Phase 2. Beyond 2020 there is scope for further volumes from Azerbaijan though this will be tempered by the availability of drilling rigs and sometimes challenging sub-surface conditions ${ }^{15}$

Russia is by far the most significant supplier of pipeline gas to Europe. While supplies in recent years have been around the aggregate of contract Take or Pay levels (or just above, as some Take or Pay levels have been reduced), Russia has a significant surplus of production capacity which has grown due to:

- Large investments in upstream fields (notably the Bovanenkovskoye field on the Yamal peninsula) in anticipation of optimistic projections of European demand growth, made in the early 2000s.

\footnotetext{
${ }^{14}$ See Stern (2014), pp $17-20$

${ }^{15}$ See Rzayeva (2015)
} 

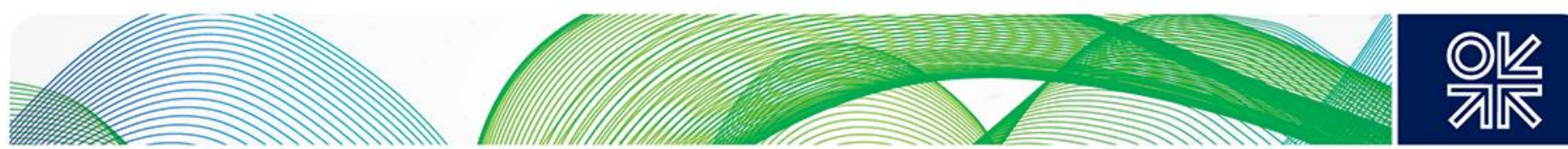

- Additional Gazprom production which is surplus to domestic market requirements as a consequence of the growth of non-Gazprom producers who have captured market share in the Russian domestic market.

The red hatched area in Figure 11 is a broad indication of spare production capacity which could be made available for Europe should demand for it develop. This underlines the role of Russia as the 'global LNG system shock-absorber' as indicated in Figure 4. Even if the Altai pipeline to China proceeds (30 bcma) it would still leave some 70 bcma of production capacity available for Europe - in addition to huge remaining West Siberian undeveloped resources to call on.

Figure 12 illustrates the scale of contractual commitments which European buyers have with Gazprom. This contract portfolio remains at levels above 100 bcma (aggregate ACQs) to 2030 and many contracts continue beyond this date.

We will assess the challenges and options available to Russia/Gazprom in the European gas market in detail in Chapter 3.

Figure 12: Russian long-term export contracts with OECD European countries to 2030: annual contract quantity and take-or-pay levels*

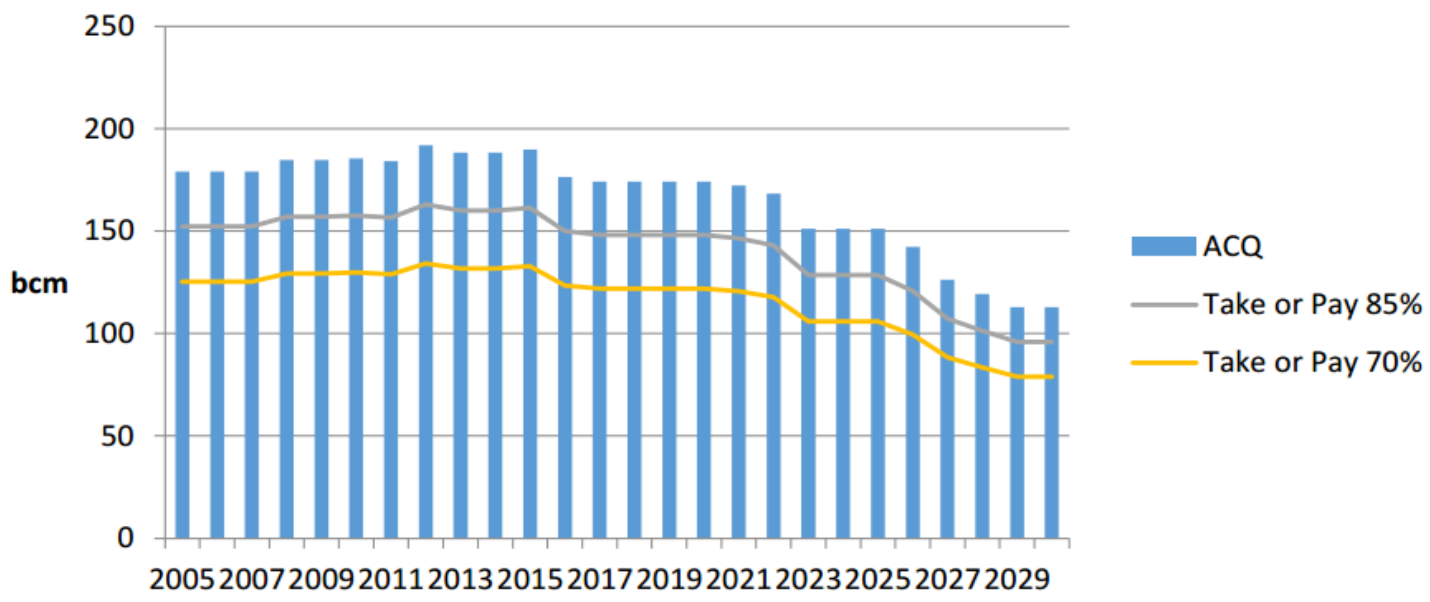

* Data in Russian units; not including Baltic and south East European countries (aside from Turkey and Greece).

Source: ERI RAS in Henderson and Pirani (2014), Figure 3.3, p. 60

This can be seen in the variability of monthly country import levels in Figure 13.

Europe has a total regas capacity of 202.7 bcma $^{16}(555 \mathrm{mmcm} /$ day) which is well in excess of even the peak import months of 2011. 

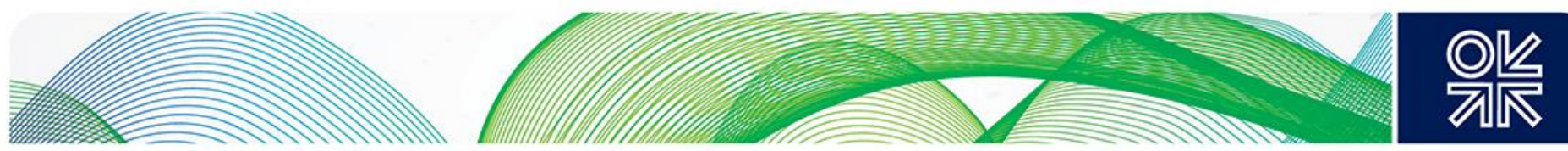

Figure 13: European Monthly LNG Net Imports 2005 - 2015

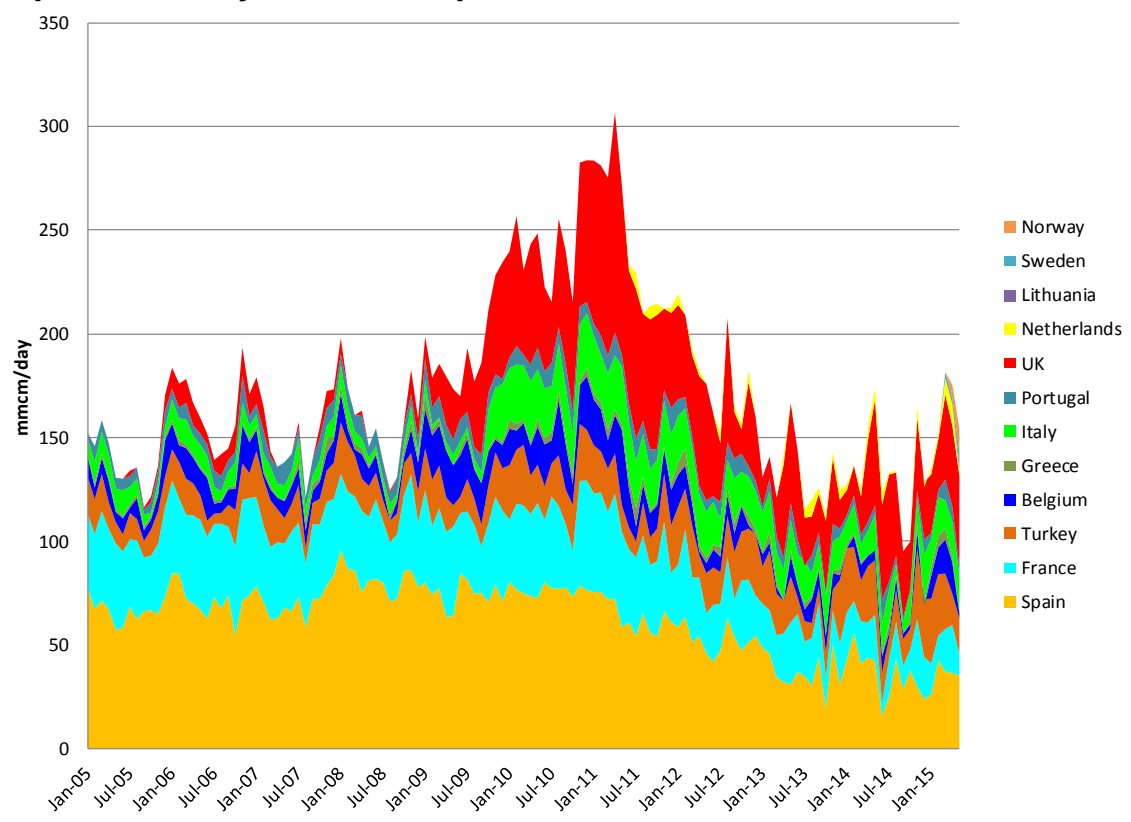

Source Platts: LNG Service

Europe represents a key nexus in terms of global gas tradeflows. Whilst there is some uncertainty on its future import requirements, particularly due to uncertainties in future demand trajectory, its status as 'market of last resort' for LNG, surplus to other regional requirements, creates uncertainty for Russia (the system 'shock absorber') and hence the potential for alternative Russian price/volume strategies, addressed in Chapter 3.

\section{Asia}

Figure 14: Asia Pacific Annual Gas Consumption 1995 - 2014

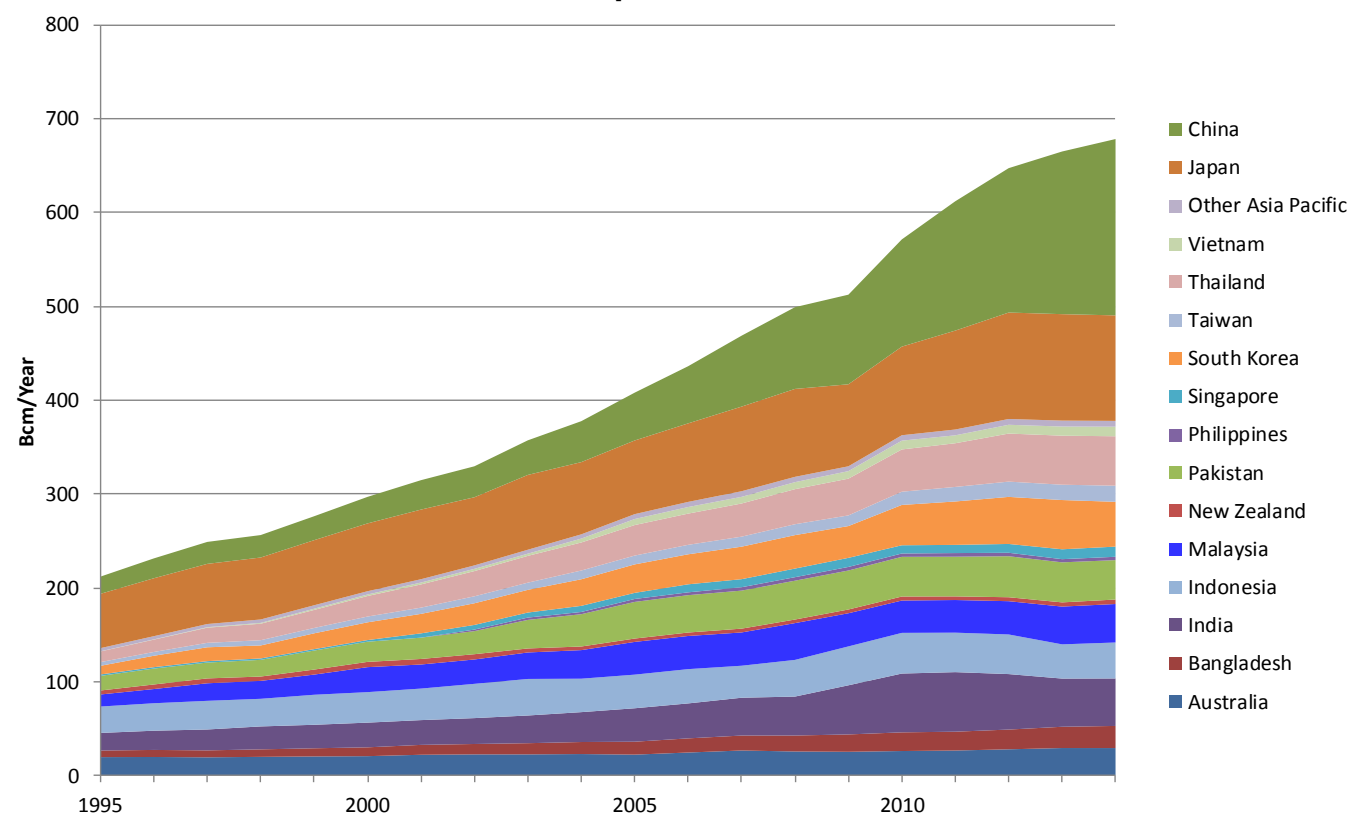

Source: BP Statistical Review of World Energy 2015 

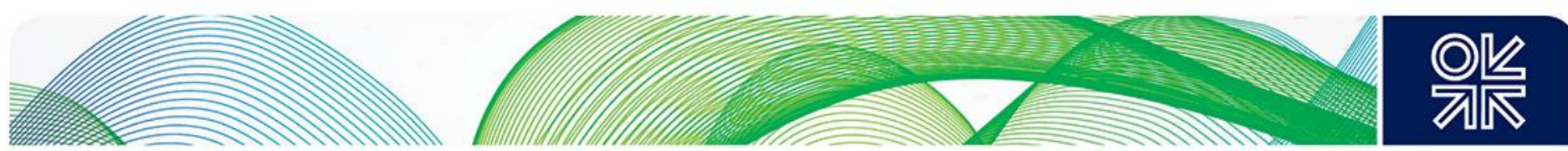

Figure 14 shows the annual gas consumption of countries classified as 'Asia Pacific' in the 2015 BP Statistical Review of World Energy ${ }^{17}$ for 1995 to 2014. Annual average demand growth for these countries in total was $6.3 \%$ in the period. Of note however is that 2014 saw a significant slowing of demand growth, with aggregate regional demand only $\%$ above 2013.

The corresponding picture of gas production in this region is shown in Figure 15, with a total demand line added to illustrate the scale of the region's net import requirement.

Although the aggregate consumption level in the 2010s for Asia as a whole is significant, i.e. some $20 \%$ above that of the European region, it is important to appreciate how modest is gas's share of total primary energy consumption in many Asian markets. Figure 16 depicts this for key LNG importing markets in the region.

Figure 15: Asia Pacific Annual Gas Production 1995 - 2014

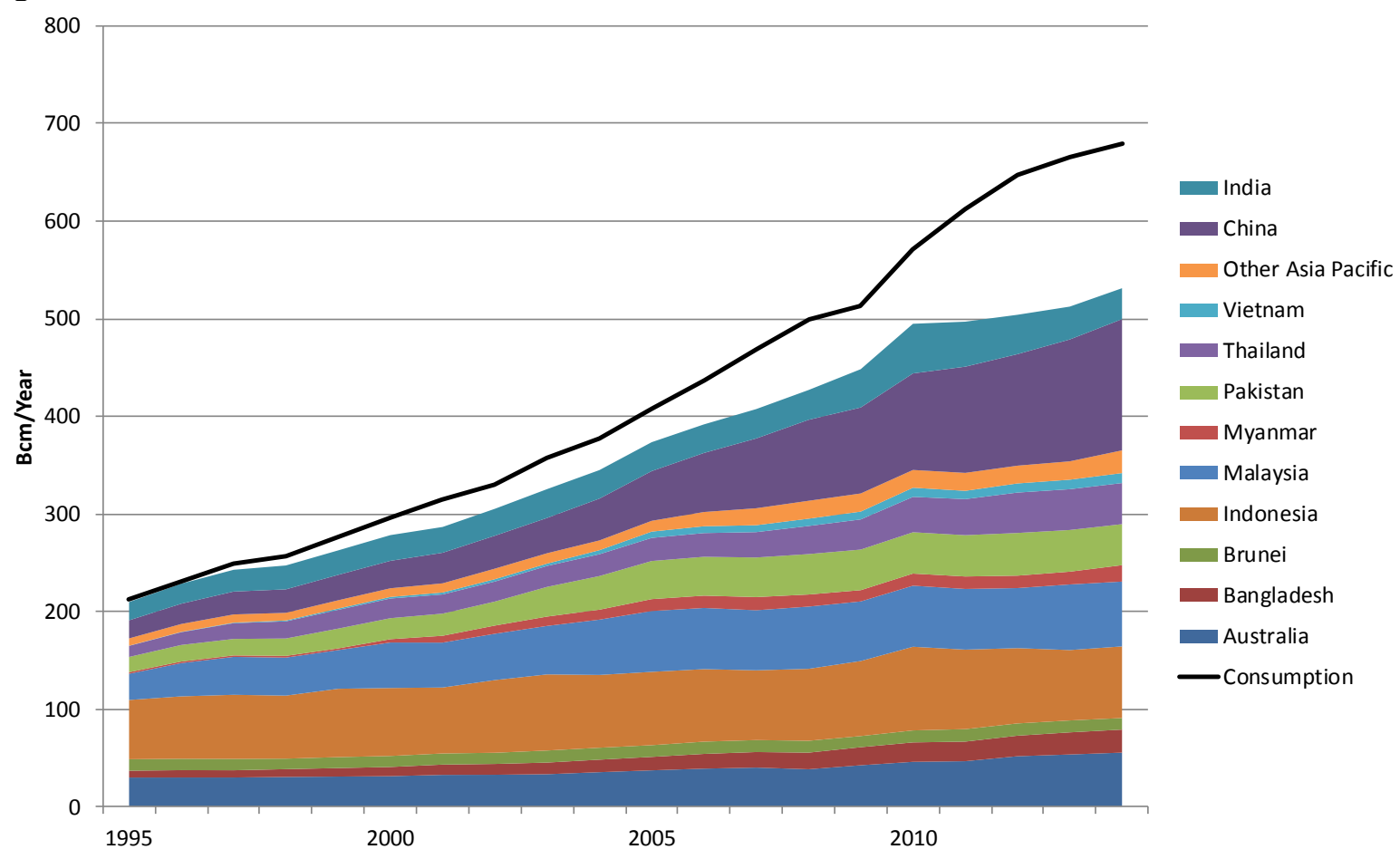

Source: BP Statistical Review of World Energy 2015

Against a gas share of primary energy consumption benchmark of $21.6 \%$ for the EU in 2014 , the corresponding figures for Japan, South Korea, Taiwan, India and China are: $22.2 \%{ }^{18}, 15.7 \%, 13.8 \%$, $7.1 \%$ and $5.6 \%$.

Japan, the world's largest LNG importer, is generally viewed as a mature market for gas. In 2014 its gas consumption was $132 \mathrm{bcma}$ of which only $2.8 \mathrm{bcma}^{19}$ was provided by domestic production; the remainder being LNG imports. The Fukushima disaster of March 2011 led to the progressive closure of all nuclear power generation plant. Start-up of a substantial portion of the (undamaged) nuclear fleet remains subject to delays. Eventual start-up may result in lower LNG import requirements,

\footnotetext{
${ }^{17}$ Workbook available at http://www.bp.com/en/global/corporate/about-bp/energy-economics/statistical-review-of-worldenergy.html

${ }^{18}$ Influenced by the post-Fukushima nuclear shutdown. In 2010 gas' share in Japanese primary energy consumption was $16.8 \%$.

${ }^{19}$ Niigata Prefecture Crude Oil and Natural Gas Production Overview,

http://www.pref.niigata.lg.jp/sangyoshinko/1277420479789.html
} 

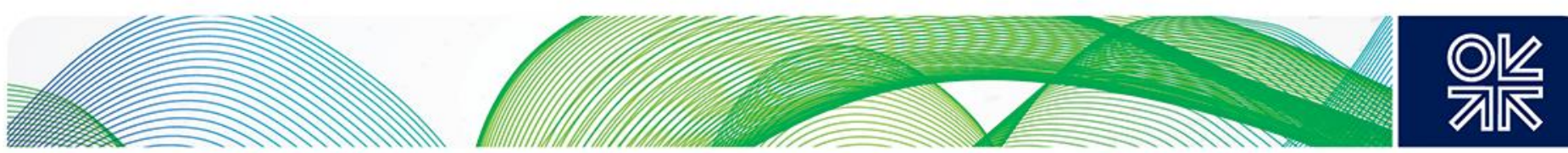

however the pace may be so slow that it is offset by continued, albeit tepid underlying demand growth.

South Korea imported 51.1 bcma of LNG in 2014, down from $54.2^{20} \mathrm{bcma}$ in 2013 . This was all the more surprising given the country's post-recession LNG consumption growth - up from 34.5 bcma in 2009. In large part the 2014 figure was a consequence of the re-start of several nuclear reactors which had been offline in 201321. A mild 2013/2014 winter may also have reduced LNG demand requirements. The future trajectory of South Korean LNG demand growth is therefore subject to uncertainty.

Figure 16: Composition of Primary Energy Consumption in Key Asian LNG Importing Markets 1995 - 2014

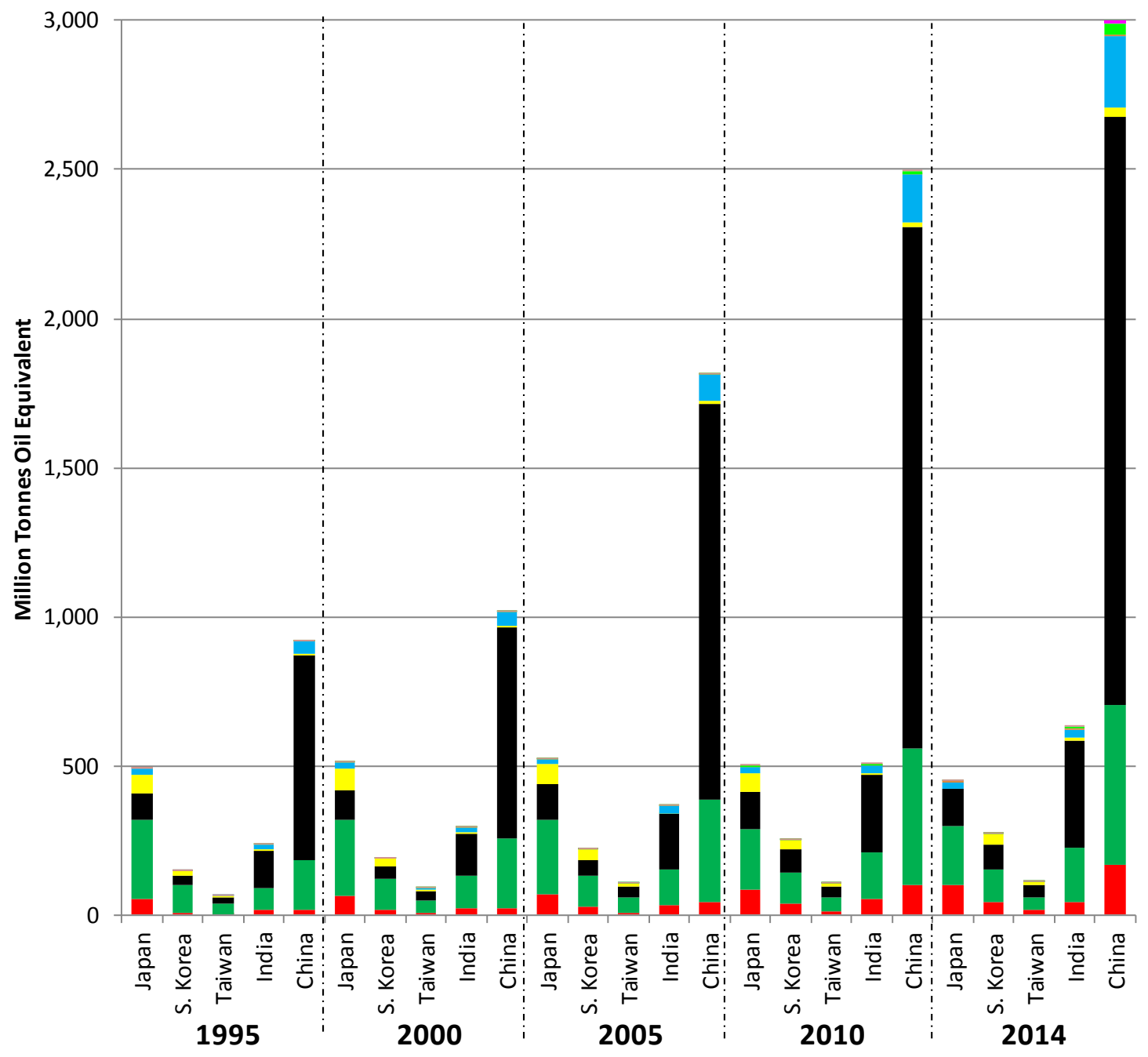

$\square$ Gas Oil $\square$ Coal Nuclear Hydro Solar Wind Geothermal, Biomass \& Other Renewables

Source: BP Statistical Review of World Energy 2015

\footnotetext{
${ }^{20}$ BP Statistical Review of World Energy 2015 and 2014

21 'South Korean LNG Imports fall as nuclear output stabilises', Interfax Global Energy, 22 $2^{\text {nd }}$ January 2015, http://interfaxenergy.com/gasdaily/article/15071/south-korean-Ing-imports-fall-as-nuclear-output-stabilises
} 

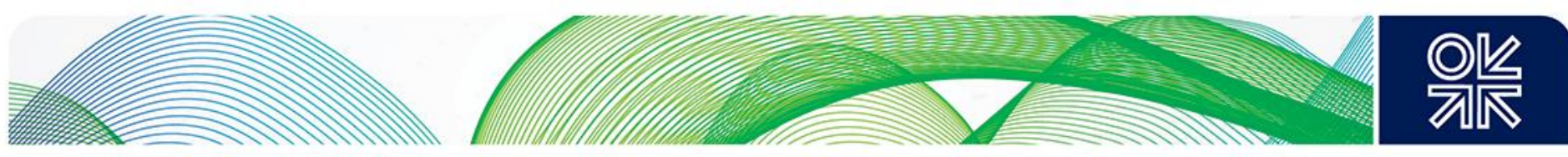

Taiwan imported $18.1 \mathrm{bcma}$ of LNG in 2014, up 5\% on its 2013 level of $17.2 \mathrm{bcma}$. Future demand may be maintained by the decommissioning of $600 \mathrm{MW}$ of coal-fired power in late 2014 and the halt to construction of one of four new nuclear power plants.

India's demand for natural gas in 2014 was satisfied by 31.7 bcma of domestic production and 18.9 bcma of LNG. Gas has a small yet complex role in the Indian energy (see Sen (2015)) ${ }^{22}$. India's gas production has declined (see Figure 15) due to unexpected reservoir issues in the KG-D6 block offshore field and a slow pace of exploration and development as a consequence of low regulated prices paid for domestic production. On the demand side gas consumption in the fertiliser sector is premised on subsidised feedstock prices. Gas cannot compete with coal in power at prices above around $\$ 5 / \mathrm{mmbtu}$ and growth in the residential commercial and industrial sectors is dependent to a degree on access-enabling infrastructure. In the absence of higher regulated prices to stimulate the domestic upstream sector, and the fulfilment of speculative pipeline import projects, India will rely on LNG imports to meet its incremental gas requirements. The outlook for India's import growth is uncertain however, but affordability and infrastructure limitations place an upper bound on expectations.

China's gas demand has grown from $18.3 \mathrm{bcm}$ in 1995 to $188 \mathrm{bcm}$ in 2014. Despite this it still only represented $5.6 \%$ of total Chinese energy demand in 2014. As demand outstripped domestic production China began imports of LNG in 2006, pipeline gas from Turkmenistan in 2010 and Myanmar in 2014. China's endeavours to develop its Coal Bed Methane resources have achieved modest results (3.6 bcm production in 2014) and shale gas may be a similar story (1.3 bcm in 2014) 23 . Several projects to develop synthetic methane from coal have been undertaken, however these have faced problems of water availability and cost overruns. With no carbon capture and storage provisions planned they would constitute a significant additional $\mathrm{CO}_{2}$ emission source (while mitigating particulate smog from coal-fired power). This is an area requiring monitoring however as some of the plants may proceed to completion ${ }^{24}$.

The largest future uncertainties relating to China's gas consumption are:

- The future economic growth rate and the nature of such growth (infrastructure, energy-intensive industry vs consumer-based industries and services).

- The nature and scale of energy policies favouring gas relative to coal, renewables, nuclear and hydro.

- The future growth of Chinese domestic production (conventional, Coal Bed Methane, Shale), Coal to Syngas production levels; and as a consequence,

- The scale of additional gas imports required, and whether this is pipeline gas (Turkmenistan and Central Asia, Russian gas from East and West Siberia), and/or LNG.

Future Chinese natural gas demand was forecast at $400-429$ bcma by 2020 by the Chinese NDRC in early $2014^{25}$. With the slowdown in economic growth (the 'new normal') and the professed aim of rebalancing away from state-directed export-oriented industry and infrastructure build, by end 2014 CNPC had produced three scenarios for future Chinese demand as shown in Figure $17^{26}$. The blue line corresponds to that of the IEA 2014 World Energy Outlook (295 bcma for 2020) in the New Policies Scenario. ${ }^{27}$

\footnotetext{
${ }^{22} \operatorname{Sen}(2015)$

23 'China's 2014 Unconventional gas output soars $42 \%$ on year to 4.9 bcm', Platts, http://www.platts.com/latest-news/naturalgas/singapore/chinas-2014-unconventional-gas-output-soars-42-27013858

24 'Can China's Bid to Turn Coal to Gas Be Stopped?, Scientific American, October 29' 2014

http://www.scientificamerican.com/article/can-china-s-bid-to-turn-coal-to-gas-be-stopped/

${ }^{25}$ Chen (2014), P. 4

26 'Challenges for Imported LNG in China', CNPC, $6^{\text {th }}$ November 2014, http://aperc.ieej.or.jp/file/2014/11/20/s2_d5_cnpc.pdf

${ }^{27}$ IEA (2014), P. 139
} 

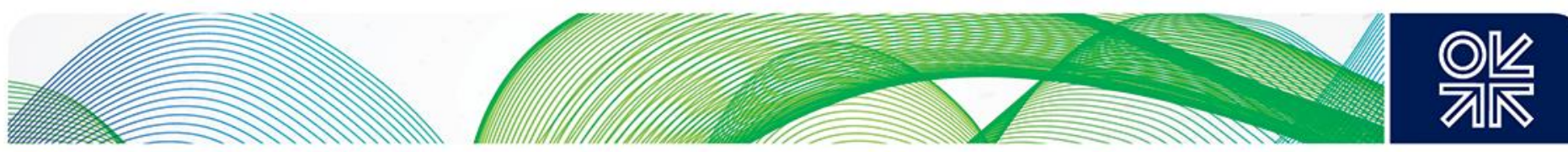

With demand for 2014 implying a slowdown in gas consumption growth, two illustrative demand projection cases were used for the purposes of this analysis - low (red line) and high (green line).

\section{Figure 17: China Natural Gas Demand - Low and High Cases}

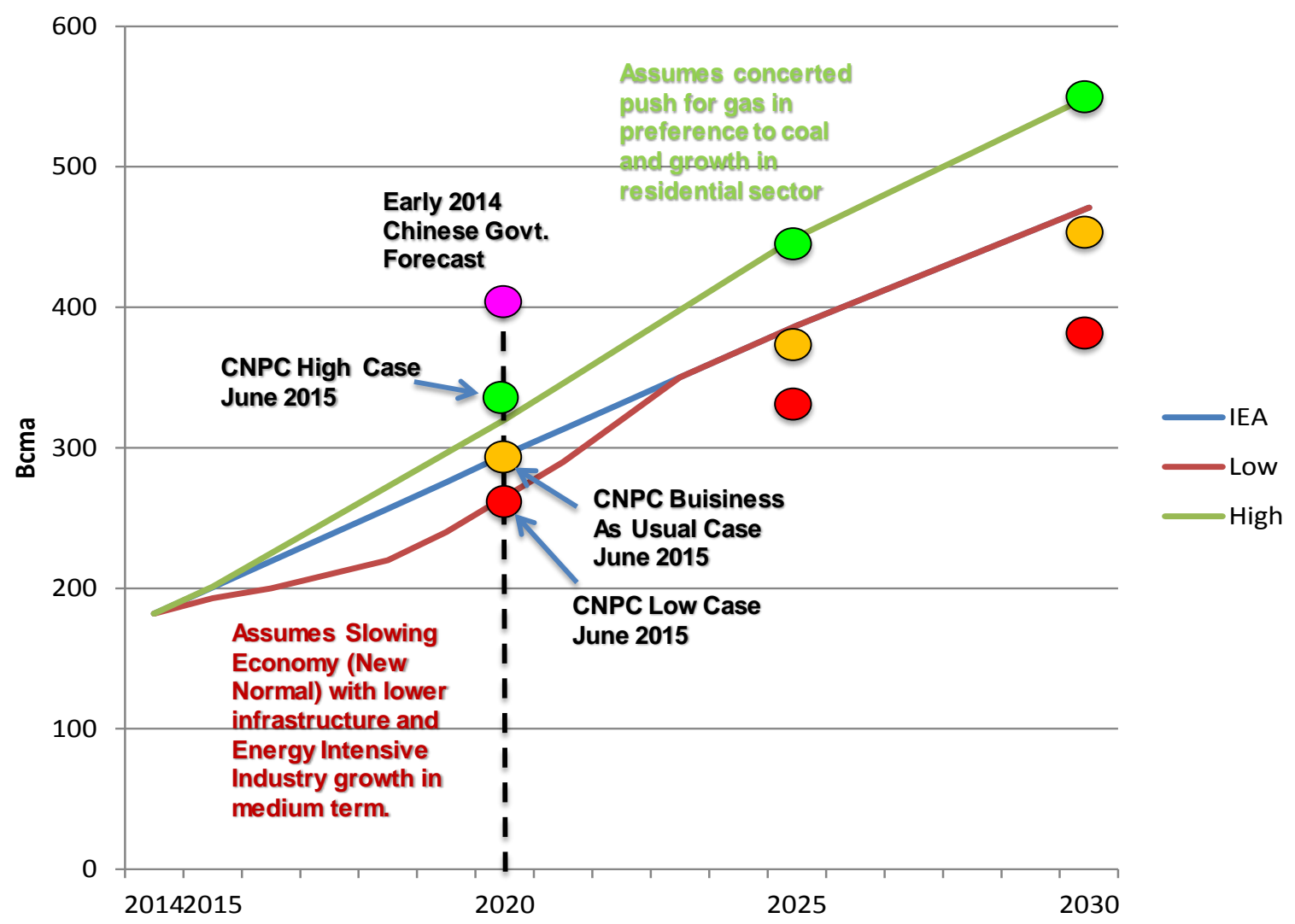

Sources: IEA (2014), Challenges for Imported LNG in China ${ }^{28}$, Author's Assumptions

From these cases, using projections for domestic production and assumptions on the level of future pipeline imports, Figures 18 and 19 show the possible supply make-up for the low and high Chinese demand cases.

It is reasonable to expect short term demand to be stimulated by low spot and contract LNG prices, potentially in the industrial sector. However this was not the case in the second half of 2014 and early 2015 despite there being unused Chinese regas capacity.

\footnotetext{
${ }^{28}$ http://aperc.ieej.or.jp/file/2014/11/20/s2_d5_cnpc.pdf
} 

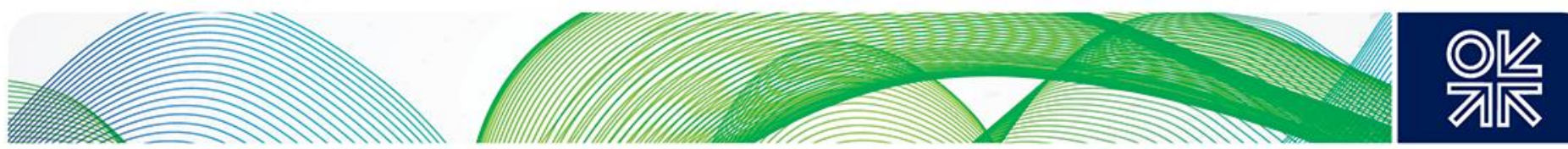

Figure 18: Chinese Demand and Supply Composition - Low Case

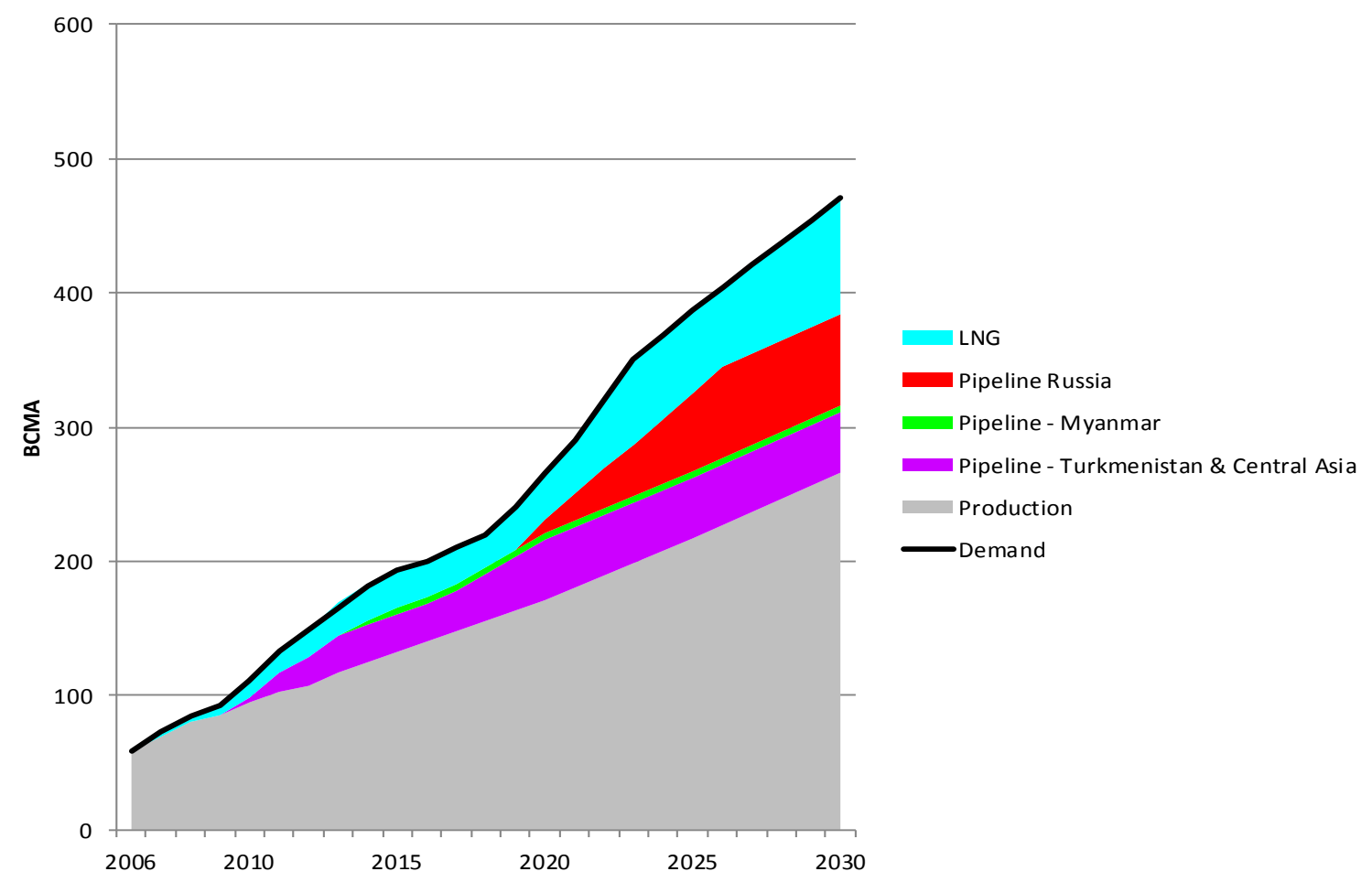

Sources: IEA 2014, Author's Assumptions

Figure 19: Chinese Demand and Supply Composition - High Case

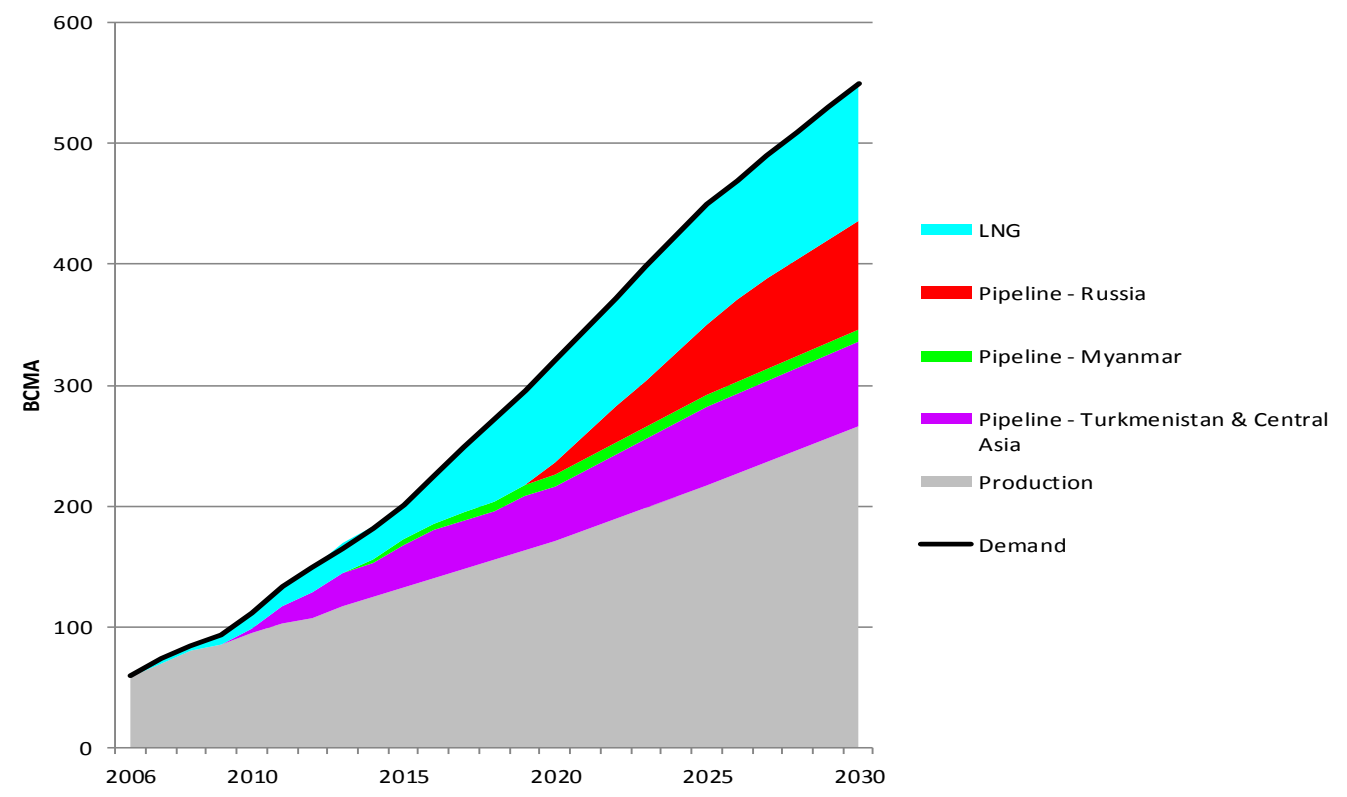

Sources: IEA 2014, Author's Assumptions

Of the other Asian LNG importers Singapore's requirements may grow to some 15 bcma by 2030 as its gas demand grows and pipeline supplies diminish. Indonesia's internal requirements for gas are 

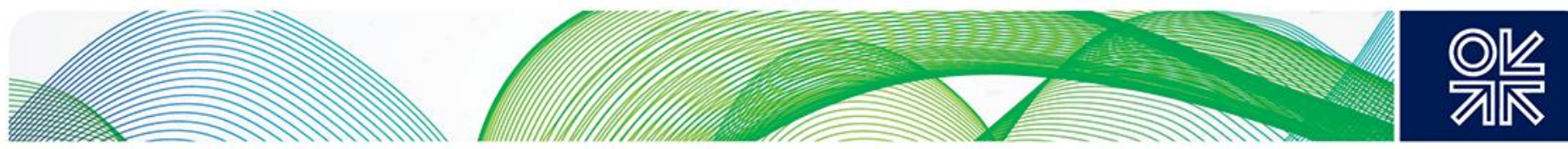

likely to be increasingly satisfied by LNG trade within the archipelago. These volumes are included in Table 1 and Figure 20, which show estimates for all Asian market LNG requirements.

\section{Table 1: Asian LNG Demand (Bcma) 2010 to 2030}

Japan

South Korea

Taiwan

India

Singapore

Pakistan

Thailand

Indonesia

Bangladesh

Vietnam

Phillipines

Malaysia

Bunkers

China (Low Case)

China (High Case) Increment

$\begin{array}{rrrrrrrrrr}2010 & 2011 & \mathbf{2 0 1 2} & \mathbf{2 0 1 3} & \mathbf{2 0 1 4} & \mathbf{2 0 1 5} & \mathbf{2 0 1 6} & \mathbf{2 0 1 7} & \mathbf{2 0 1 8} & \mathbf{2 0 1 9} \\ 96 & 107 & 119 & 119 & 122 & 119 & 120 & 119 & 118 & \\ 46 & 49 & 50 & 55 & 51 & 46 & 51 & 52 & 53 \\ 16 & 17 & 17 & 17 & 18 & 18 & 17 & 18 & 18 \\ 13 & 17 & 19 & 18 & 20 & 20 & 24 & 26 & 28 \\ 0 & 0 & 0 & 1 & 2 & 3 & 3 & 4 & 4 \\ 0 & 0 & 0 & 0 & 0 & 2 & 3 & 3 & 3 \\ 0 & 1 & 1 & 2 & 2 & 4 & 7 & 7 & 7 \\ 0 & 0 & 0 & 0 & 1 & 4 & 4 & 4 & 5 \\ 0 & 0 & 0 & 0 & 0 & 0 & 0 & 0 & 0 \\ 0 & 0 & 0 & 0 & 0 & 0 & 0 & 1 & 3 \\ 0 & 0 & 0 & 0 & 0 & 0 & 0 & 0 & 0 \\ 0 & 0 & 0 & 1 & 2 & 3 & 3 & 4 & 5\end{array}$

$\begin{array}{rrrrr}\mathbf{2 0 1 9} & \mathbf{2 0 2 0} & \mathbf{2 0 2 1} & \mathbf{2 0 2 2} & \mathbf{2 0 2 3} \\ 118 & 118 & 119 & 119 & 12 \\ 54 & 55 & 56 & 57 & 58 \\ 19 & 20 & 20 & 21 & 2 \\ 30 & 32 & 35 & 37 & 4 \\ 5 & 6 & 6 & 7 & \\ 4 & 4 & 4 & 4 & \\ 7 & 7 & 7 & 7 & \\ 7 & 8 & 10 & 11 & 1 \\ 0 & 0 & 0 & 0 & \\ 1 & 1 & 2 & 2 & \\ 1 & 1 & 1 & 2 & \\ 6 & 6 & 6 & 7 & \end{array}$

Total High Case

Figure 20: Asian LNG Demand 2010 - 2030

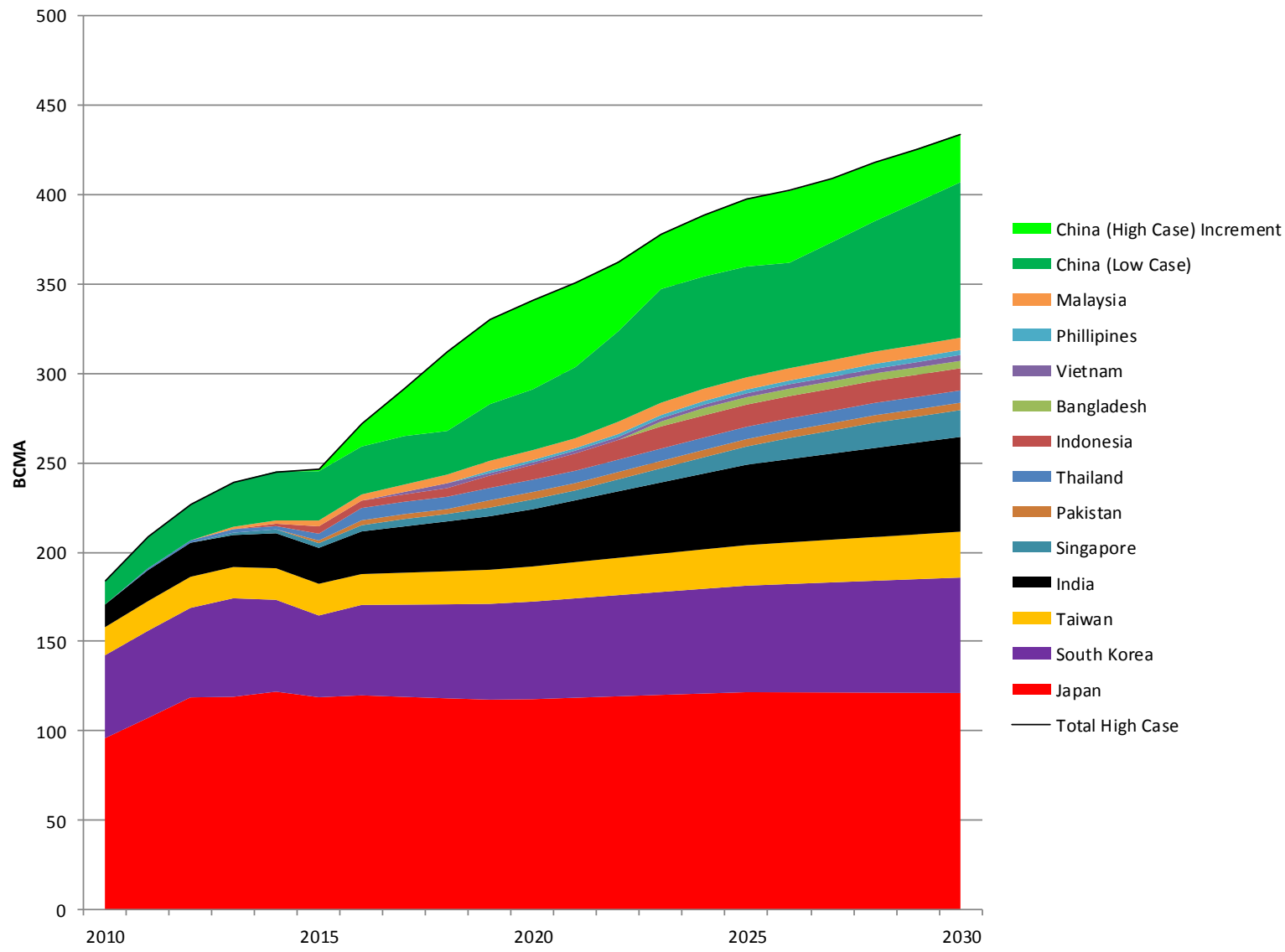

Sources: IEA 2014, Platts Monthly LNG Service, Ledesma OIES, Author's Assumptions 

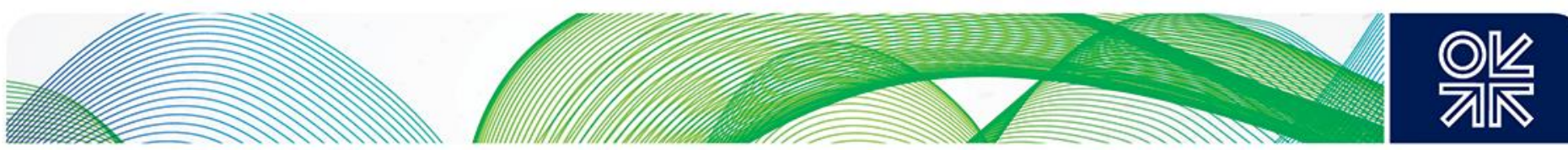

\section{Non-Asian Niche and New Markets}

Figure 21: Niche and New Market LNG Demand 2010 - 2030, Bcma

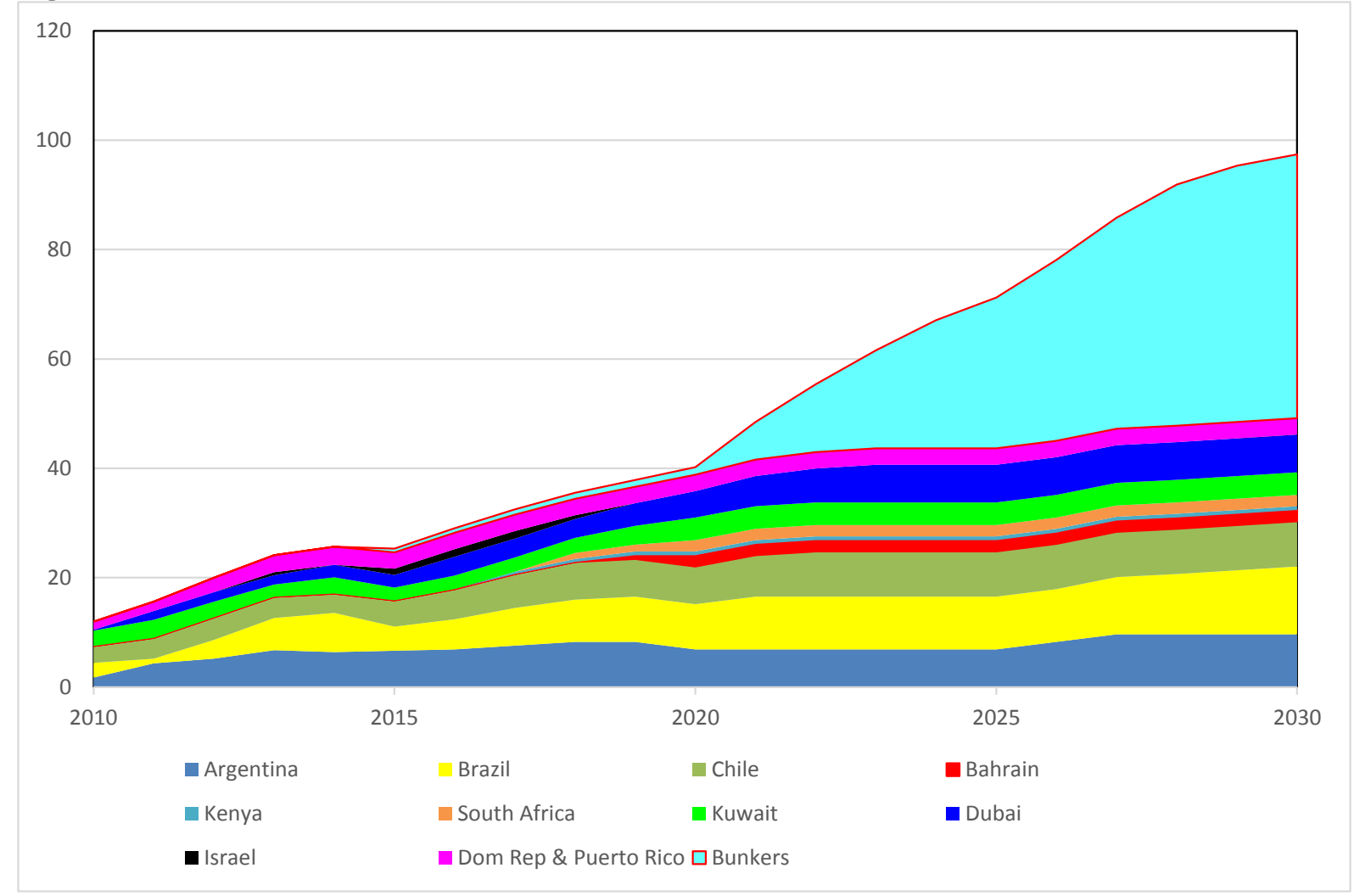

Sources: GIIGNL, Ledesma OIES, Author's Estimates

Figure 21 shows LNG demand in what are here termed niche and new markets. Projecting future LNG demand in Argentina, Brazil and Chile is complicated by factors such as the timing of future domestic gas production as upstream investment frameworks and regulated pricing is improved and, in the case of Brazil, the vagaries of hydro availability (heavily influenced by the El Nino phenomenon). Existing and potential Middle East and African markets will depend more or less on LNG to supplement their failure to reform low regulated wholesale gas prices and thus incentivise the development of domestic gas production. Dominican Republic and Puerto Rico are small and established LNG markets whose upside potential is limited by market scale. The use of LNG as a maritime fuel (Bunkers) will potentially become very significant in the 2020s. At present estimates vary significantly and the trajectory in Figure 21 is a notional early estimate.

Apart from Bunkers, the aggregate demand for these new and niche markets is of secondary importance in the context of the wider 'system' scale. 

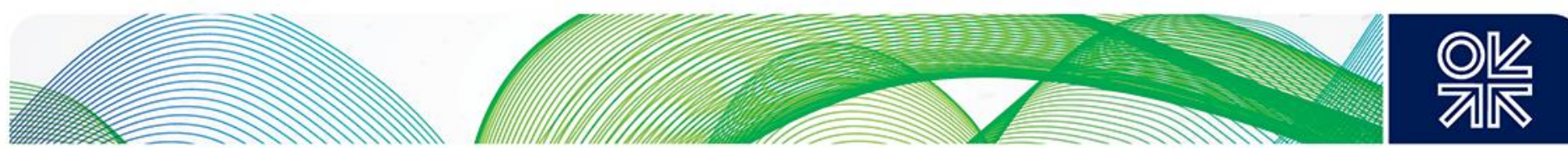

\section{LNG Supply}

Figure 22: LNG Supply 2008 - 2020

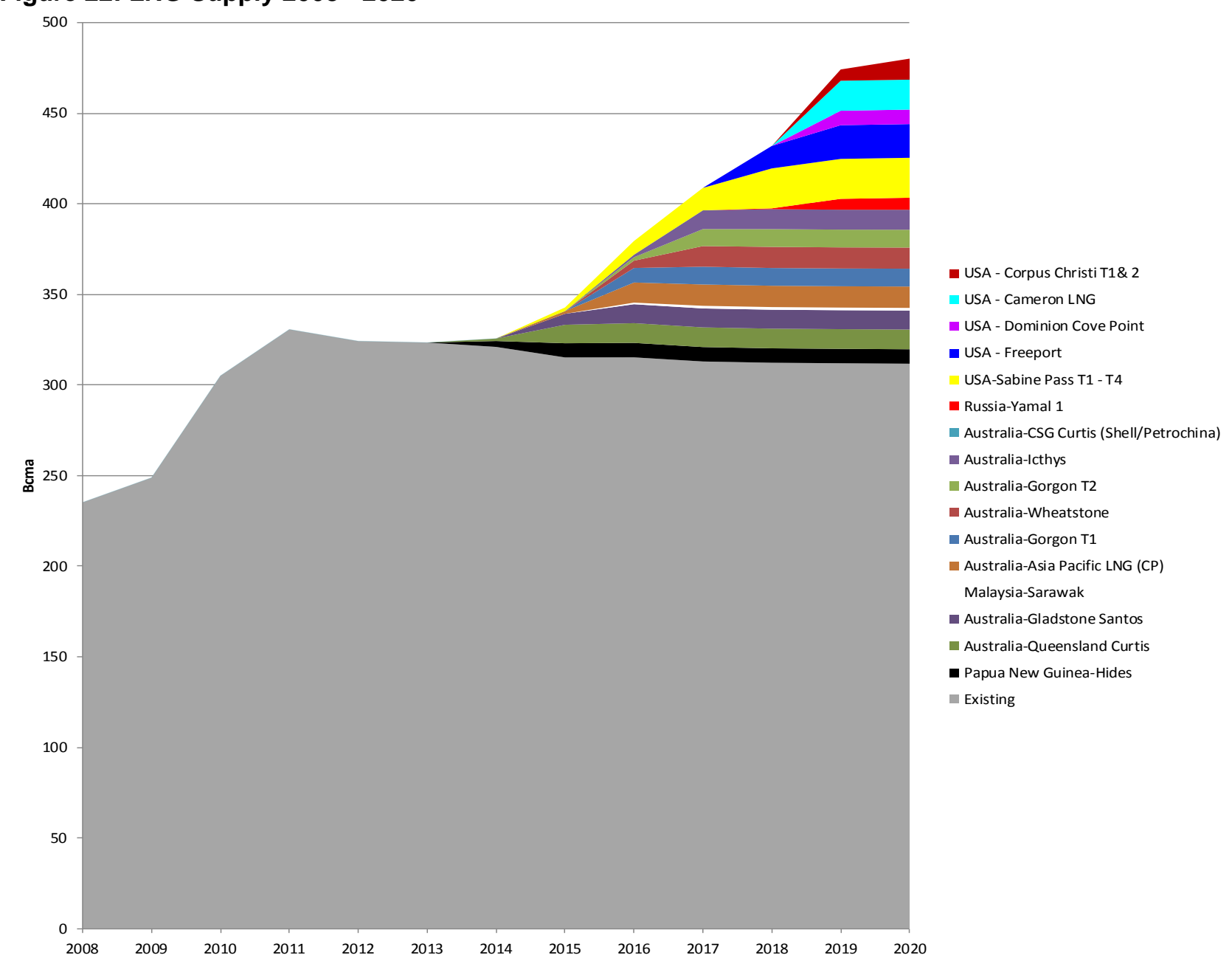

Source: Company Reports

Figure 22 shows, in grey, the LNG output from existing LNG liquefaction plant prior to the start-up of Papua New Guinea in $2014^{29}$. The coloured layers represent the supply potential to 2020 from LNG projects which have achieved FID and are under construction or have recently commenced production. This illustrates the scale of the ramp-up from new projects after the hiatus in the growth of global LNG supply between 2011 and 2015.

Figure 23 shows the projected view of global LNG supply to 2030 with probability factors applied to the less certain future projects which have not yet achieved FID. This is based on project FID timings as viewed in early 2014, prior to the fall in oil price and increased uncertainty on future Asian LNG demand. The specific assumptions for each of the future projects considered are contained in Table 2 in Appendix 1. It is however worth addressing the increased challenges facing LNG project developers in the market environment of 2015.

\footnotetext{
${ }^{29}$ Note that the decline in output from the early Indonesian plants and the ongoing under-performance of Egypt, Algeria, Nigeria and Yemen explain the recent and projected decline in output from existing facilities.
} 

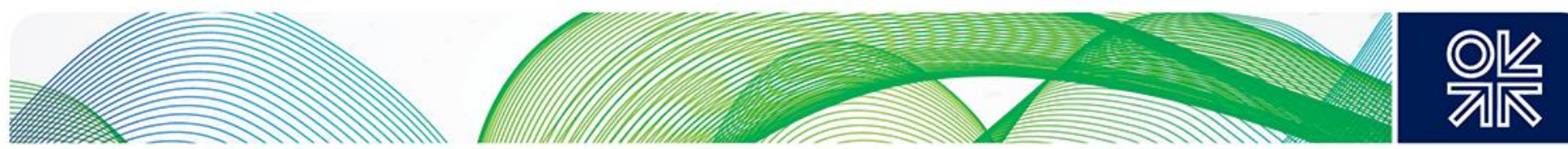

Figure 23: Global LNG Supply 2008 - 2030

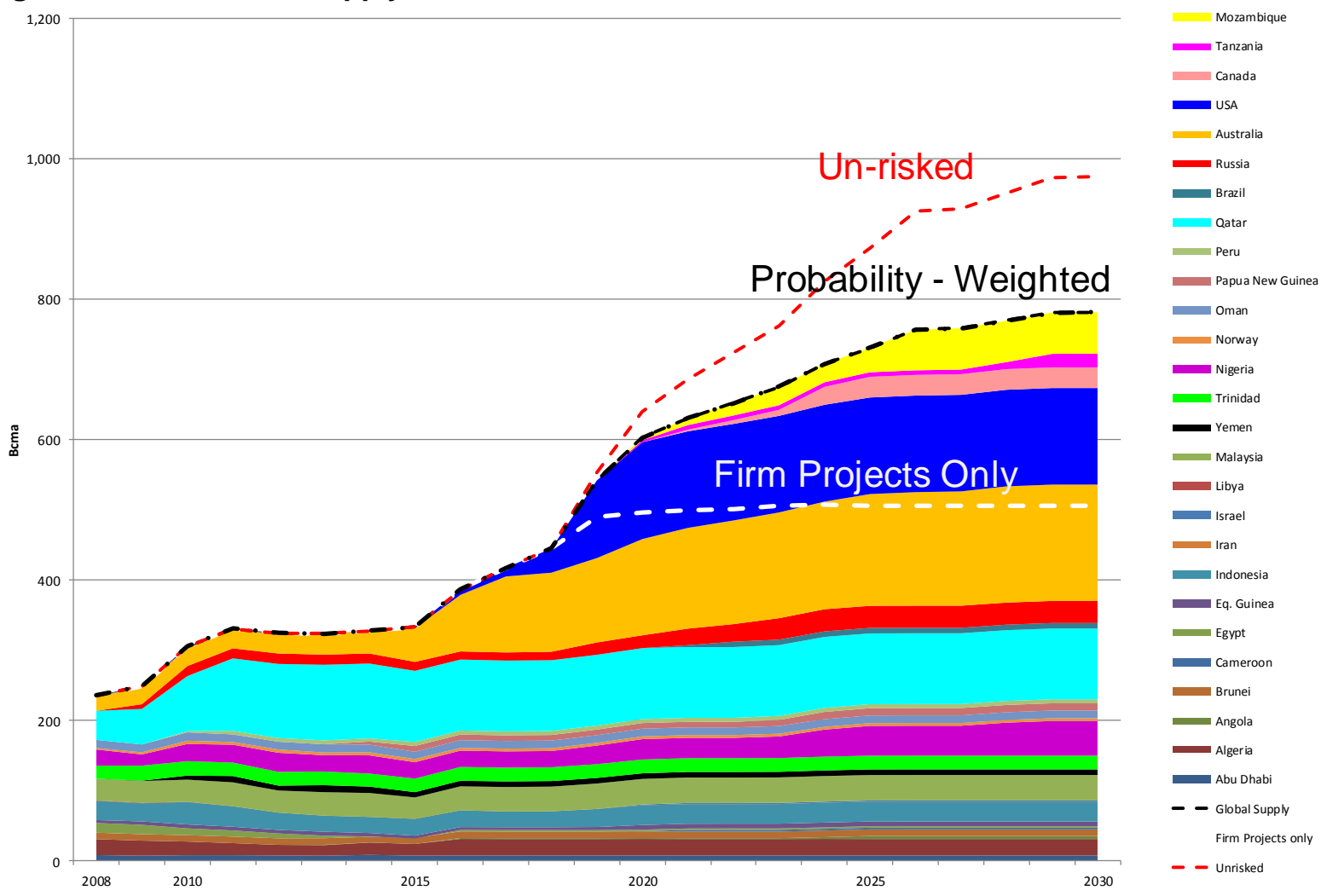

Sources: GIIGNL, Ledesma OIES, Own Assumptions

\section{LNG Cost Base and Project break-even pricing}

A review of LNG plant cost escalation by Brian Songhurst ${ }^{30}$ concluded that whilst during the period 2005 to 2010 like for like comparison of project unit liquefaction costs appeared to have doubled in line with upstream E\&P costs in general, a number of projects (mainly Australian greenfield projects) experienced significantly higher capital costs than the general trend. This was due, inter alia, to project scale and complexity, adverse exchange rate movements and a scarcity of skilled labour due to union-led regulations on temporary imported skills.

While the expected cost base for new 'brownfield' expansion projects in Australia may be improved by sharing facilities and infrastructure already in place, the analysis of the break-even prices needed for new projects in the US, Australia, Canadian West Coast and East Africa shown in Figure 24, based on 2014 cost estimates, shows a requirement for Asian prices in excess of $\$ 10 / \mathrm{mmbtu}^{31}$. 

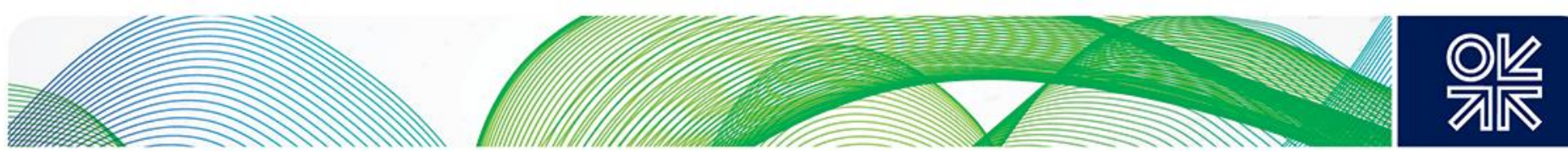

Figure 24: Comparison of Delivered Costs to Japan (Project Breakeven Price)

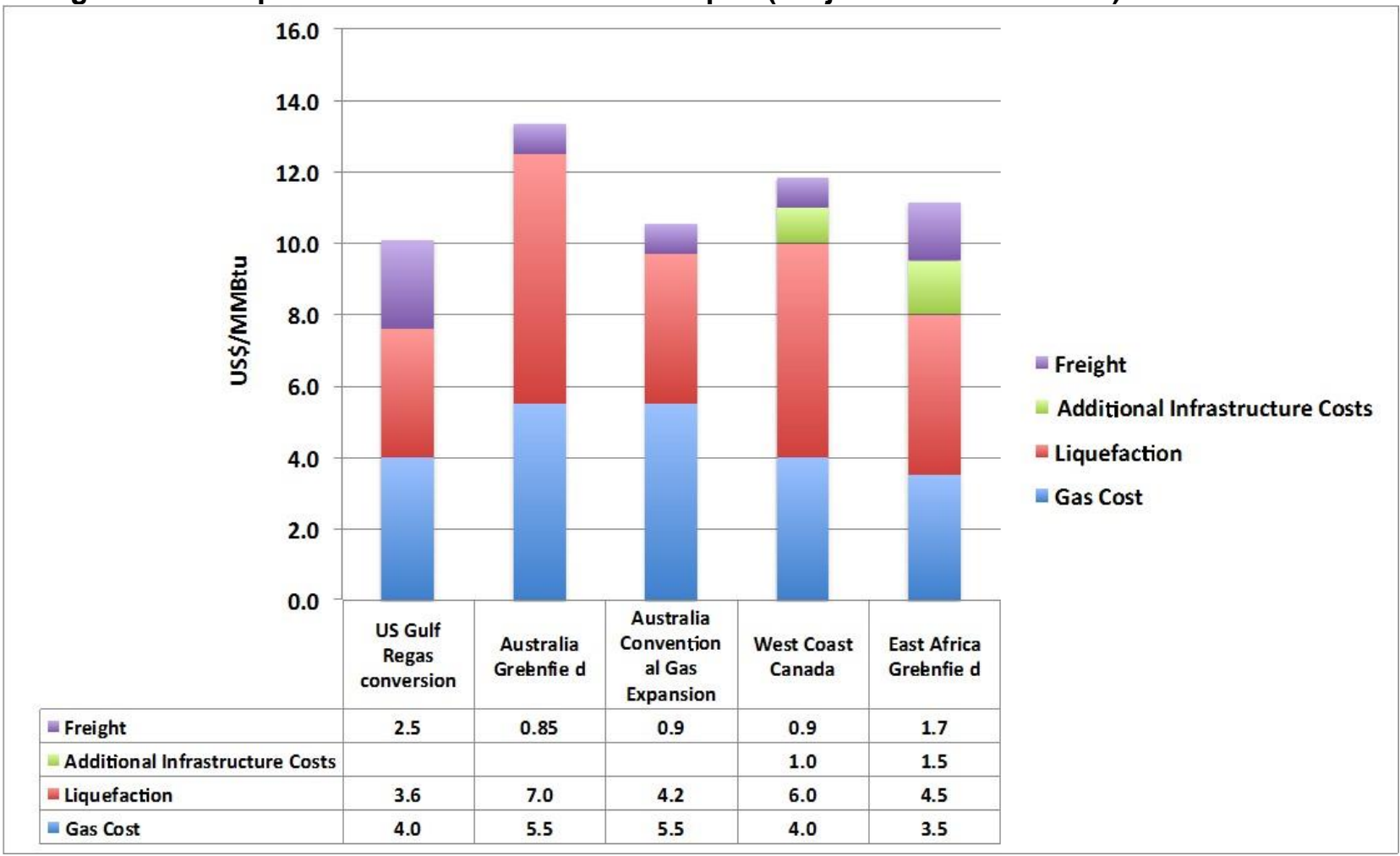

Note: Freight assumes: $174,000 \mathrm{~m}^{3}$ vessel; $\$ 75,000 /$ day charter rate; $\$ 400 / \mathrm{MT}$ Bunker Cost; $\$ 10 / \mathrm{MMBtu}$ boil-off; $\$ 0.19 / \mathrm{MMBtu}$ Panama Canal fee.

Source: Ledesma, Palmer \& Henderson (2014) - updated

Songhurst ${ }^{32}$ suggests that project capital costs could be reduced, over time, by the following measures:

- The use of floating liquefaction facilities on smaller developments to avoid construction delays and labour related cost escalation of onshore facilities.

- Introducing competition into liquefaction processes, compressors and drivers and EPC contractors.

- Co-operation between separate projects in the same locale to exploit synergies and share utility costs.

- Simplification of the pre-FID FEED stage by avoiding multi-contractor competitions.

Since the oil price fall of Q3 2014, while there has been much discussion of reduced contractor rates, however these have not yet been reflected in statistical analysis ${ }^{33}$.

Specific challenges for LNG producers by location are:

Australia: Labour availability (cost base pressure), Coal Bed Methane upstream performance in Queensland. 34

\footnotetext{
32 lbid

${ }^{33}$ Such as in IHS CERA's upstream capital cost index, Updated in May 2015 at

https://www.ihs.com/info/cera/ihsindexes/index.html
} 

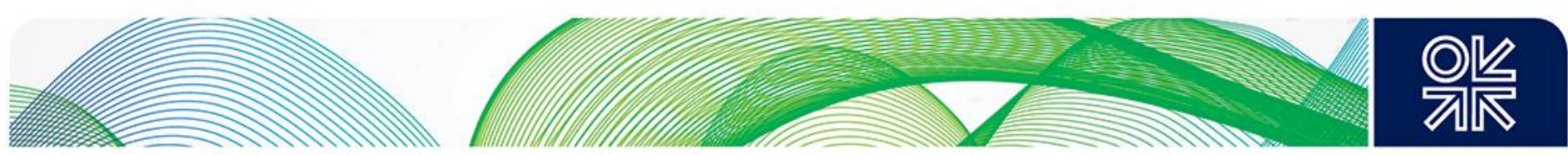

East Africa: Lack of existing infrastructure, ability of governments (Mozambique and Tanzania) to approve an acceptable legislative framework for projects to move to FID. Lack of condensate coproduction. ${ }^{35}$

Canada: Lack of existing infrastructure, pipeline distance from upstream production to liquefaction plant, First Nation issues, overlapping approval jurisdictions, lack of full fiscal clarity. ${ }^{36}$

US: FERC approval process prior to FID.

Russia: Sanctions imposed by US and Europe have reduced the appetite of non-Russian investors and hence IOC's with liquefaction experience. ${ }^{37}$ The situation has been exacerbated by financial constraints due to lower oil prices and lack of access to capital markets, concerns over an extension of sanctions that could include liquefaction technology and customer reluctance to contract with Russia given geo-political uncertainty.

Qatar: Although, with the associated production of condensate and NGLs in the production of liquefaction feed gas from the North field, Qatar is the lowest-cost producer of LNG on an integrated, full-cycle basis, the moratorium imposed in 2005 precludes additional LNG train investment. As of 2015 there are no indications that the moratorium will be lifted ${ }^{38}$

The other key uncertainty, namely the price formation basis of future LNG contracts, will be addressed in Chapter 4.

\section{Summary - Supply and Demand Trends}

This chapter has reviewed the key supply and demand trends in the global gas 'system' connected by flexible LNG in which the outlook of key players has been changed during 2014 by uncertainty over, and a more pessimistic view of, Asian (and specifically Chinese) future LNG demand. In addition, and in part as a consequence of this, the lower prices seen on European gas trading hubs and Asian spot LNG trades from early 2014, and the reduction in oil linked LNG and Russian pipeline gas contract prices, has created uncertainty over the economic viability of many new LNG projects. In Europe, gas demand has slumped from the peaks seen at the end of the 2000s. While 2014 demand was particularly low due to a warm 2013/2014 winter, there is uncertainty as to the future trajectory of demand with the expected impact of future space heating and industrial efficiency effects countered by possible upside in the power sector (as old nuclear and coal plant are retired), and the future pace of renewables investment is unclear. Having described the, albeit uncertain, market fundamental demography in this chapter we now proceed to examine the key strategic challenges facing the two key agents which represent the bulk of new supply tranches to 2030. Chapter 3 focusses on Russia and Chapter 4 on LNG project investors.

\footnotetext{
${ }^{34}$ Ledesma, Palmer and Henderson (2014)

35 Ledesma (2014)

${ }^{36}$ Gomes (2015)

${ }^{37}$ Henderson (2014)

${ }^{38}$ Fattouh, Rogers and Stewart (2015)
} 

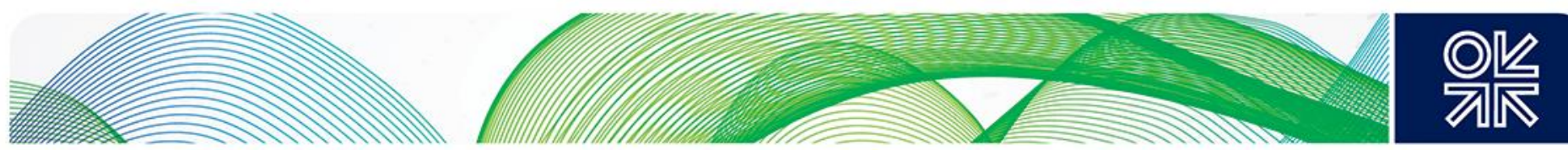

\section{Russian Price - Volume Strategy in the European Market}

As shown in Figure 12, Russia's monopoly pipeline exporter Gazprom holds a substantial portfolio of contracts with European buyers, many with a term extending to 2030 and beyond. Since 2007, Gazprom's pipeline exports to the European region have remained in the 139 to 166 bcma range as shown in Figure 25. They were depressed by the impact of the financial crisis and recession in 2009 and 2010 (and also by the increase in LNG imports to Europe in 2010) and by generally falling demand. In 2013 reduced pipeline imports from Algeria benefitted Gazprom's sales volumes. Gazprom's market share of European demand has grown from $26 \%$ in 2007 to $32 \%$ in 2014, although this growth is overwhelmingly a consequence of falling European demand.

\section{Figure 25: Russian Pipeline Gas Imported into Europe 2007 - 2010}

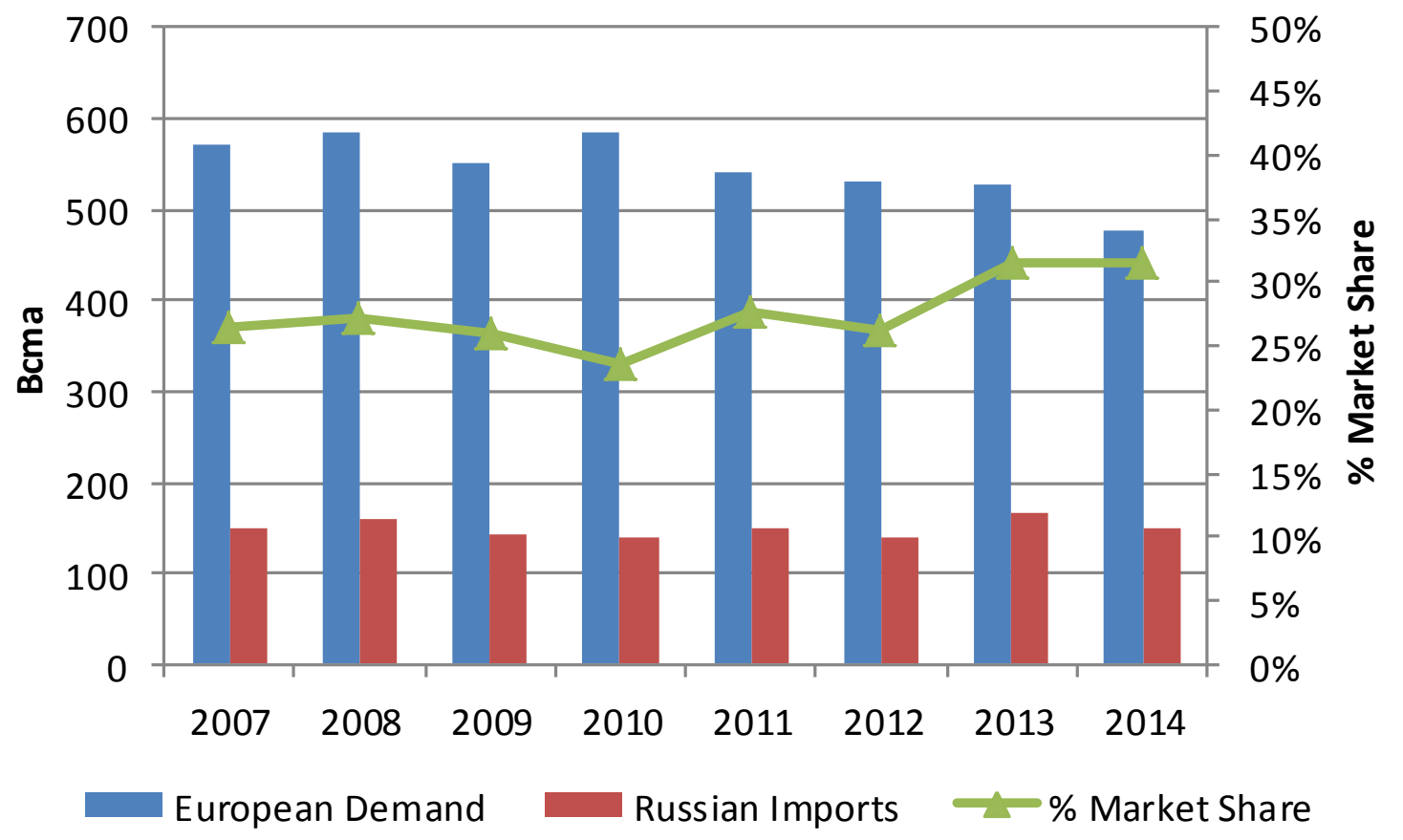

Source: IEA Monthly Gas Data Service, Gazprom in Figures 2009-2013, p.67. Gazprom Export Press Conference June 2014, J. Stern OIES.

In Stern and Rogers $(2014)^{39}$, Chapter 1, the following evolution in European hub price formation and its impact on Gazprom's contracts is described:

- Prior to 2009, there was an extremely strong correlation between the German Border Gas Price (BAFA) and a composite index containing a 9 month rolling average of gasoil and fuel oil prices. At that time German gas imports were mainly, if not all, purchased under long term contracts with prices linked to oil products. Had this formula remained in place unaltered, oil-indexed pipeline gas contract prices would have reached $\$ 13$ to $\$ 14 / \mathrm{mmbtu}$ in the period 2011 to mid-2014.

- As a surge of LNG imports in 2010 and 2011 catalysed the liquidity of the nascent continental European hubs (particularly TTF in Holland), large end-users began to demand prices related to those on the hub. This created an existential financial exposure for some of Gazprom's midstream long term contract buyers, who demanded a reduction in contract price and threatened arbitration

\footnotetext{
${ }^{39}$ The Dynamics of a Liberalised European Gas Market
} 

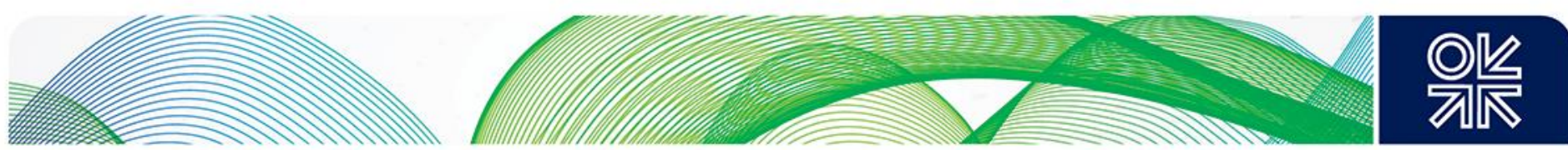

if this was not forthcoming. Other upstream sellers, notably Statoil and GasTerra began to include hub indices in their contract price formulae.

- Gazprom's concessions to individual buyers (either through negotiation or as a result of arbitration awards) included elements of: 40

- Reductions in the base contract price $\left(\mathrm{P}_{0}\right)$

- Hub-related pricing for volumes above Take or Pay levels.

- Reduction in Take-or-Pay levels.

- Retroactive rebates covering most of the difference between contract prices and hub prices for prior periods.

- Adoption of a hub index in the contract in place of the oil product linked price formula.

These changes were reported anecdotally in the European energy media from 2010 onwards ${ }^{41}$. Given the number of Gazprom contracts, and the confidentiality provisions surrounding them, it is not possible to ascertain the proportions of Gazprom's contract portfolio which have been subject to each or a combination of the above concessions or modifications.

However, two important strands of evidence indicate that the aggregate extent of these price concessions is considerable. The first is found in the various estimates of Russian contract prices shown in Figure 26. The green line is the UK (NBP) hub price for reference. The solid red line is the formula which accurately described the relationship between German Border Price (BAFA - shown as the black line) and a lagged 9 month average of gas oil and fuel oil prices prior to mid-2009. The dotted red line is a $15 \%$ discount to the fitted formula relationship (sometimes used as a reference in the energy media). The blue line is the quarterly (sometimes half yearly) price of Gazprom gas sold in North West Europe derived by Henderson, OIES, from Gazprom's financial statements. It is not clear whether this includes an allowance for retrospective rebates. In general however, the blue line in Figure 26 indicates that Gazprom's concessions to its contract prices have moved considerably towards hub prices (represented by NBP), especially since 2012 .

The second strand of evidence is found in the 2014 price study conducted by the International Gas Union (IGU) ${ }^{42}$ which, through a comprehensive survey, determines the proportion of gas in the wholesale market sold under a variety of pricing categories.

\footnotetext{
${ }^{40}$ For details see Stern, in Henderson and Pirani eds (2014), Chapter 3.

${ }^{41}$ For example: 'Eni in spot market gas deal with Gazprom', May 2014, http://www.ft.com/cms/s/0/3b79b0e4-e284-11e3-a82900144feabdc0.html\#axzz3agK91g9k

42 IGU (2015)
} 

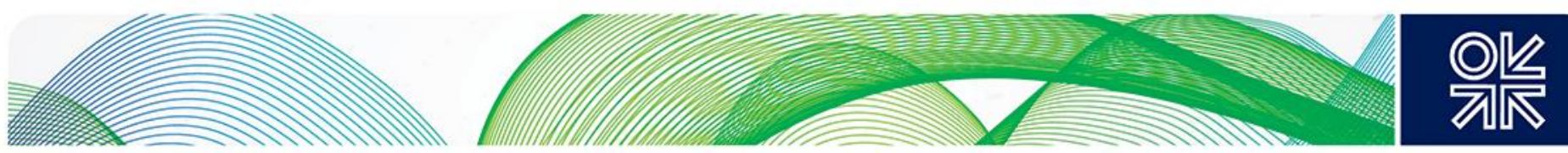

Figure 26: NBP and Estimates of Russian Contract Prices 2008 - 2015

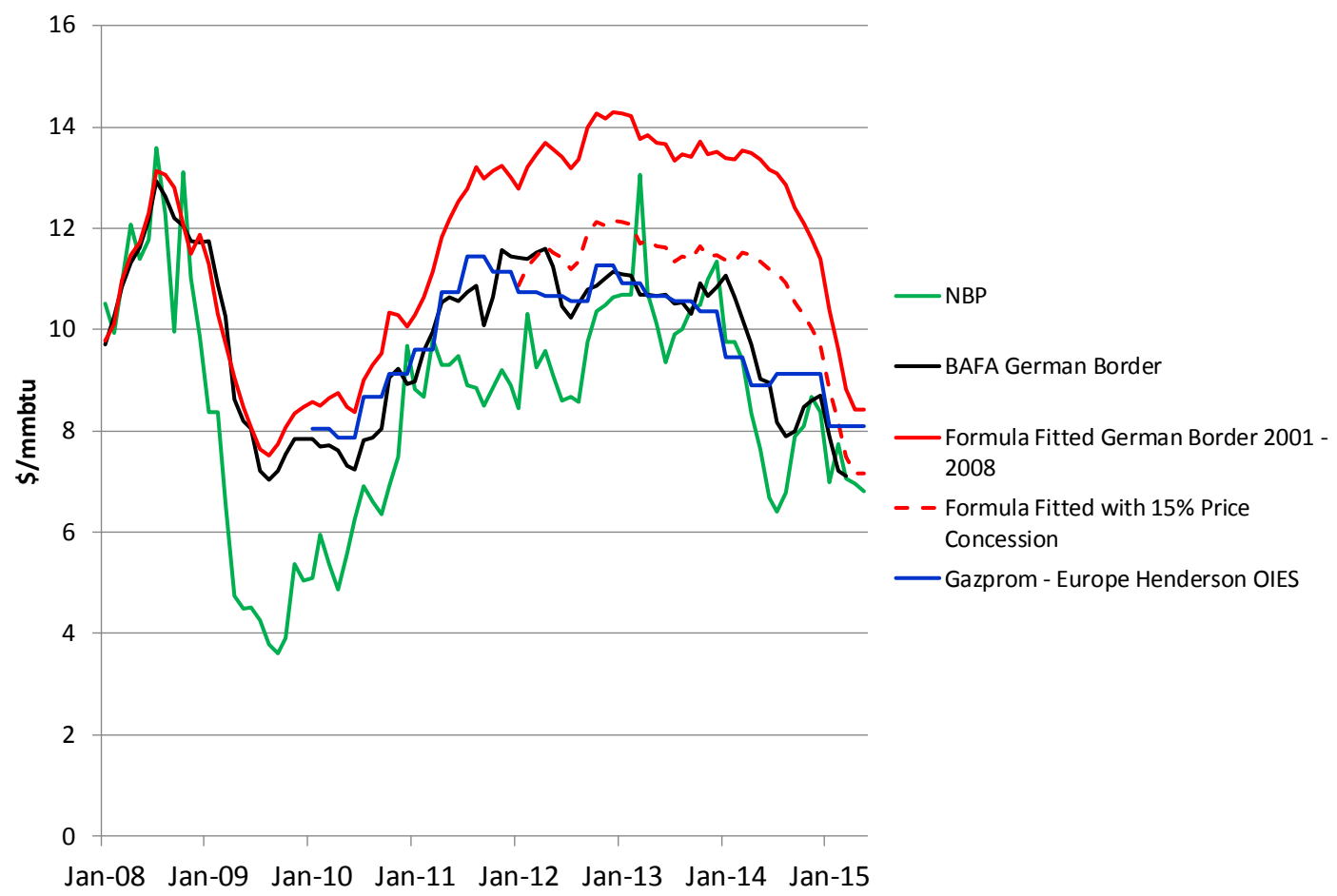

Sources: Platts, BAFA, Henderson OIES

Figure 27: 2014 IGU Price Survey Results - Europe

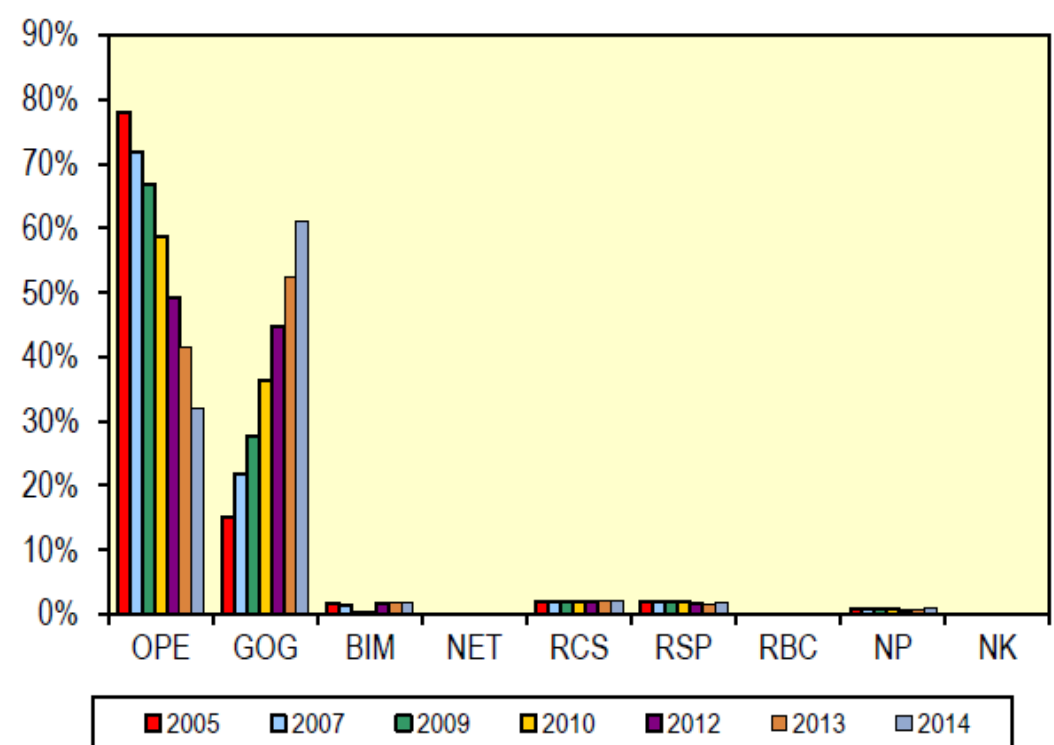

Source: IGU (2015)

Notes: OPE: Oil Price Escalation, GOG: Gas-on-Gas Competition, BIM: Bilateral Monopoly, NET: Netback from Final Product, RCS: Regulation Cost of Service, RSP: Regulation Social and Political, RBC: Regulation Below Cost, NP: No Price, NK: Not Known 

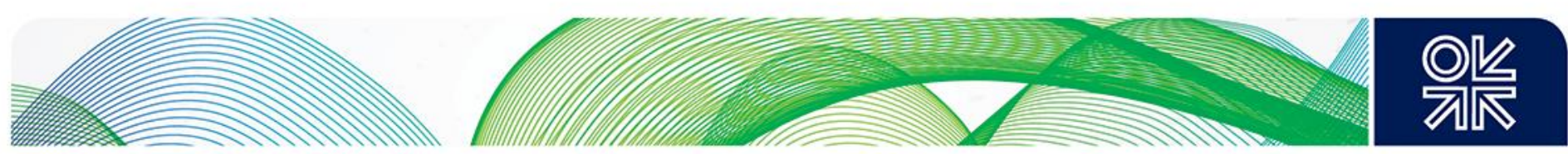

Figure 27 shows the results for Europe. The shift from oil-indexation to gas-on-gas (hub) pricing from 2007 to 2014 is significant and sustained in its momentum. The 2014 Survey notes:

- A further move to gas-on-gas particularly in Germany, France and Italy plus Central Europe.

- Northwest Europe is now $88 \%$ gas-on-gas, Central Europe over $50 \%$.

- Most of oil price indexation is now in Southeast Europe: Algerian pipeline contracts and LNG contracts, residual amounts in Russian contracts.

Gazprom has strongly defended the principle of oil-indexation ${ }^{43}$ despite, as the above discussion strongly suggests, agreeing contract price reductions either wholly in line with, or to a significant extent towards, hub prices. The key strategic question for Gazprom in the commercial sphere is how best to market its gas in a future European market given that:

- Hub pricing has become 'the norm' in Northwest Europe and is likely to continue to spread south and eastwards across Europe.

- New LNG supply, whether from the US or elsewhere, will consider Europe (which has $203 \mathrm{bcma}$ of regas capacity ${ }^{44}$ ) as a secondary or (in the case of US exporters) an equally attractive market to Asia.

- Gazprom has at least 100 bcma of 'shut-in' productive capacity at low incremental cost to produce. ${ }^{45}$

On this last point, analysis from J. Henderson (OIES) (Figure 28) concludes that (following Rouble devaluation), Gazprom's Yamal field breaks even at a European border price of $\$ 5.50 / \mathrm{mmbtu}$ on a full cycle basis and at around $\$ 3.50 / \mathrm{mmbtu}$ on the basis of operating costs, transport and taxes.

At present Gazprom's contracting model is as depicted in the upper portion of Figure 29. Physical volumes of Russian gas are delivered to the buyer in line with contract nominations. The buyer is obliged to take delivery of (or pay for) the Take or Pay volume over the contract year. Subject to the Take or Pay constraint, the buyer can optimise its purchases of gas between long term contract deliveries and purchases of gas from traded hubs. Where the contract has been moved to hub price indexation the buyer may be indifferent between these two sources, however there is a risk on the Seller's part that 'over nomination' will depress hub prices.

\footnotetext{
${ }^{43}$ For Example 'Gazprom Mounts Defence of Oil Price Indexation', Interfax, May 2014; for background see: Stern, J.P. and Rogers, H. 'The Transition to Hub-Based Pricing in Continental Europe: A Response to Sergei Komlev of Gazprom Export', OIES, 12 February 2013. http://www.oxfordenergy.org/?s=komlev http://interfaxenergy.com/gasdaily/article/8890/gazprommounts-defence-of-oil-indexation

${ }^{44}$ GIIGNL (2015), P. 31

45 The Gazprom CEO claimed that the company could have produced $617 \mathrm{Bcm}$ in 2014 compared with an actual figure below $444 \mathrm{Bcm}$, implying shut-in production capacity of $173 \mathrm{Bcm}$. Speech by Alexey Miller at conference "Europe and Eurasia: Towards the New Model of Energy Security", April 13, 2015 http://www.gazprom.com/press/miller-journal/029076/
} 

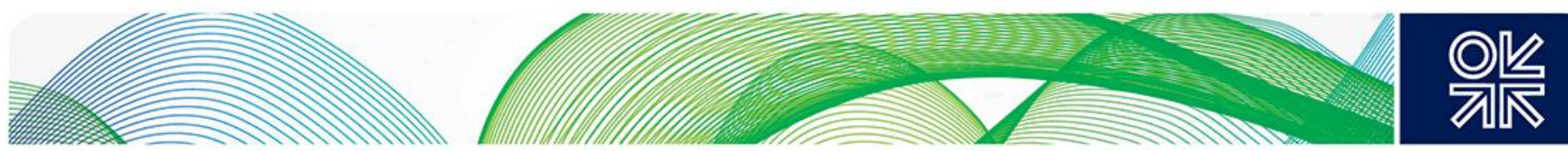

Figure 28: The Breakeven Price of Gazprom Exports to Europe

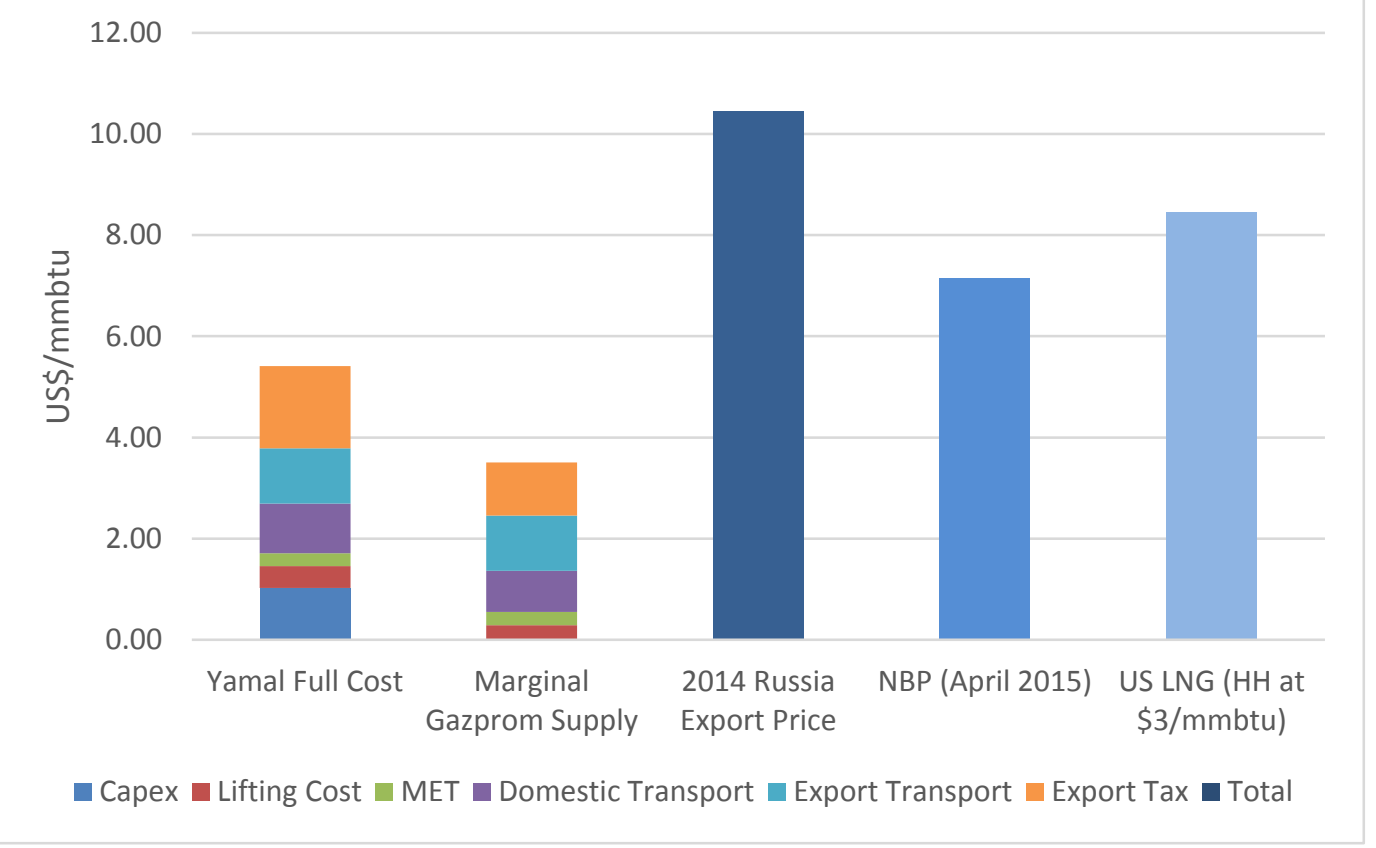

Source: Henderson OIES

Such a situation can be avoided and additional benefits conferred to the Seller by moving to the Hub Re-delivery Model, shown in the lower portion of Figure 29. This enables the Seller to fulfil the Buyer's nomination with a mixture of physical upstream supply from Russia and gas which has been purchased off the hub and re-delivered. The option also exists to sell physical upstream supply directly onto the hubs. In order to function this requires the contract delivery point to be moved to the hub, a move Gazprom is alleged to have resisted but which is a feature of the Gas Target Model ${ }^{46}$. The Hub Re-delivery Model would allow Gazprom to directly influence European hub prices by controlling the quantity of physical gas flowing from West Siberia into the European gas market.

Although it has the in-house capability to operate the Hub Re-Delivery Model Gazprom has shown no willingness to move to this construct, preferring presumably to rely on enforcing its sales volumes through the Take or Pay mechanism (albeit that Take or Pay levels have been lowered in some contracts).

In the period August to 2014-March 2015 Gazprom appeared to at times deliberately fail to deliver volumes of gas in response to buyer nominations, even though these were within the contractual specified limits. It is thought that these actions on Gazprom's part were instituted to:

\footnotetext{
${ }^{46}$ See Yafimava (2013)
} 

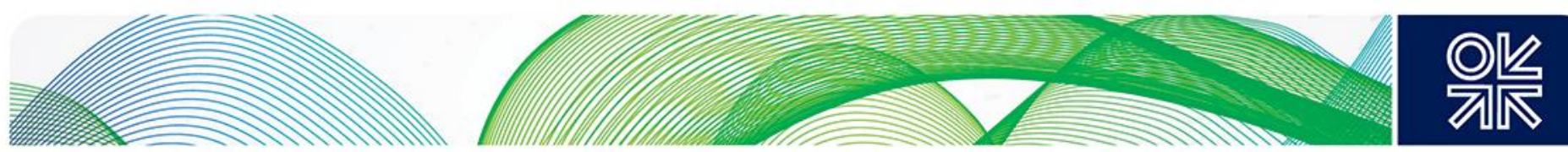

Figure 29: Current and Future Contractual Models

\section{Status Quo}

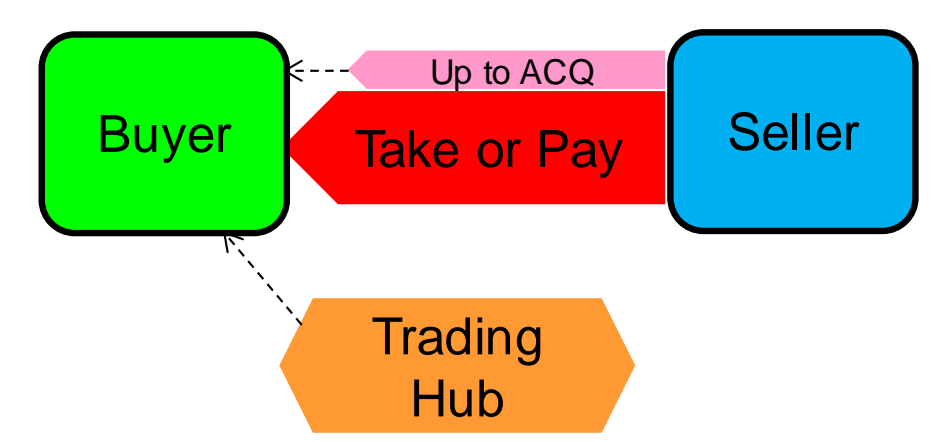

\section{Hub Re-Delivery Model}

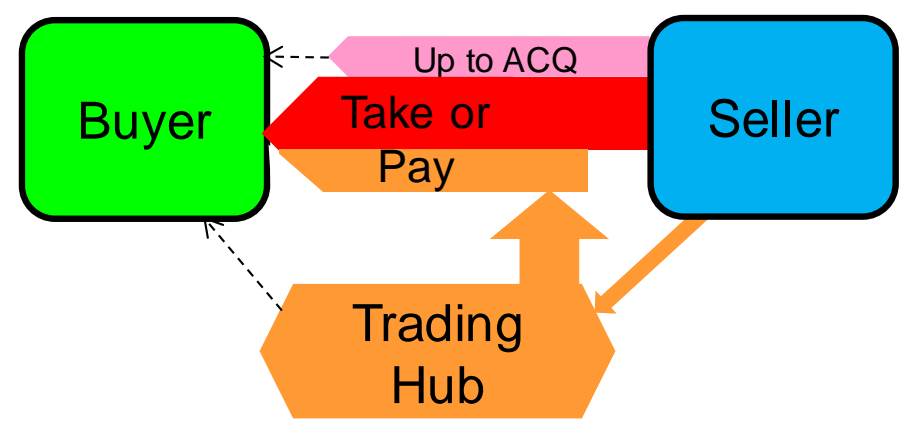

- Restrict reverse flows to Ukraine, whilst negotiation and arbitrations between Gazprom and Ukraine were ongoing; and,

- Prevent buyers receiving more gas than Gazprom calculated was required by end-users. If 'excess' volumes were delivered and sold onto the European trading hubs, this would depress hub prices and result in Gazprom receiving a lower price from buyers who had successfully negotiated full or partial hub-based contract price concessions.

In the political sphere, Gazprom's attention is also focussed on the problems facing its Turkish Stream (formerly South Stream) pipeline project ${ }^{47}$, the ongoing situation with Ukraine ${ }^{48}$, and the DG COMP Enquiry regarding Gazprom's affiliate activities in Poland, Czech Republic, Austria, Bulgaria, Hungary, Latvia, Estonia and Lithuania.

Gazprom, in mid 2015, is clearly an organisation with 'a lot on its plate' and the degree to which political and business considerations overlap does not engender a clear commercial strategy. The significance of this will become clear in Chapter 5 when we examine the impact on Russian gas exports to Europe under different scenarios. 

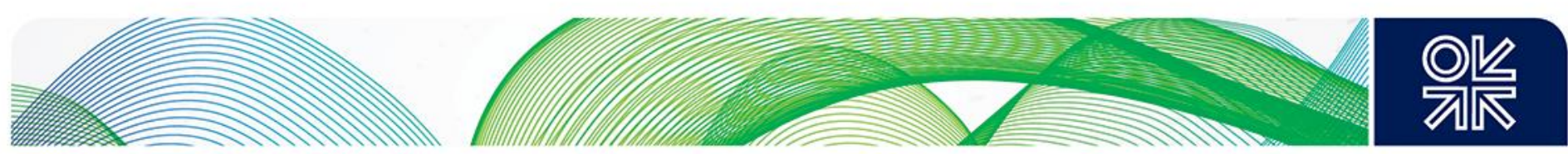

\section{Contract Price formation for future LNG projects to Asia}

Chapter 2 described the situation of the LNG Industry where significant new LNG volumes from plant under construction will enter the market between 2015 and 2020, but the current price levels (hub or JCC-linked LNG contract prices) and Asian LNG demand uncertainties have resulted in a pause in new project FID's outside the US.

In Rogers and Stern (2014) the case for moving away from JCC pricing in Asian LNG contracts was assessed in detail. Asian LNG buyers are in mid 2015 seeing much lower contract prices and hence may view the need to change future contract price formation structures as being less urgent. As Figure 3 above shows, the forward curve for crude oil shows a recovery to $\$ 67 / \mathrm{bbl}$ by end 2015 which would take Japanese LNG contract prices on average to $\$ 9 / \mathrm{mmbtu}$. If the current linkage between Asian LNG spot prices and European hub prices persists then, on the basis of the NBP forward curve, Asian spot LNG prices at end 2015 would be around $\$ 7.50 / \mathrm{mmbtu}$. A renewed sense of urgency to move away from oil-indexed LNG pricing would be spurred by a recovery in oil prices while spot prices remain at low levels (compared to the 2011 - 2013 period) due to plentiful supply.

Possible alternatives to JCC pricing for future LNG contracts are discussed below:

\section{An Asian Spot Index - such as: Platts JKM, ICIS' East Asia Index (EAX) or Argus' NEA}

As discussed in Rogers and Stern (2014), these indices are based on a subset of Asian spot cargoes. Liquidity is also constrained by the physical size of LNG cargoes - i.e. the 'lumpiness' of this market. Total spot trade in Asia in 2014 was $57 \mathrm{bcma}$, or $5.5 \mathrm{bcf} / \mathrm{d}$. An average LNG cargo is $2.8 \mathrm{bcf}$ of natural gas - so even if all spot trades were reported the deal frequency would be around 2 cargoes per day plus any re-trades. Figure 1 above demonstrates the significant seasonal volatility during the period 2011 to 2013. Sellers would, with some justification claim that such spot indices lack depth, exhibit too much volatility and could be influenced by individual players. They are unlikely therefore, in their present form, to be adopted as the basis for price indexation in long term LNG contracts.

\section{Henry Hub plus Liquefaction and Transport costs}

This price formation basis has already been used for LNG contracts based on some US brownfield projects. As Figure 30 shows, the future curve for Henry Hub appears to follow a stable rising trend. Adding some $\$ 3 / \mathrm{mmbtu}$ for liquefaction and $\$ 3 / \mathrm{mmbtu}$ for shipping to Asian markets would provide a price range of $\$ 9$ to $\$ 11.50 / \mathrm{mmbtu}$ at the regas terminal between 2015 and 2027 , based on this futures curve. There is some attraction from the perspective of an LNG seller (wherever located) in seemingly locking in a price in this range if it is sufficient to ensure project viability. The historic data in Figure 30 provides a note of caution however. Although future Henry Hub actual prices may not show the volatility seen in the late 2000s, 2012 and 2014 witnessed some significant price excursions. Most of the contract price under this price formation mechanism would essentially comprise fixed costs and so upside will be constrained. There is very limited scope for feedback from end-market demand signals which would influence this price. From the Buyer's perspective this lack of market demand reflectiveness should be an issue to consider. Such a price formation construct would not reflect the lower prices available when the LNG market is well supplied and spot LNG prices fall below long run marginal costs. 

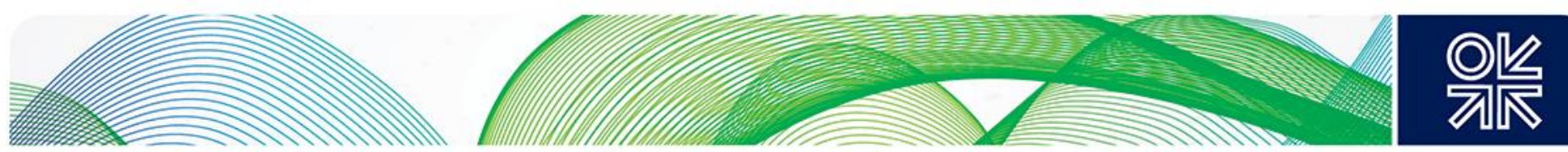

Figure 30: Henry Hub Historic and Future Monthly Prices

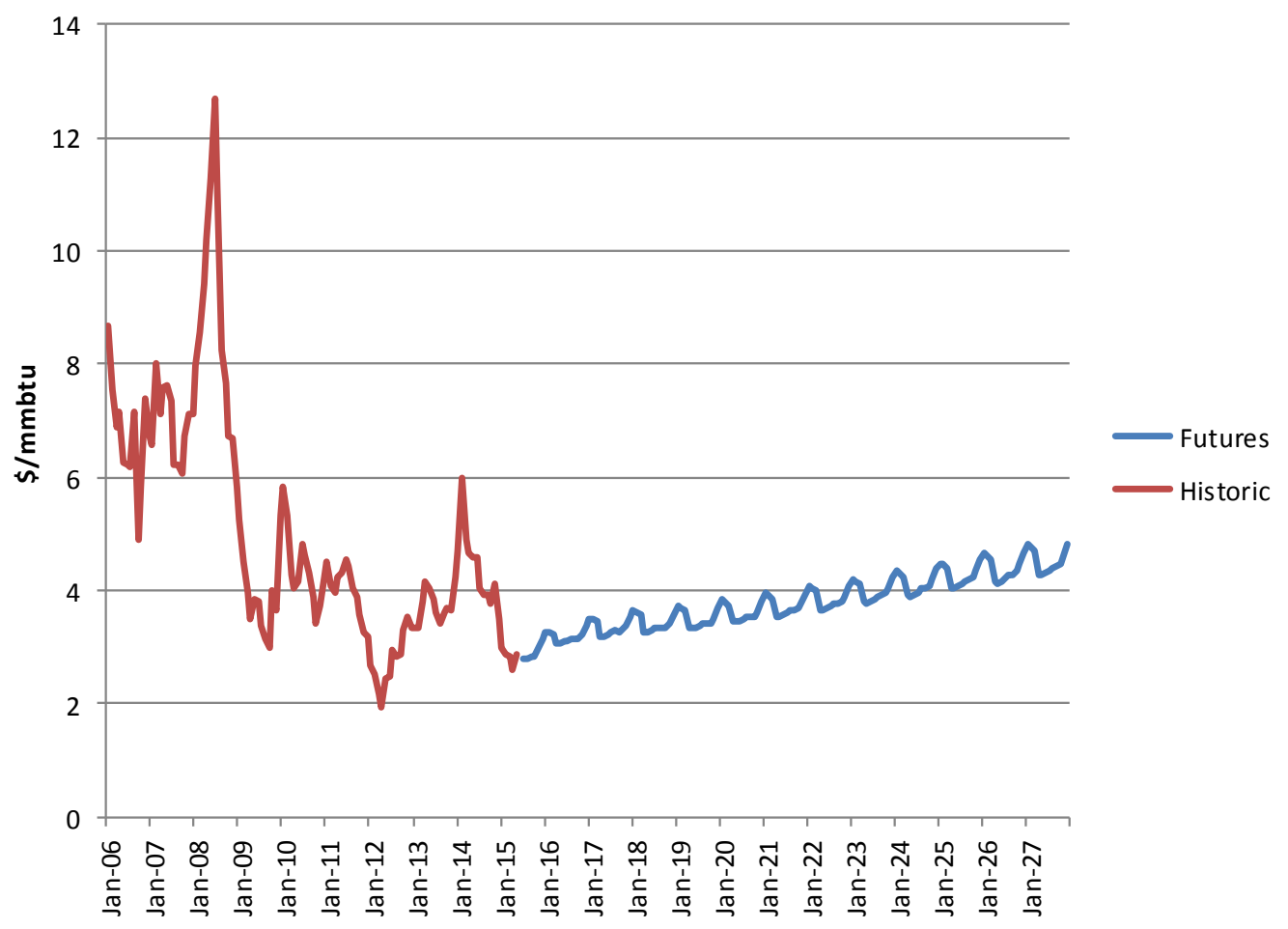

Sources: EIA, CME http://www.cmegroup.com/trading/energy/natural-gas/naturalgas_quotes_settlements_futures.html

\section{European Hub plus Transport Cost Differential}

This should have more appeal to buyers. In a well-supplied LNG market, Europe becomes the market of last resort and its hub prices should be reduced for the period of any 'LNG glut'. Thus an LNG contract linked to European hubs should more accurately reflect the dynamics of the LNG spot market (in turn impacted by Asian LNG demand) and benefit from the liquidity of trading on hubs such as NBP and TTF. Sellers are likely to be more wary of the potential for such low price episodes and also the potential market power of Russia to influence European hub prices (see Chapter 5).

\section{Hybrid Pricing}

Although there has been limited disclosure of 'hybrid' pricing terms for LNG contracts relating to recent or prospective projects, media articles have mentioned the use of oil indexation and Henry Hub plus costs ${ }^{49}$. It is likely that, if buyers maintain their opposition to the sole use of oil indexation in contract price clauses, the use of a weighted combination of Henry Hub plus costs, European Hub and oil indexation could be adopted, with a provision to move to an Asian hub if and when it is established and achieves a specified churn rate in the future. Hybrid pricing is at best a short term expedient; in effect the mixture described above is the same as signing three separate contracts with distinctive pricing formulae - with the pros and cons of each as described above.

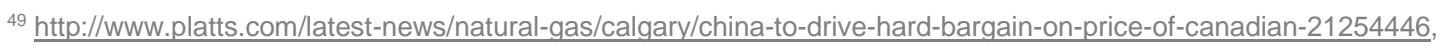
http://csis.org/publication/coming-change-asian-Ing-market, http://www.bloomberg.com/news/articles/2014-03-25/anadarkoplans-Ing-mozambique-sales-based-on-u-s-gas-oil-price.
} 

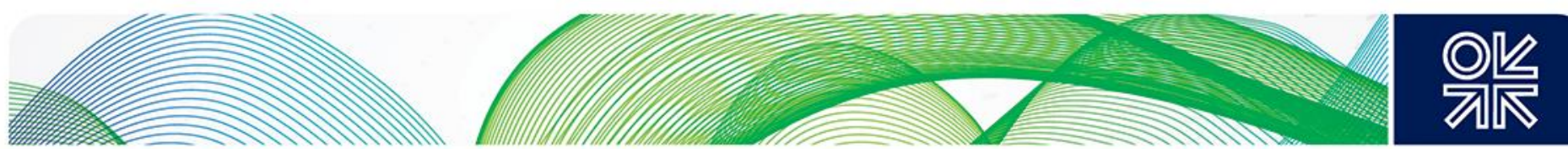

\section{Formation of one or more Asian Hubs}

This is discussed in Rogers and Stern 2014. Figure 31 shows in schematic form the stages of development required to achieve a gas trading hub with sufficient liquidity on which to base a contract price formula.

\section{Figure 31: Stages of Hub Development}

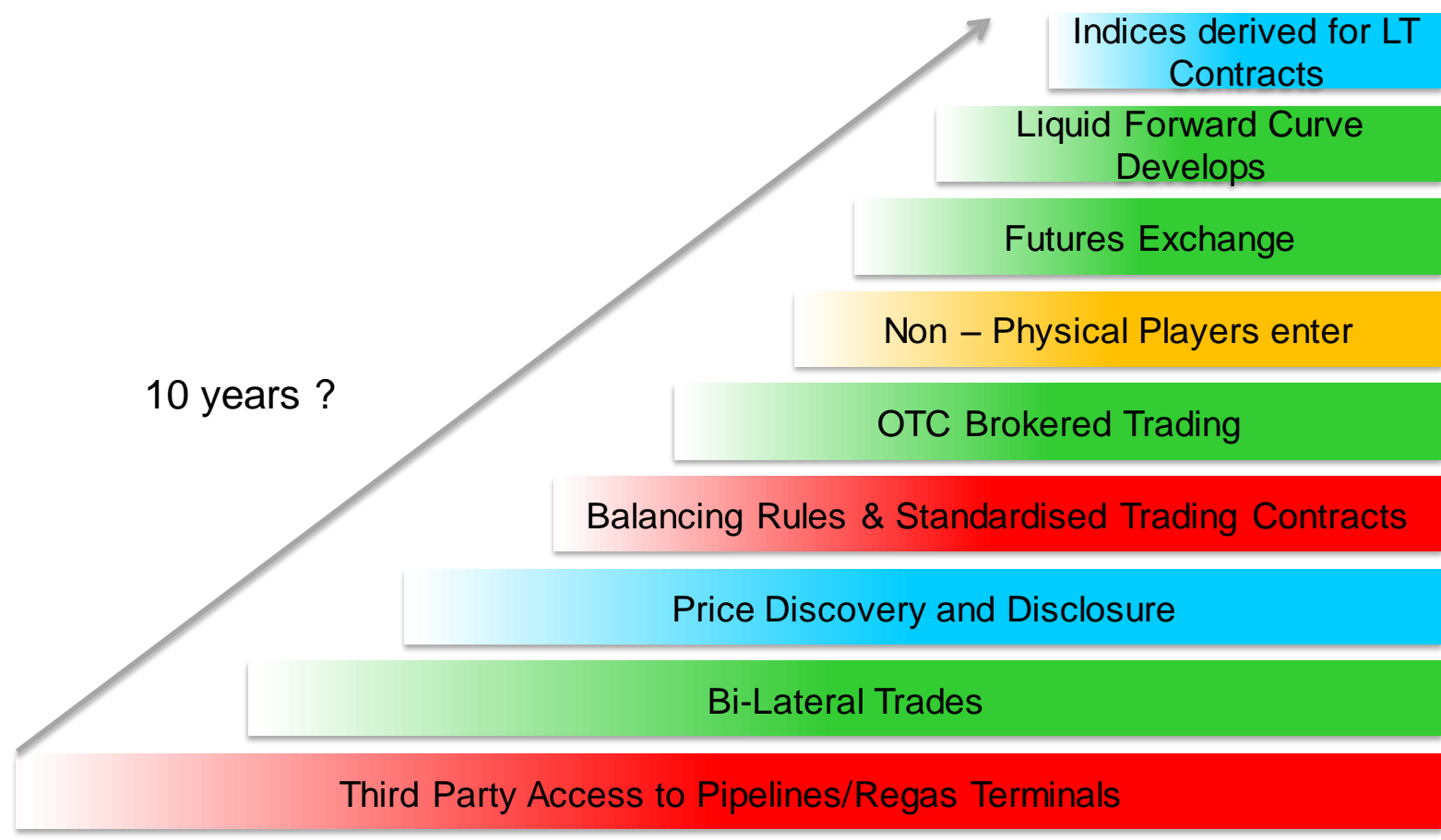

Source: Author

Related to the point regarding the limited average number of LNG spot trades taking place per day in Asia, it is important to recognise that whilst such a hub could provide the price index for LNG contracts, the hub itself would be based on gas (pipeline or regassified LNG) rather than LNG cargoes in order to attract a sufficient number of participants and deal in contract 'bundles' which would allow necessary levels of liquidity to develop.

Shanghai has approved the establishment of a platform for the physical spot trade of oil, LPG and natural gas in its Free Trade Zone ${ }^{50}$. Clarifying the arrangements for Third Party Access, price discovery and standardised contracts will determine how well this moves forward. In Japan a liberalisation roadmap is in place for the gas and electricity markets with unbundling of infrastructure specifically addressed, but in the case of gas liberalisation is only planned to start in 2022. In the Author's view the plan to launch an LNG futures market (i.e. to leapfrog the first 6 stages of development shown in Figure 31) is unlikely to prosper in the absence of a liquid prompt market.

The advantage of having liquid gas hubs in Asia is that price signals would reflect not just supply, but also the changing demand requirements of the markets. Arbitrage of the global pool of flexible LNG would respond to differences between Henry Hub, European hubs and Asian hubs and result in a rapid and efficient deployment of supply. Regional hub price spreads would be determined by US liquefaction and transport cost differentials over the long run. In times of 'oversupply' the spread

${ }^{50}$ http://www.platts.com/latest-news/natural-gas/singapore/chinas-shanghai-pushes-ahead-with-trading-hub-26988685 

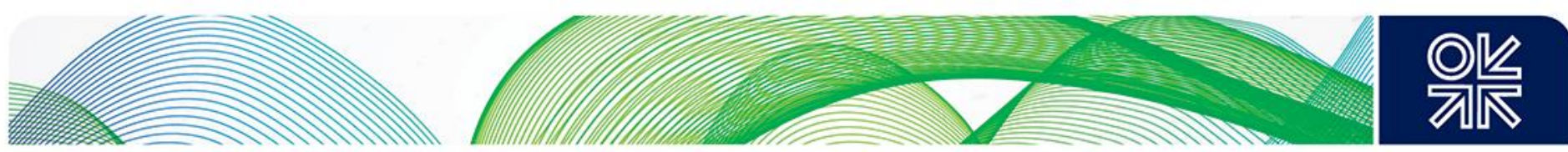

between Henry Hub and the European and Asian hubs would collapse to short run marginal costs of transportation only - thus spurring a demand response at the resulting lower prices prevailing.

However, based on experience of gas market liberalisation and hub formation in North America, the UK and continental Europe, it may take 10 to 15 years to achieve one or more liquid hubs in Asia. In the meantime, hybrid pricing for new LNG projects is likely to be the norm for the Asian market. In Europe any new LNG contracts will be based on hub prices, apart from in South Eastern Europe. However one would expect that contracts would provide for a move to hub pricing there also once South East European hubs develop. Given the problems with legacy pipeline contracts described in Stern and Rogers 2014, new European LNG contracts are likely to be relatively short by historic standards i.e. 5 to 10 year terms.

The problem for the LNG industry in mid 2015 is that current European hub price levels ( $\$ 6$ to $\$ 7 / \mathrm{mmbtu}$ ) and JCC related prices $(\$ 8 / \mathrm{mmbtu})$ are too low for new project viability. New LNG project investors will need to gain confidence that market conditions in the early 2020s (which is when new LNG projects could come onstream) will be more supportive. The next Chapter examines a range of such future scenarios. 

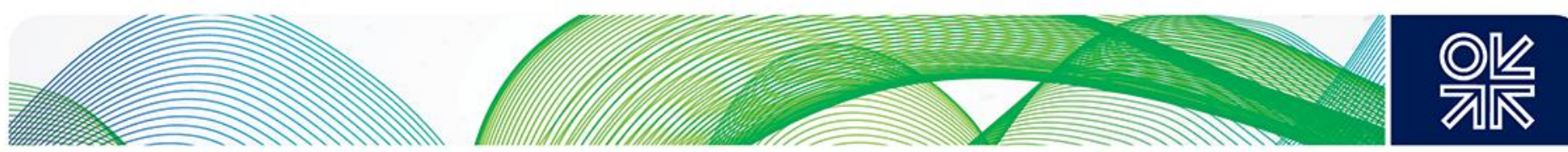

\section{Global Gas Dynamics Post 2015}

We will now examine the key dynamics of the system shown in Figure 4, based on the assumptions set out in Chapter 2 and the issues addressed in Chapters 3 and 4 . The analysis will be based on four scenarios which are defined in Figure 32, based on combinations of low and high Chinese LNG demand and 'Base Case' and low European natural gas demand. We also have two further dimensions to consider:

- The speed with which new LNG FIDs are made as investors become more confident in future market conditions; and,

- Whether Gazprom, having moved to the 'Hub Re-Delivery Model' in its contracts decides to target a high or low European hub price by adjusting its physical export volumes to Europe. Maintaining a high price will over time encourage more competing supply in the form of LNG, which once onstream has very low variable costs. Targeting a low European price will discourage new LNG FIDs and in time lead to higher Russian export volumes to Europe and increased market power in the 2020s.

Figure 32: Scenarios - Combinations of Chinese and European Demand Cases

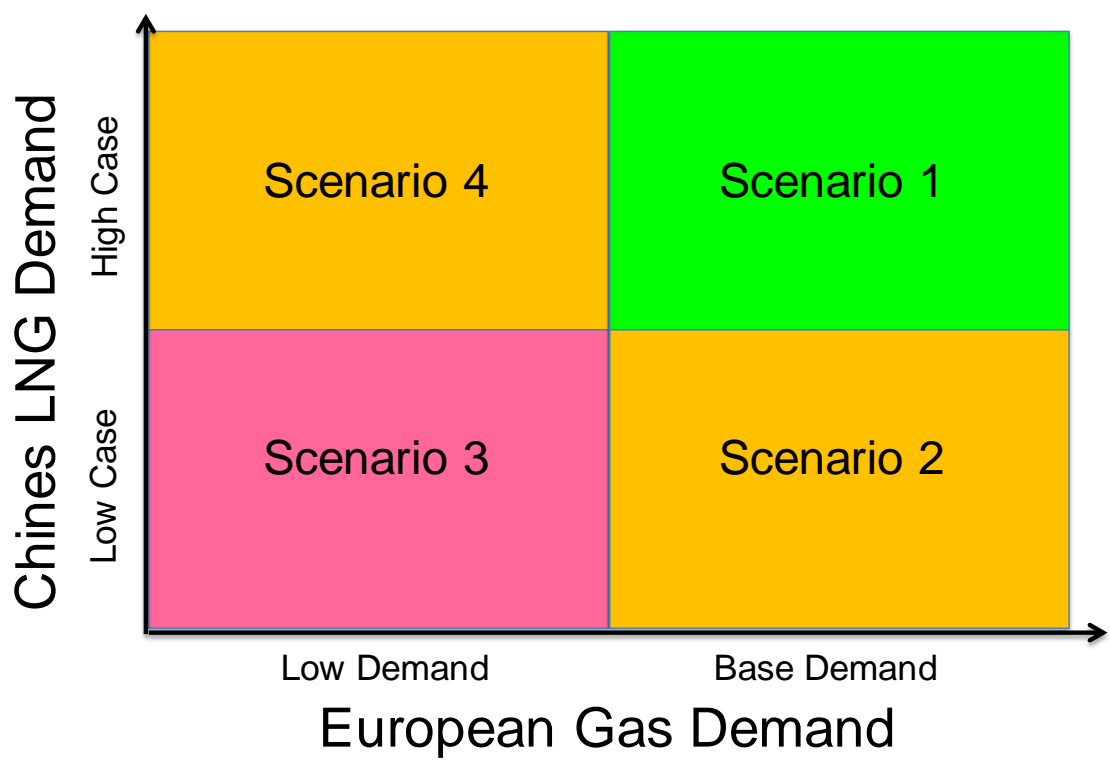



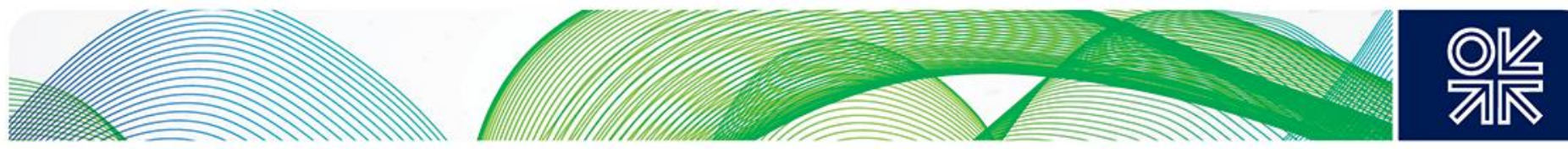

Figure 33 shows Scenario 1 with Russia maintaining a price high enough to allow for new LNG FIDs.

Figure 33: Scenario 1, High Chinese LNG Demand, Base Case European Demand, Russia Supports European Hub Prices
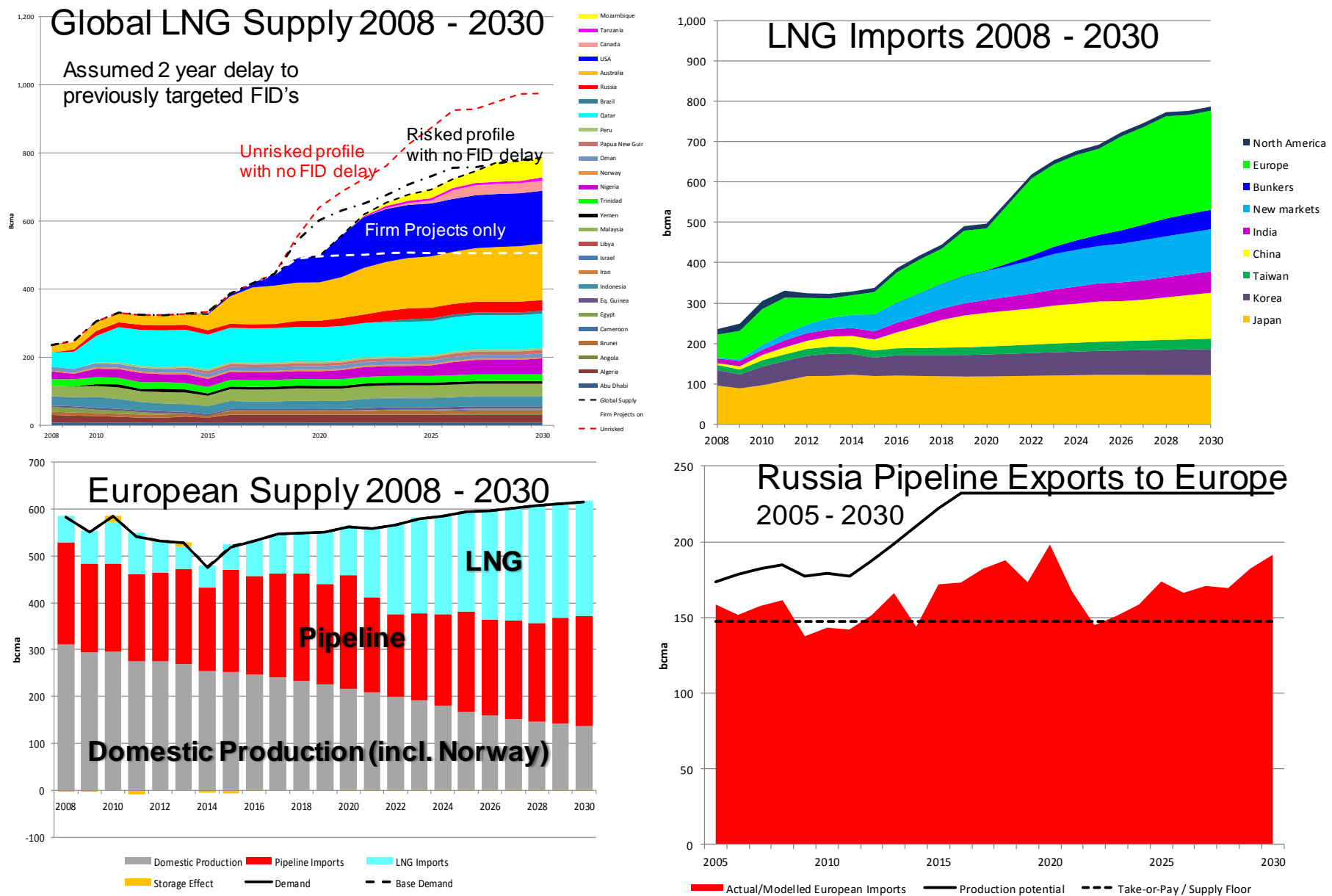

Source: Author's Analysis

In Figure 33 the top left graphic shows global LNG supply, with projects which have not achieved FID by mid 2015 delayed by 2 years relative to the dates expected in early 2014, prior to the fall in gas and oil prices. The top right graph shows which markets this LNG is delivered to, with European volumes growing post 2020. The bottom left graphic shows the European demand and supply mix with the increase in LNG imports broadly offsetting the decline in domestic production. The bottom right chart shows Russian pipeline gas exports to Europe which are generally some 20 - 30 bcma higher than in 2014.

In Figure 34, the top graphics show the global LNG supply and market delivery demographics. In this scenario, low Chinese LNG demand growth results in a 3 year delay to all new LNG projects. This combination results in a reduction in Russian pipeline gas exports to Europe compared to Scenario 1. 

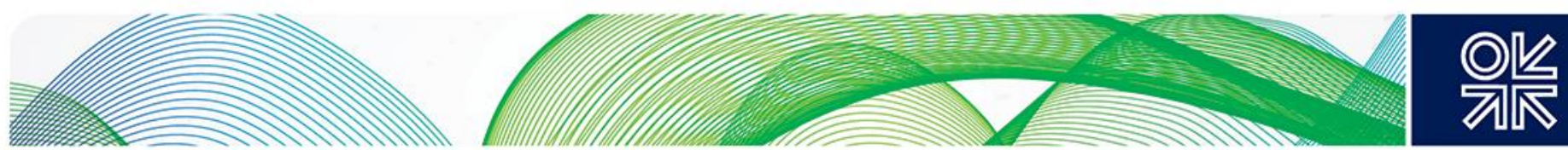

Figure 34: Scenario 2, Low Chinese LNG Demand, Base Case European Demand, Russia Supports European Hub Prices
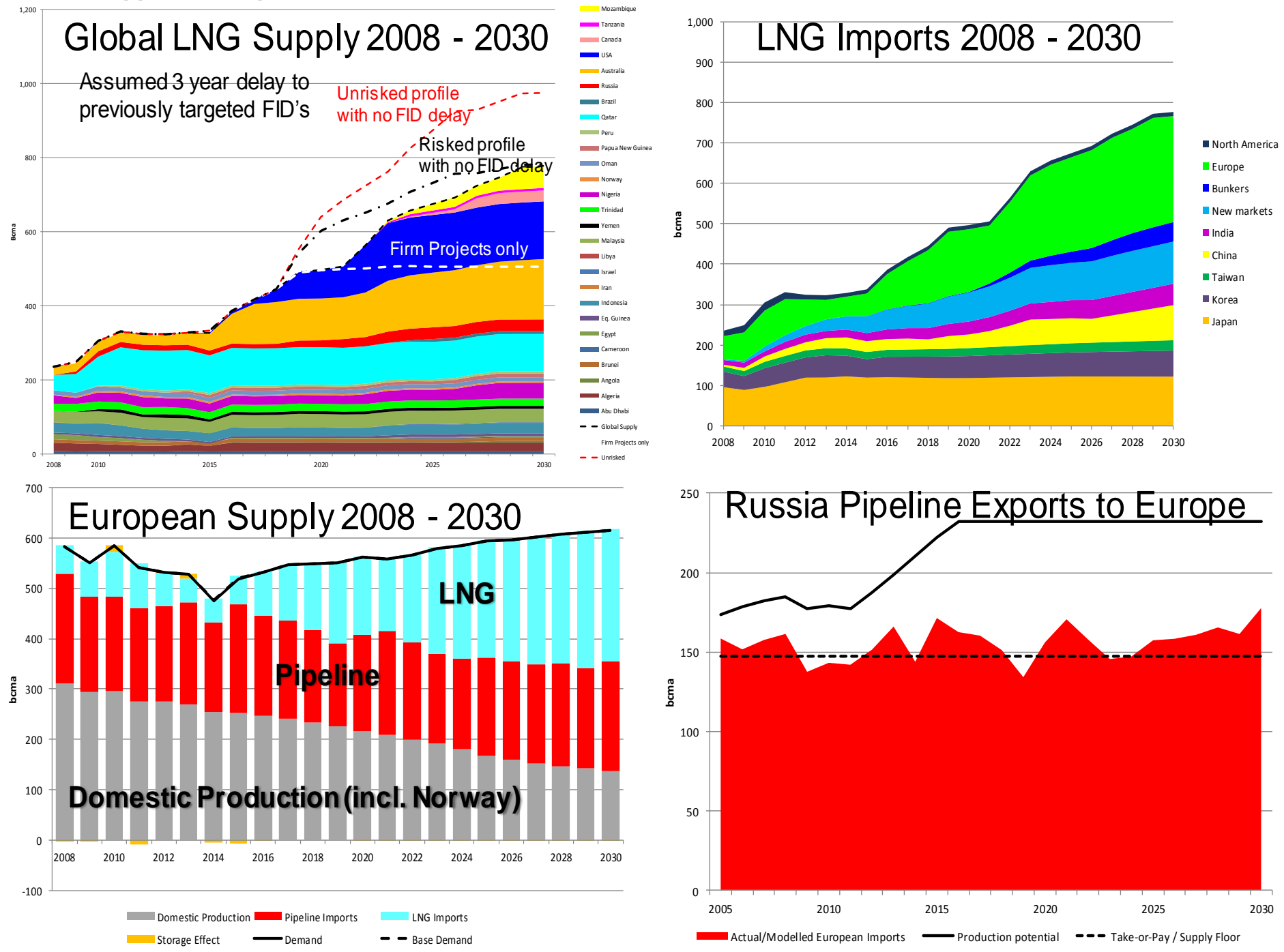

Source: Author's Analysis

Figure 35 shows the indicative price paths consistent with Scenarios 1 and 2 . It is assumed that Henry Hub rises to around $\$ 5.50 / \mathrm{mmbtu}$ by 2020 in order to stimulate sufficient production for the US market and LNG exports which reach 150 bcma by the late 2020s. European hub prices of $\$ 10.50$ and Asian spot LNG prices of $\$ 12.50$ would enable new US and other LNG projects to achieve FID assuming cost base savings are made by the LNG industry in the next 3 to 5 years.

Figure 36 shows the illustrative impact of Russia using its market power to keep European hub prices below levels required to achieve FID on new LNG projects, at least until the mid to late 2020s. Asian LNG spot prices (and possibly hub prices towards 2030) are also lowered through arbitrage, with the assumption that the $\$ 2 / \mathrm{mmbtu}$ premium is the additional transport cost of US LNG (assumed to be the marginal flexible LNG supplier). 

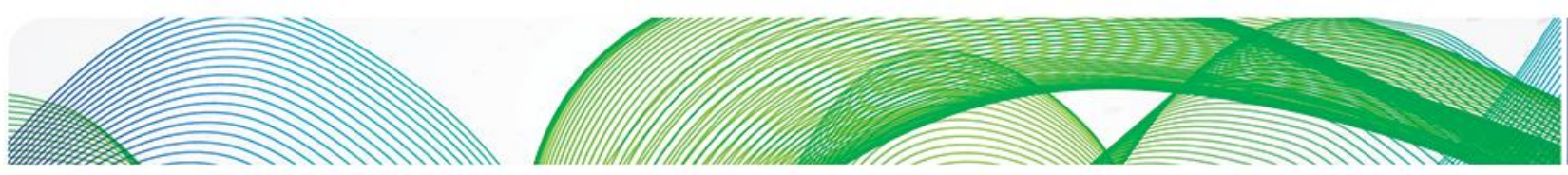

Figure 35: Indicative Price Paths 2010 to 2030 for Scenarios 1 and 2, with Russia supporting European Hub Prices

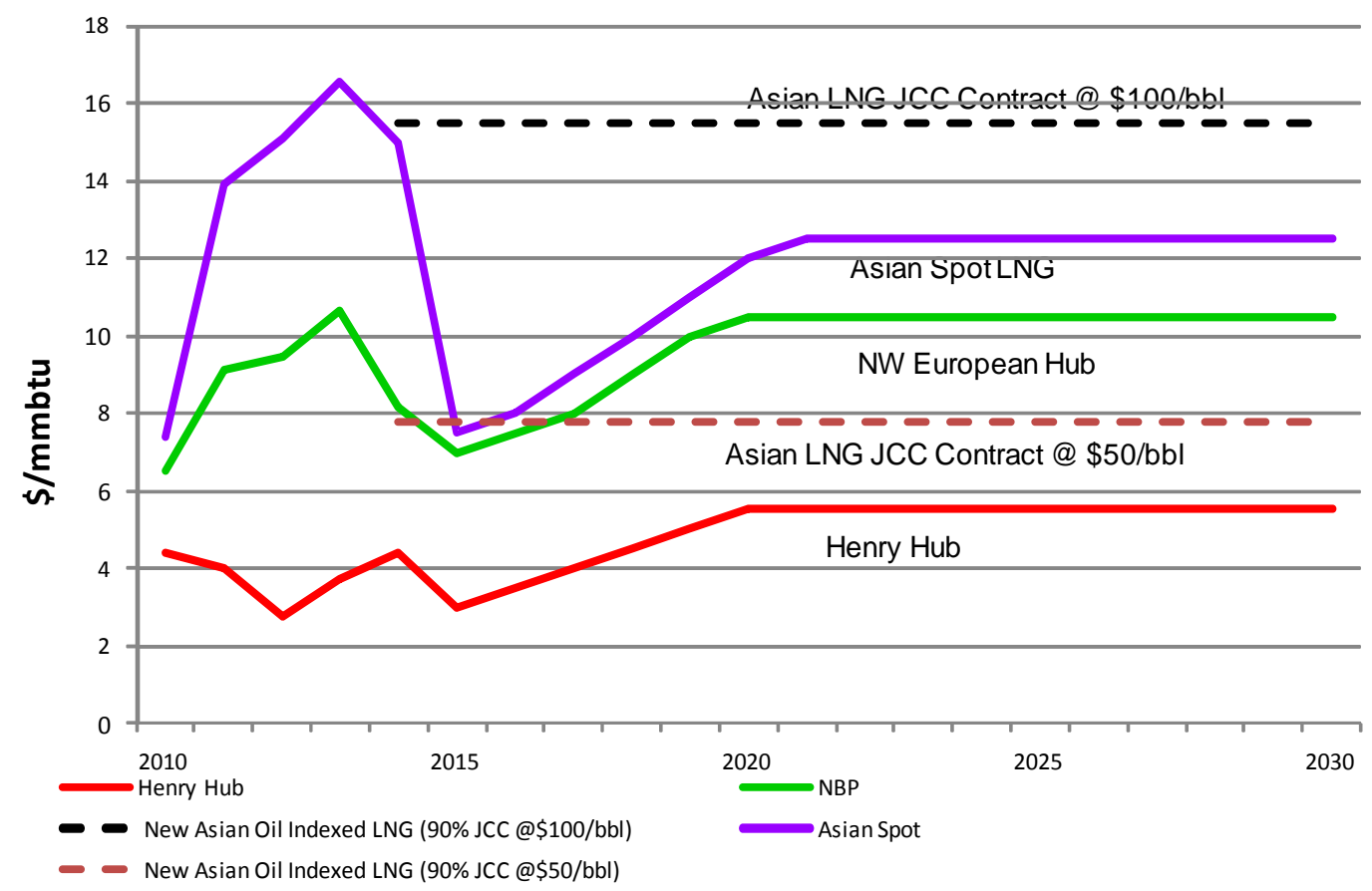

Sources: EIA, Platts, Author's Calculations and Assumptions

Figure 36: Indicative Price Paths 2010 to 2030 for Scenarios 1 and 2, with Russia Keeping European Hub Prices Low

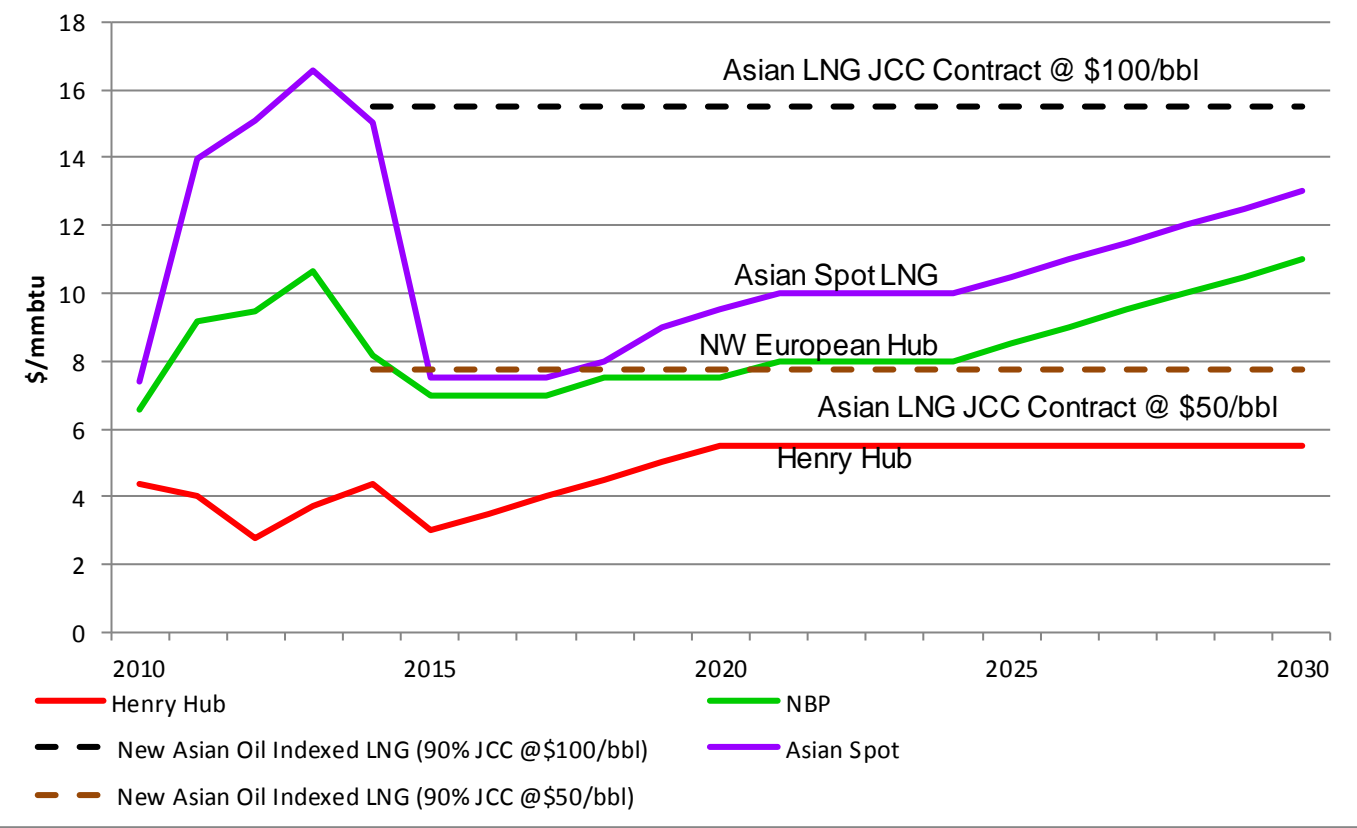

Sources: EIA, Platts, Author's Calculations and Assumptions 

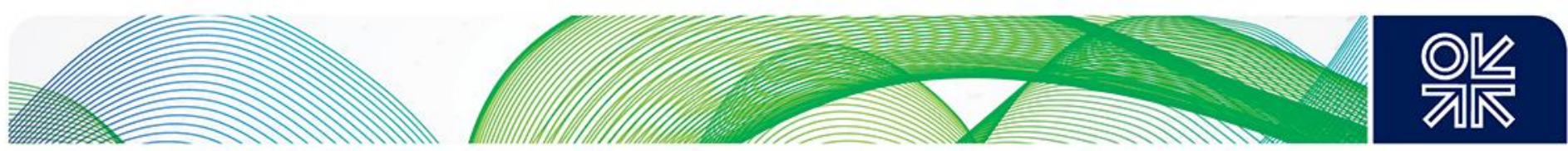

Figure 37 shows the consequences of this Russian price strategy in Europe. It is assumed that no new US LNG projects achieve FID and that non-US LNG project FIDs are delayed.

\section{Figure 37: Scenario 2, Low Chinese LNG Demand, Base Case European Demand, Russia Keeps European Hub Prices Low}
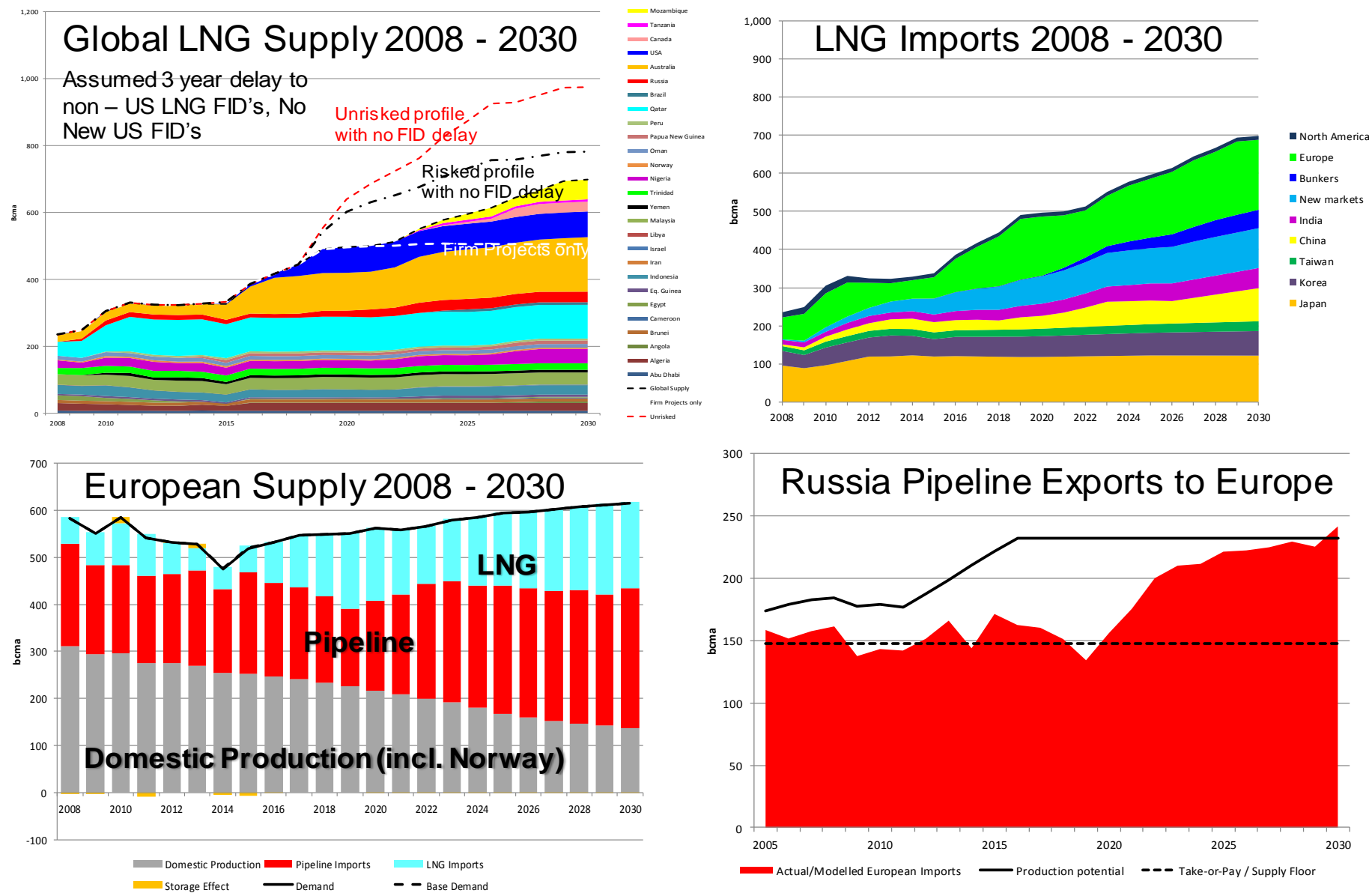

Source: Author's Analysis

The most striking feature of this case is the significant ramp-up in Russian supply to Europe post 2020.

We now turn to the scenarios in which European demand remains essentially stagnant through to 2030.

Figure 38 shows Scenario 3 (Low Chinese LNG Demand, Low European Demand, Russia Supports European Hub Prices). New US and non-US projects achieve FID albeit 3 years later that anticipated in early 2014. The consequences of Russia maintaining European hub prices (and by arbitrage Asian spot prices and towards 2030 possibly hub prices) is a major loss of Russian export volumes to Europe. The Hub Re-Delivery model would allow buyers of Russian contract gas to meet Take or Pay levels, but the physical volumes delivered from West Siberia would diminish markedly. 

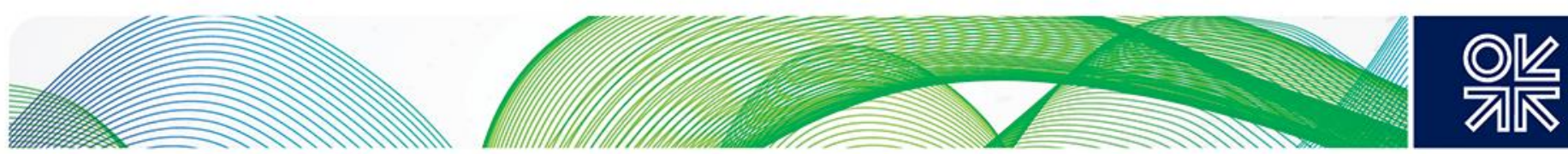

Figure 38: Scenario 3, Low Chinese LNG Demand, Low European Demand, Russia Supports European Hub Prices
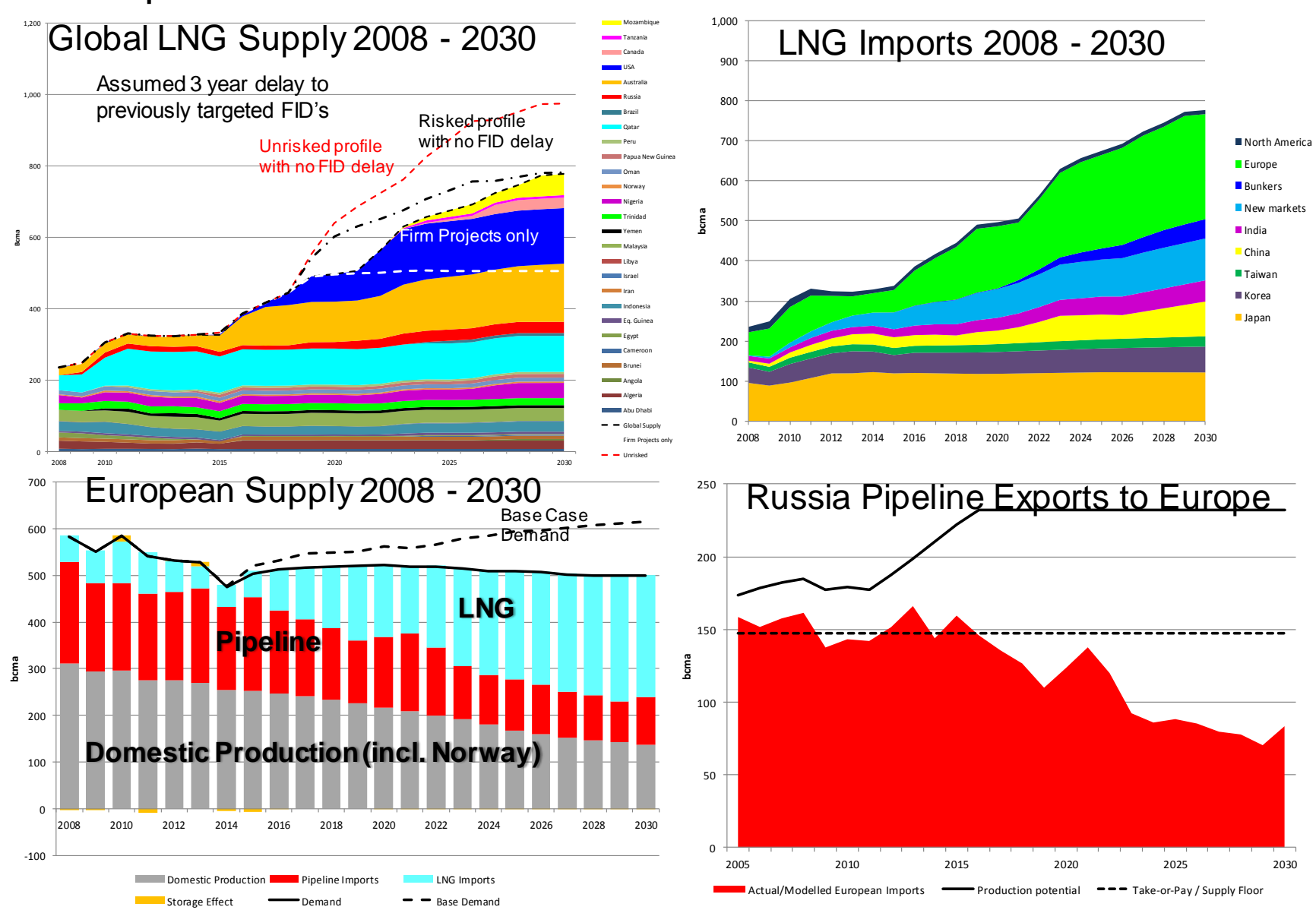

Source: Author's Analysis 

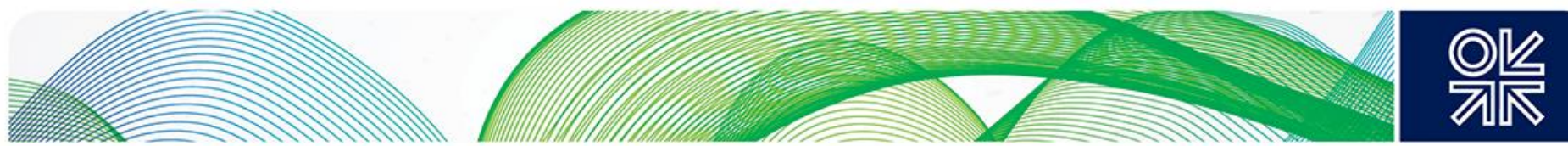

Figure 39: Scenario 4, High Chinese LNG Demand, Low European Demand, Russia Supports European Hub Prices
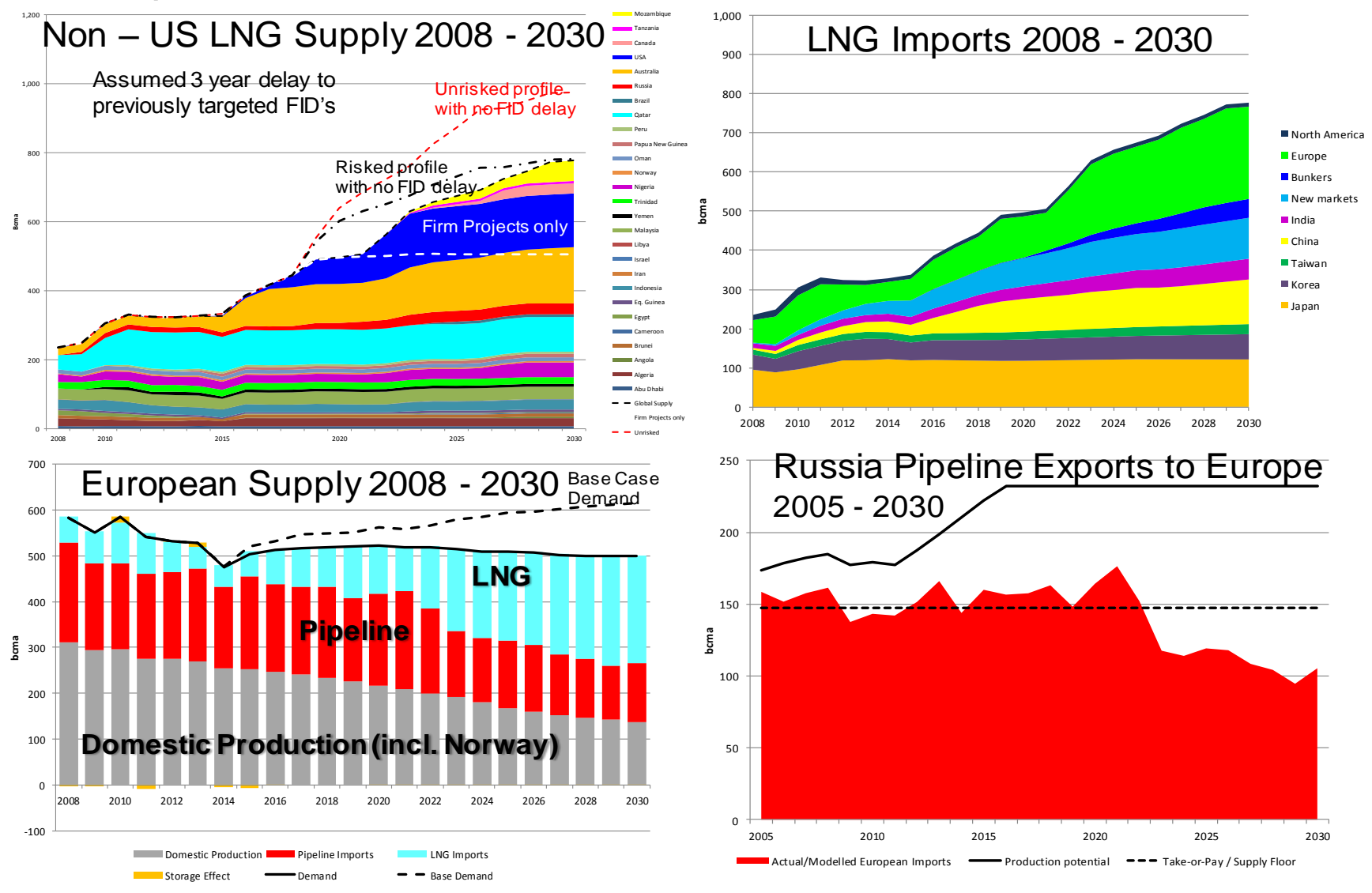

Source: Author's Analysis

Figure 39 shows the comparable scenario with the high Chinese LNG demand assumption. Russia's loss of exports to Europe is confined to the post 2020 period but is still significant. For Scenarios 3 and 4 shown in Figures 38 and 39 the assumed price paths are those shown in Figure 35.

Finally we look at the impact of Russia keeping European hub prices low (as shown in Figure 36), thus deferring new US LNG FIDs. The outcome, in Figure 40 is one where Russia achieves a modest growth in exports to Europe post 2020 through discouraging new US LNG export projects. 

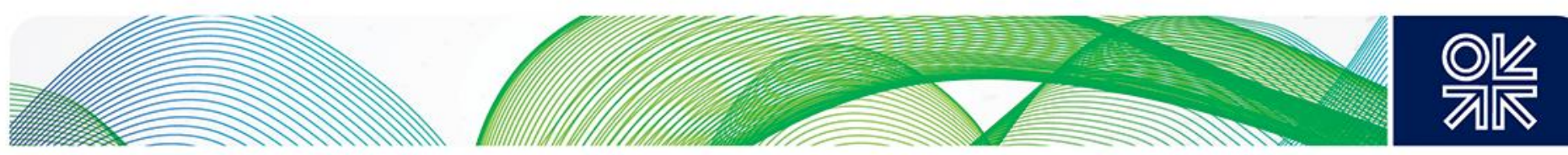

Figure 40: Scenario 4, High Chinese LNG Demand, Low European Demand, Russia Keeps European Hub Prices Low
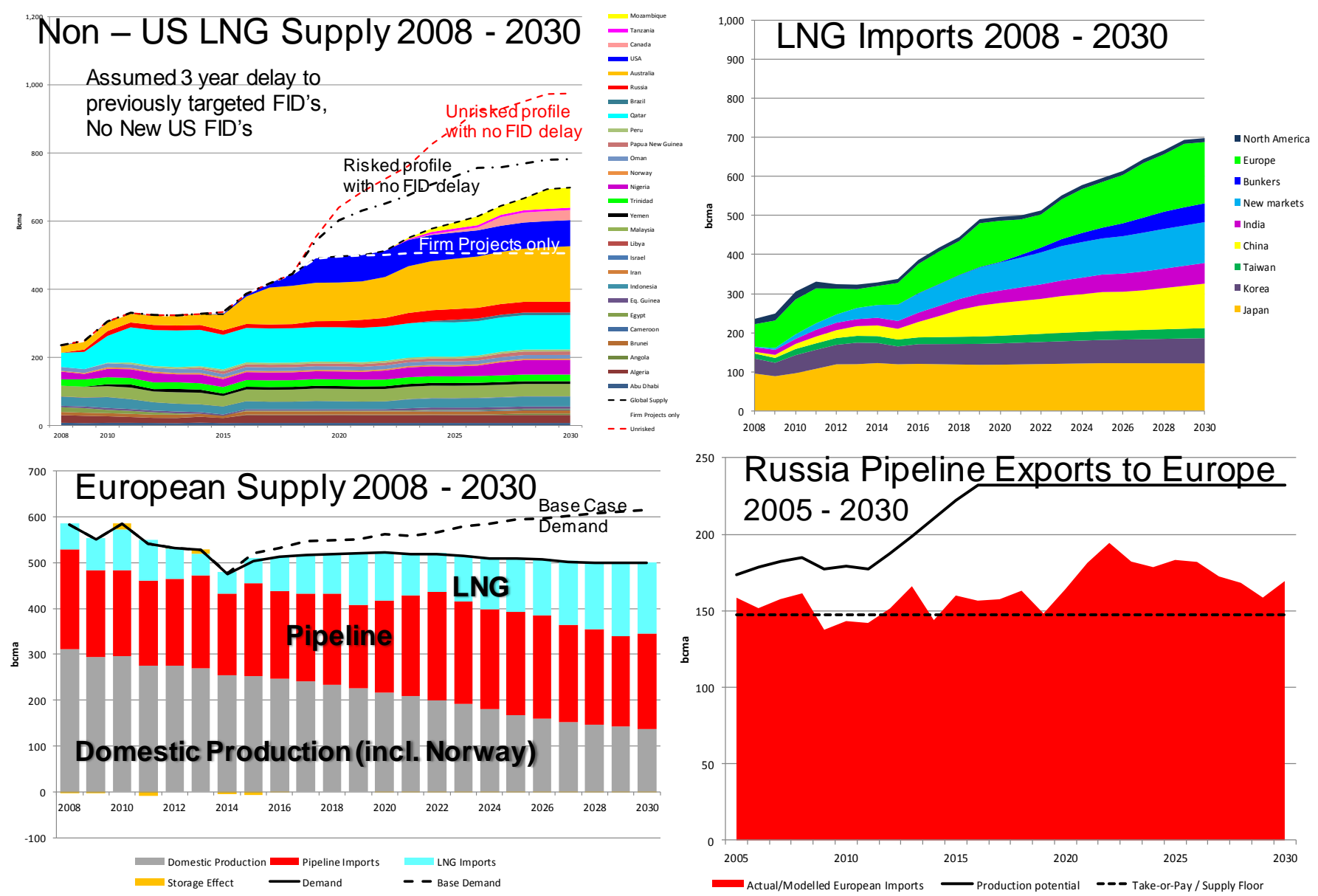

Source: Author's Analysis

Scenario analysis such as that described above is useful in identifying the consequences of a specific set of assumptions, system linkages and 'rules' to govern the behaviours of key players involved. The following addresses additional questions raised by the analysis.

We have modelled Gazprom's behaviour in terms of moving to the Hub-Redelivery Model in order to either support European hub prices (at a level which encourages LNG FIDs and hence competing supply) or keep hub prices low (to discourage such competition). What if Gazprom stays as it is (i.e. merely fulfils buyer nominations with gas transported from West Siberia)? Such a state could persist until buyers' behaviour makes Gazprom's position untenable (either due to significant sales volume loss or hub prices which are below those viewed in Moscow as 'fair'. In Chapter 3 we discussed the apparent response of short term interruptions instituted by Gazprom to a belief that buyers were nominating 'too high' and stimulating hub volumes by selling contract volumes onto them. This is obviously a temptation for buyers whose contracts have been moved to hub linkage pricing, especially when such an action could result in lower prices which made gas more competitive in the power generation sector. If all buyers in this position (re hub pricing in contracts) were similarly motivated, this would tend to lead towards the 'low hub price' path. What Gazprom's response to this would be is unclear. If this was a trend it was unhappy with it could move to the Hub Re-Delivery Model to take back control of prices. 

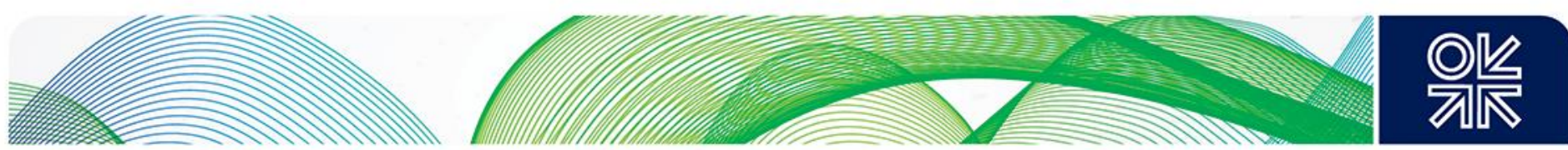

A situation which is likely to arise in a continued stagnant European demand situation is one where Europe's LNG imports are in excess of the 'contestable demand' above domestic production, other imports and Russian contract Take or Pay levels. Maintaining a hard line on meeting Take or Pay levels would send European hub prices down to power sector coal switching levels (circa $\$ 4.50$ to $\$ 5.00 / \mathrm{mmbtu}$ in Continental Europe), result in a loss of revenue for Gazprom, and place buyers who still have an element of oil indexation in their contracts potentially under renewed financial stress. Again a move to the Hub Re-Delivery Model would avert this.

If LNG project FIDs are significantly delayed might we see a 'boom and bust' situation developing in the 2020s? In 2015 this is a widespread industry concern. A guide to the answer is contained in the volumetrics shown in Figure 37. If Russia chose not to increase exports to Europe in line with the ramp-up shown in the 2020s, this would lead to a shortage of LNG relative to demand. Of course the resulting hub price spike would elicit more LNG FIDs but only after a delay of 5 to 6 years. Given its spare production capacity this would not be a rational move by Russia, however it is likely that much of the additional Russian export volumes would need to be sold on the hubs directly by Gazprom ${ }^{51}-\mathrm{a}$ policy it has not favoured to date.

Another potential 'boom and bust' development would be caused by a sudden increase in Chinese demand for LNG, either as a consequence of an unforeseen resumption in rapid economic growth or significant delays in, for example, either of its two Russian gas pipeline projects. In general however, given its experiences in the mid to late 2000s, China has become wary of the costs it suffers when it exerts a sudden import pull on global commodities and is unlikely to intentionally place itself in a position of needing large volumes of LNG at short notice.

\footnotetext{
${ }^{51}$ Given the ongoing problems of European midstream buyers of Russian gas detailed in Stern and Rogers 2014, it is unlikely that many new contracts for Russian supply would be signed.
} 

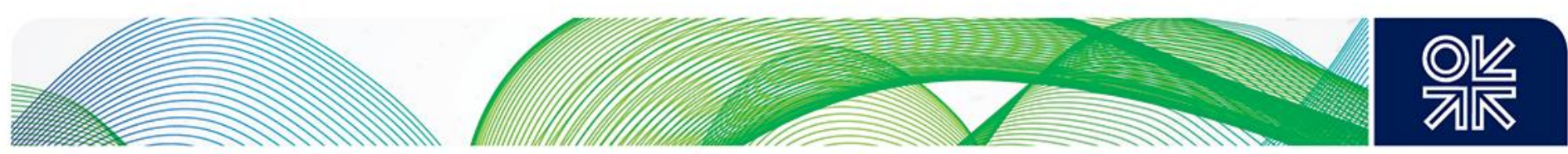

\section{Summary and Conclusions}

The aftermath of warmer than normal 2013/2014 winters in Europe and Asia, evidence of slowing Asian LNG demand growth through 2014 and the collapse of the oil price in late 2014 has resulted in a painful 'new normal' for key players in the global gas system, specifically LNG project investors and Russia/Gazprom. Although this paper has used a similar approach to previous work by the author relating to global LNG interactions ${ }^{52}$, the context in mid 2015 has changed markedly and while the gas industry has in the past experienced and weathered periods of low prices, this time 'it really does feel different'.

At one level we can rationalise the slowdown in Asian LNG demand and stagnant European gas demand as having a direct causal impact on European hub and LNG spot prices. The oil price fall has in parallel brought oil-indexed gas and LNG contract price levels down to levels unimaginable just two years ago. With project economics challenged and cashflows crimped, investors in new gas supply projects, especially LNG, will inevitably hold back, cut costs and await a more positive market outlook.

At a more fundamental level however, what we may be about to witness is a significant disruption to regional gas equilibria as a wave of new (Australian) LNG supply meets a slowing Asian market and a significant regional component (US/North America) re-connects with the global system in the form of 77 bcma (and counting) of new LNG export projects. Europe will be a passive recipient of excess supply at a time when its gas demand growth is at best tepid, but its import requirement may be rising due to declining domestic production.

This paper has addressed the following questions:

1) What has been the impact of lower oil and lower gas prices on existing and future gas and LNG projects?

2) What is the outlook for the period to 2030 for markets connected by flexible LNG supplies given the uncertainty in regional demand outlooks in the light of new LNG supply currently under construction?

3) What is the impact of the probable delay to new LNG project FIDs given demand uncertainties and the apparent need to move from oil indexation to new contract price formation structures?

4) To what extent can Russia, using its market power in Europe to 'control' hub prices influence such outcomes?

On the first question, as the majority of upstream gas projects are undertaken by oil and gas companies (whether IOCs or NOCs), lower oil and gas prices feed directly through to lower discretionary cashflow and hence funds available for capital investment. Capital allocation is prioritised on projects with the most robust returns, although such decisions are based on a view of long term price developments, given that these projects will have productive lives beginning 4 to 8 years in the future and generating revenues for some 20 to 30 years thereafter. The problem faced by oil and gas companies at present is accentuated by uncertainties related to Asian economic growth (particularly China) on the demand side for both oil and gas and the future potential of shale (tight) oil production in the US. The oil price outlook is, as always, prey to geo-political events, mainly relating to the MENA region which could reduce or increase oil supply and hence influence price. For gas the oil price collapse has undermined the rationale for relying on this pricing basis as the 'gold standard' for underpinning the economics of high cost-base LNG projects (and Russian pipeline export contracts). The current (mid 2015) level of hub prices and oil-linked contract reference prices would render virtually all tranches of incremental gas supply uneconomic - apart from the 100-plus bcma of

52 Stern and Rogers (2014) 

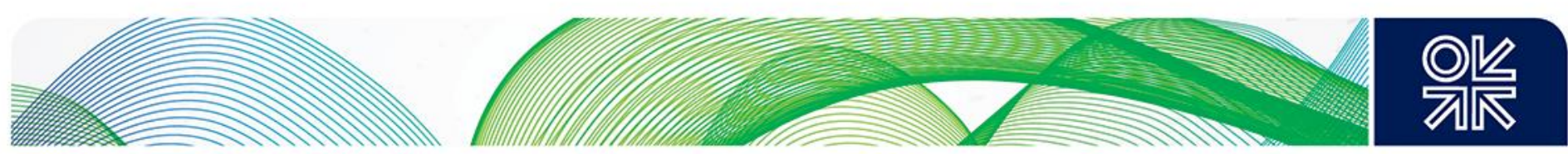

developed, but 'shut-in' Russian gas which could flow to the European border at a price of around $\$ 3.50 / \mathrm{mmbtu}$ (see Figure 28).

The second question brings in the considerable range of uncertainties regarding trends on supply and demand in the global system connected by flexible LNG as depicted in Figure 4. In conventional wisdom, the creation of a network of physical commodity flows might be expected to lower general volatility of supply and demand balance at specific points (the portfolio risk diversification effect). With gas being a low energy density fuel (in terms of heat content per unit of volume) this is not necessarily the case. In order to recover fixed costs all gas producers tend to produce at maximum sustainable rates, storage facilities are rarely sized to compensate for multi-year demand fluctuations and hence demand and supply events will tend to have an impact on all markets connected by gas tradeflows whether by pipeline or LNG. By contrast, the situation of Russia is unique. Gazprom has built up excess productive capacity of more than $100 \mathrm{bcma}$ - in part through investments in the Yamal peninsula in anticipation of higher European demand than has transpired, and also due to the erosion of its Russian domestic market share by competing producers such as Rosneft, Lukoil and Novatek.

Looking forward, the main uncertainties on demand in this 'system' are:

- The future growth of Asian (and particularly Chinese) demand for gas and LNG.

- The emergence of 'new' markets for LNG in the 2020s, particularly marine transportation fuel ('Bunkers').

- The uncertainty around European future demand recovery for gas, which is subject to the rate of nuclear and coal plant closures and the future pace of renewable investment and capacity build.

The three key uncertainties on the supply side on this system are:

- The scale and pace of US LNG exports which, given the likely affirmation of resource base, depends on the future pace of project FIDs beyond the $77 \mathrm{bcma}$ of projects under construction.

- The scale and pace of non-US LNG projects from Australia (85 bcma under construction but additional brownfield/expansion potential), Canada, East Africa and Russia (other than Yamal, which are likely to be delayed by the current imposition of sanctions).

- Russian pipeline export volumes. These relate both to China - where its two pipeline export deals are by no means immune to future renegotiation and delay, but also to Europe where Russia will likely be forced to make a choice between a 'high volume, low price' or a 'low volume high price' strategy as the threat of losing market share to LNG volumes from existing (including under construction) and new projects looms.

For future research we might add an additional element of uncertainty to the supply side - specifically the rate of decline of domestic production in the European region. Here the three main producing centres - UK, Netherlands and Norway have reached maturity and in the case of the UK and The Netherlands are declining. Future production levels depend on the successful development of new (but typically smaller and price sensitive) discoveries and the rate of decline of older fields approaching abandonment (notoriously difficult to predict). The ongoing uncertainty on Groningen capacity limits is also highly relevant here.

To an extent these demand and supply side uncertainties are price related, however it is important to be aware of the real world constraints to such price responses. On the demand side the response to lower wholesale gas prices will generally operate on a multi-year timescale. Midstream utilities/local distribution companies in a liberalised market context will have purchased supplies up to two years in advance on forward markets. Lower prices will take a while to feed through into domestic tariffs and even then it is questionable whether consumers will consciously increase gas usage (turn thermostats up) as a consequence. In a non-OECD setting domestic and commercial consumption is generally a function of infrastructure making gas available as an alternative to LPG, oil or coal and hence government policy. In the industrial sector gas consumption is a function of GDP growth and long term trends in the preponderance of energy intensive industry in national economies - rather than a 

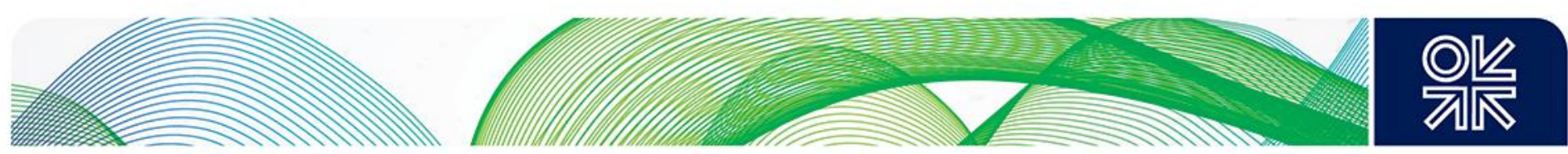

short term response to gas prices. In power, gas prices would generally (in mid 2015) have to drop below $\$ 5 / \mathrm{mmbtu}$ to materially displace coal in power generation (probably $\$ 6 / \mathrm{mmbtu}$ in the UK with a higher carbon price). The demand response to lower gas prices therefore is generally longer term and subsumed within other economic trends, except in periods of gas prices below $\$ 5 / \mathrm{mmbtu}$ - where the demand response may be shorter term in markets with a responsive power sector.

On the supply side we need to distinguish between gas from fields (and LNG facilities) already in production - which will tend to continue at maximum rate (with the exception of Russian supply), future supply from projects already under construction (which will be produced at design rates when commissioned) and future projects for which FID has not yet been taken. Here it is likely that such investment decisions will be delayed until market fundamentals support a view on the part of project investors that future prices (in the case of LNG projects those from 5 years into the future and beyond) will be sufficient to remunerate an adequate return on project investment. In the case of future non-US LNG projects, this is compounded by the stated desire of Asian buyers to seek 'hybrid' (some Henry Hub 'plus costs', some oil indexation and potentially some European hub indexation) terms with the possibility (through price reopeners) to move to Asian hub pricing in the future. North West European LNG buyers in the first instance will be unable to buy LNG on anything other than a hub basis and may be unwilling to sign contracts for more than 5 or 10 years.

This brings us to questions 3 and 4 which are somewhat inter-related. Current gas hub or spot prices are clearly signalling that the market at present is adequately supplied. This is not particularly helpful for a project which, if it takes FID in 2015 will come onstream around 2020. Neither is the current low oil price a particularly valid signal as to the need or otherwise for new LNG project FIDs. In the scenarios analysed in this paper it has been assumed that delays of between 2 and 3years apply to new LNG FIDs due to the uncertainty on Asian and European demand trends. Equally important is the future strategy which Russia might adopt. Given its comparative advantage of 100 plus bcma of developed (currently 'shut-in') production at low variable cost, Russia might decide to manage physical exports to Europe (through the Hub Re-Delivery Model) to keep European hub prices (and by arbitrage Asian LNG spot prices) too low to support new LNG projects which have not secured contracts with an Asian buyer on an acceptable 'hybrid' price basis. This would see Russia's gas market share increase substantially in Europe through the 2020s, but at some point the temptation to use such market power to increase price levels would probably prove hard to resist - resulting in a subsequent renewed surge of competing new LNG supply in all likelihood.

While this 'new great game' dynamic is certainly possible, and has a compelling logic, there is scant evidence in mid 2015 that Russia is immediately contemplating such a course of action. Its hand may be forced should

a) its buyers continue to nominate high volumes in order to sell some of this on the hubs and hence stimulate gas demand (in the belief that concessions and rebates from Gazprom would keep them financially whole); or,

b) a surge of European LNG imports (such volumes of LNG being not required elsewhere) take hub prices down to levels which either Gazprom deems 'too low' or where its midstream buyers, unable to meet take or pay requirements demanded further substantial contractual concessions, including perhaps immediate contract termination.

From a more positive perspective, more flexible use of 'spare' West Siberian production capacity would moderate a potential early 2020s 'tight' LNG market situation (perhaps caused by a sudden acceleration in Asian LNG demand). From a less positive perspective, Russia's market power would, in this system extend beyond Europe. The impact of higher or lower Russian physical flows would certainly impact European hubs and also (by arbitrage) Asian LNG spot prices. In certain circumstances (eg overbuilt US LNG export capacity not fully utilised) European hub price levels could also, through arbitrage, influence the Henry Hub price, especially if US LNG exports continued on the basis of covering just variable shipping and regas costs. The moderating factor, however, is 

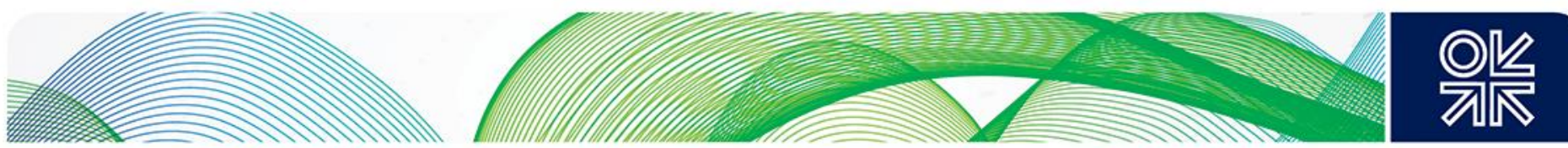

that if Russia maintains European hub prices at levels high enough to trigger new LNG FIDs, this would create competing supply which once built has very low variable costs and so will tend not to respond to subsequent lower prices.

However, the lack of clarity on Russia's future preferred commercial behaviour adds a level of complexity most market participants would prefer to ignore. Gazprom is occupied on many fronts in both political and commercial spheres. At some point however the need to adopt a more marketoriented strategy is likely to rise on its list of priorities. While the timing of this is at present uncertain, the conclusions of this paper would strongly suggest that this is a development that players in the wider LNG-connected global system should be closely monitoring. 

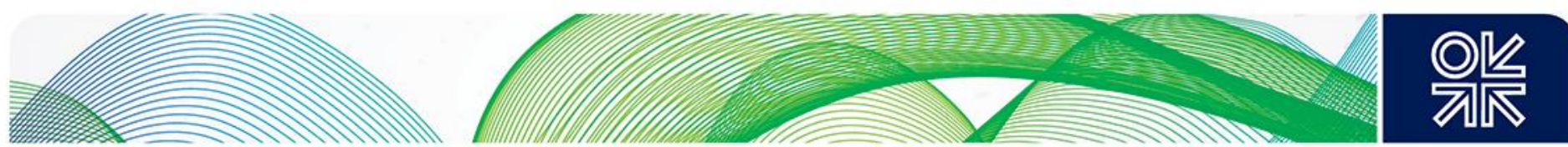

Appendix 1. Timings and Probability-Weighted Capacities of Future LNG Liquefaction Projects with Start-up timings as viewed in early 2014

Table 2: Timings and Probability-Weighted Capacities of Future LNG Liquefaction Projects with Start-up timings as viewed in early 2014

\begin{tabular}{|c|c|c|c|c|}
\hline \multirow[b]{2}{*}{ Angola } & \multirow[b]{2}{*}{ AngolaT1 } & \multicolumn{2}{|c|}{$\begin{array}{l}\text { Capacity } \\
\text { bcma }\end{array}$} & \multirow[t]{2}{*}{ Probability ( $100 \%$ if blank) } \\
\hline & & Jun-13 & 7.2 & \\
\hline Angola & Expansion & Jun-24 & 3.6 & $50 \%$ \\
\hline Australia & Browse Expansion & Mar-25 & 3.6 & $50 \%$ \\
\hline Australia & Gorgon T1 & Jan-16 & 10.3 & \\
\hline Australia & Gorgon T2 & Sep-16 & 10.3 & \\
\hline Australia & Icthys & Oct-16 & 11.6 & \\
\hline Australia & Sunrise & Jun-25 & 2.4 & $50 \%$ \\
\hline Australia & Browse & Mar-22 & 3.6 & $50 \%$ \\
\hline Australia & Gloadstone Santos Expansion & Aug-24 & 3.0 & $75 \%$ \\
\hline Australia & Wheatstone & Jul-16 & 12.3 & \\
\hline Australia & Pluto2 & Jun-19 & 3.4 & $50 \%$ \\
\hline Australia & Bonaparte & Jun-21 & 1.4 & $50 \%$ \\
\hline Australia & Asia Pacific LNG (CP) & Oct-15 & 12.4 & \\
\hline Australia & Prelude & Jul-17 & 5.0 & \\
\hline Australia & Pluto3 & Jul-22 & 3.0 & $50 \%$ \\
\hline Australia & Wheatstone T4 & Aug-27 & 4.1 & $50 \%$ \\
\hline Australia & Gorgon T4 & Jun-19 & 3.4 & $50 \%$ \\
\hline Australia & Asia Pacific (CP/Arrow) T3 & Jul-19 & 4.7 & $75 \%$ \\
\hline Australia & Curtis BG Train 3 & Jul-20 & 3.0 & $75 \%$ \\
\hline Australia & CSG Curtis (Shell/Petrochina) & Jul-19 & 8.3 & $50 \%$ \\
\hline Australia & Wheatstone Train 3 & Jul-20 & 3.1 & $50 \%$ \\
\hline Australia & CSG Expansion & Sep-19 & 2.8 & $50 \%$ \\
\hline Australia & CSG Expansion T3 & Apr-24 & 2.8 & $50 \%$ \\
\hline Australia & Gorgon 5 & Jul-20 & 3.4 & $50 \%$ \\
\hline Brazil & Petrobras \& BG & Jul-21 & 8.3 & $50 \%$ \\
\hline Cameroon & Cameroon LNG & Sep-20 & 2.5 & $50 \%$ \\
\hline Canada & Price Rupert Ph 1 & Oct-22 & 5.0 & $50 \%$ \\
\hline Canada & Pacifc NW Phase 1 & May-21 & 6.8 & $75 \%$ \\
\hline Canada & Various & Jan-24 & 27.6 & $50 \%$ \\
\hline Eq. Guinea & EG LNG T2 & Oct-19 & 3.0 & $50 \%$ \\
\hline Indonesia & Tangguh T3 & Aug-19 & 3.9 & $75 \%$ \\
\hline Indonesia & Abdabi/Masala Floating & Aug-18 & 3.4 & \\
\hline Indonesia & Project 1 & Apr-20 & 1.4 & $50 \%$ \\
\hline Indonesia & Project 2 & Jun-22 & 1.4 & $50 \%$ \\
\hline Indonesia & Project 3 & Apr-24 & 1.4 & $50 \%$ \\
\hline Israel & Train 1 & Feb-20 & 1.7 & $50 \%$ \\
\hline Malaysia & MLNG T9 & Sep-15 & 5.0 & \\
\hline Malaysia & FLNG (Sabah) & Aug-18 & 1.7 & \\
\hline Malaysia & Sarawak & Mar-16 & 1.7 & \\
\hline Mozambique & East Africa LNG Project 1 & Jun-20 & 10.3 & $75 \%$ \\
\hline Mozambique & East Africa LNG Project 2 & Jun-22 & 10.3 & $75 \%$ \\
\hline Mozambique & East Africa LNG Project 3 & Apr-22 & 6.9 & $50 \%$ \\
\hline Mozambique & Various & Aug-25 & 34.5 & $50 \%$ \\
\hline Nigeria & NLNG T7 & Apr-19 & 5.9 & $50 \%$ \\
\hline Nigeria & Train 8 & Jun-24 & 6.9 & $50 \%$ \\
\hline Nigeria & Brass River & Aug-23 & 6.9 & $50 \%$ \\
\hline Nigeria & OloKola LNG & Mar-28 & 6.9 & $50 \%$ \\
\hline Papua New Guinea & ELK & Jul-23 & 2.8 & $50 \%$ \\
\hline Russia & Yamal 1 & Nov-18 & 7.6 & \\
\hline Russia & Yamal 2 & Jan-21 & 7.6 & \\
\hline Russia & Yamal 3 & Dec-22 & 7.6 & \\
\hline Tanzania & East Africa LNG BG & Jun-20 & 6.9 & $50 \%$ \\
\hline Tanzania & Upside & Aug-28 & 13.8 & $50 \%$ \\
\hline USA & Sabine Pass T5 \& 6 & Jan-19 & 10.3 & \\
\hline USA & Gloden Pass & Jan-20 & 21.5 & \\
\hline USA & Jordan Cove & Jan-19 & 8.3 & \\
\hline USA & Corpus Christi & Jan-19 & 11.6 & \\
\hline USA & Lake Charles & Jan-19 & 20.7 & \\
\hline USA & USA Other & Jan-21 & 18.0 & \\
\hline & Total (Probability weighted) & & 428.1 & \\
\hline
\end{tabular}



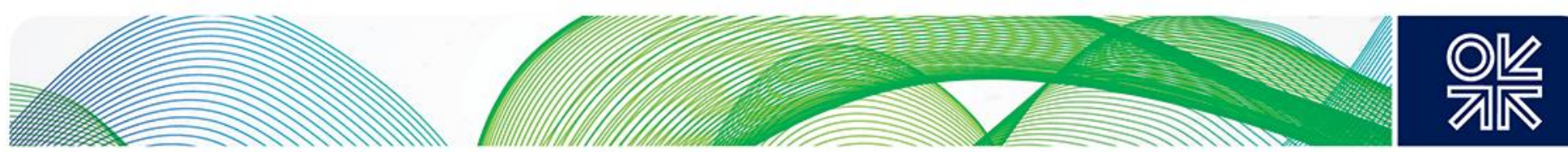

\section{Glossary}

$A C Q$, Annual Contract Quantity - The amount notionally agreed to be sold and purchased under a contract. Actual quantities sold may be higher or lower than the ACQ, within limits specified.

Argus - An energy publisher, Argus Global LNG used as a source in this paper.

Brownfield - Refers to a project built as an expansion of, or sharing facilities with an existing plant.

CME - CME Group - an energy and commodity trading house.

CNPC - Chinese National Petroleum Corporation

Coal Bed Methane - Methane held within the fissures and matrix of coal seams.

DG COMP - European Commission Director General for Competition

EIA - The US Energy Information Administration

ERI RAS - The Energy Research Institute of the Russian Academy of Science

FEED - Front End Engineering Design

FERC- US Federal Energy Regulatory Commission

FID - Final investment decision

GIE - Gas Infrastructure Europe

GIIGNL - International Group of Liquefied Natural Gas Importers

Greenfield - Refers to a project sited on land remote from existing similar facilities.

Henry Hub - The physical location of the interconnection of major gas pipelines in Erath, Louisiana. It is the key (but not only) pricing point for natural gas in the US.

Hub, Trading Hub - a real or virtual point where natural gas is traded via bi-lateral, brokered or exchange facilitated trading platforms.

ICIS - An energy published and price reporting agency.

IEA - The International Energy Agency

IGU - International Gas Union

IOC - International Oil and Gas (upstream) Companies.

JCC- Japanese Customs Cleared Crude - an internationally recognised crude oil price marker.

JKM - Japan Korea Marker - an LNG spot reference price quoted by Platts

Liquefaction - The process of turning natural gas to a liquid at minus 162 degrees $C$ through cryogenic cooling.

LNG - Liquefied Natural Gas

MENA - Middle East and North Africa

NBP - National Balancing Point - the UK's virtual gas trading hub.

NOC - National (State Owned) Oil (and in some cases) Gas Companies.

$\mathrm{PO}$ - The initial price at the commencement of a gas contract.

Platts - An energy publisher and price reporting agency. 

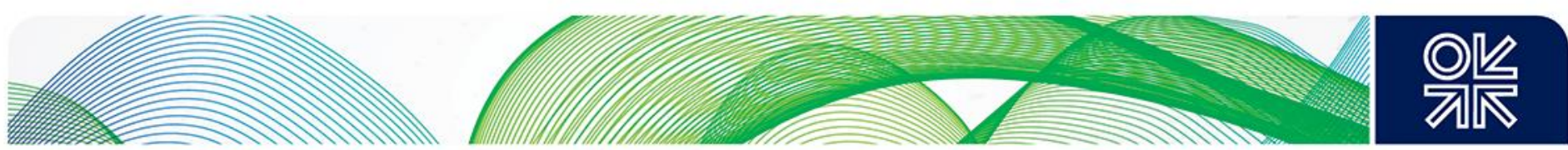

Regas, Regassification - The conversion of LNG to gaseous natural gas through heating.

Take or Pay - The annual quantity of gas (less than the ACQ) which the buyer is obliged to pay for, whether it is able to physically take such volume or not.

UKCS - UK Continental Shelf

WEO - World Energy Outlook 

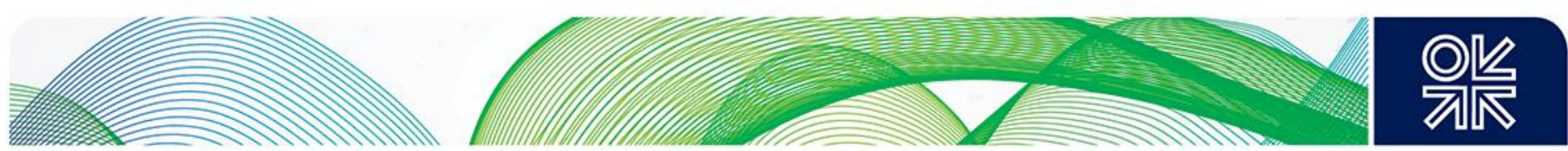

\section{Bibliography}

BP Statistical Review of World Energy 2015 and 2014, http://www.bp.com/en/global/corporate/aboutbp/energy-economics/statistical-review-of-world-energy/statistical-review-downloads.html

Chen (2014): The Development of Chinese Gas Pricing - Drivers, Challenges and Implications for Demand, Michael Chen, NG89, OIES, 2014, http://www.oxfordenergy.org/2014/07/the-developmentof-chinese-gas-pricing-drivers-challenges-and-implications-for-demand/

Fattouh, Rogers and Stewart (2015): 'The US Shale Gas Revolution and its Impact on Qatar's Position in Gas Markets', B Fattouh, H Rogers, P Stewart, March 2015, Columbia, SIPA, http://www.oxfordenergy.org/2015/03/the-us-shale-gas-revolution-and-its-impact-on-qatars-positionin-gas-markets/

GIIGNL (2015): 'The LNG Industry 2014', GIIGNL, http://www.giignl.org/sites/default/files/PUBLIC_AREA/Publications/giignl_2015_annual_report.pdf

Gomes (2015): 'Natural Gas in Canada: what are the options going forward?', leda Gomes, May 2015, NG 98, OIES, http://www.oxfordenergy.org/2015/05/natural-gas-in-canada-what-are-theoptions-going-forward/

Henderson (2014): 'The Commercial and Political Logic for the Altai Pipeline', J Henderson, December 2014, OIES, http://www.oxfordenergy.org/2014/12/commercial-political-logic-altai-pipeline/

Henderson and Pirani (2014): 'The Russian Gas Matrix: How Markets are Driving Change', J.Henderson, S.Pirani, (editors), OIES, http://www.oxfordenergy.org/shop/the-russian-gas-matrixhow-markets-are-driving-change/

Honore (2014): 'The Outlook for Natural Gas Demand in Europe', Anouk Honore, NG87, OIES, June 2014, http://www.oxfordenergy.org/2014/06/the-outlook-for-natural-gas-demand-in-europe-2/

IEA (2014): 'World Energy Outlook 2014, IEA, http://www.iea.org/bookshop/477-

World_Energy_Outlook_2014

IEA Monthly Gas Data Service: A subscription service at: http://www.iea.org/statistics/mgds/

IGU (2015): Wholesale Gas Price Survey 2015 Edition, International Gas Union, 2015,

http://www.igu.org/sites/default/files/node-page-

field_file/IGU\%20Whole\%20Sale\%20Gas\%20Price\%20Survey\%20Report\%20\%202015\%20Edition.p df

Ledesma (2014): 'East Africa Gas - The Potential for Export', D Ledesma, March 2014, NG 74, OIES, http://www.oxfordenergy.org/2013/03/east-africa-gas-the-potential-for-export/

Ledesma, Palmer and Henderson (2014): The Future of Australian LNG Exports - Will domestic challenges limit the development of future LNG export capacity ?, D. Ledesma, N. Palmer and J. Henderson, NG 90, OIES, 2014, http://www.oxfordenergy.org/2014/09/the-future-of-australian-Ingexports-will-domestic-challenges-limit-the-development-of-future-Ing-export-capacity/

Pirani (2014): Ukraine's Imports of Russian Gas - How a Deal Might Be Reached, S. Pirani, OIES, July 2014, http://www.oxfordenergy.org/2014/07/ukraines-imports-of-russian-gas-how-a-deal-mightbe-reached/

Rogers and Stern (2014): 'Challenges to JCC Pricing in Asian LNG Markets, H. Rogers \& J. Stern, February 2014, NG81, OIES, http://www.oxfordenergy.org/2014/02/challenges-to-jcc-pricing-in-asianIng-markets-2/ 

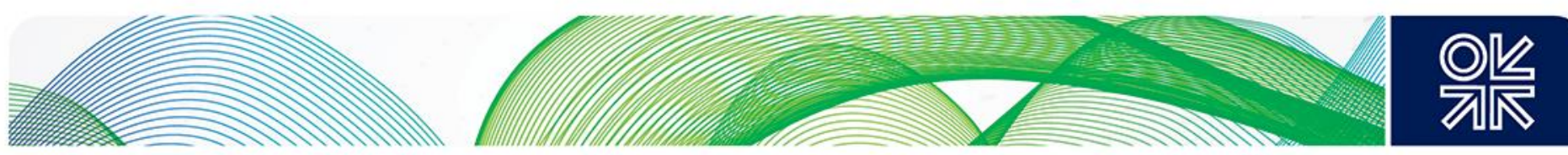

Rzayeva (2015): 'The Outlook for Azerbaijani Gas Supplies to Europe - Challenges and Perspectives', Gulmira Rzayeva, June 2015, NG 97, OIES, http://www.oxfordenergy.org/2015/06/theoutlook-for-azerbaijani-gas-supplies-to-europe-challenges-and-perspectives/

Sen (2015): 'Gas Pricing Reform in India - Implications for the Indian gas landscape', Anupama Sen, 15th April 2015, NG 96, OIES, http://www.oxfordenergy.org/2015/04/gas-pricing-reform-in-indiaimplications-for-the-indian-gas-landscape-2/

Songhurst (2014): LNG Plant Cost Escalation, Brian Songhurst, NG83, OIES, February 2014, http://www.oxfordenergy.org/wpcms/wp-content/uploads/2014/02/NG-83.pdf

Stern (2014): 'Reducing European Dependence on Russian Gas - distinguishing natural gas security from politics', J. Stern et al, NG92, OIES, October 2014,

http://www.oxfordenergy.org/2014/10/reducing-european-dependence-on-russian-gas-distinguishingnatural-gas-security-from-geopolitics/

Stern, in Henderson and Pirani eds (2014): The Russian Gas Matrix: How Markets are Driving Change, J. Henderson and S. Pirani, OIES 2014, http://www.oxfordenergy.org/shop/the-russian-gasmatrix-how-markets-are-driving-change/

Stern, Pirani and Yafimava (2015): 'Does the Cancellation of South Stream Signal a Fundamental Reorientation of Russia Gas Export Policy?', J. Stern, S. Pirani and K. Yafimava, OIES, January 2015, http://www.oxfordenergy.org/2015/01/cancellation-south-stream-signal-fundamentalreorientation-russian-gas-export-policy/

Stern and Rogers (2014): 'The Dynamics of a Liberalised European Gas Market', J. Stern \& H. Rogers, December 2014, NG94, OIES, http://www.oxfordenergy.org/2014/12/dynamics-liberalisedeuropean-gas-market-key-determinants-hub-prices-roles-risks-major-players/

Yafimava (2013): 'The EU Third Package for Gas and the Gas Target Model: major contentious issues inside and outside the EU', Katja Yafimava, April 2013, NG 75, OIES,

http://www.oxfordenergy.org/2013/04/the-eu-third-package-for-gas-and-the-gas-target-model-majorcontentious-issues-inside-and-outside-the-eu-2/ 